\title{
SULFUR POLYMER STABILIZATION/SOLIDIFICATION TREATABILITY STUDY OF MERCURY CONTAMINATED SOIL FROM THE Y-12 SITE
}

P. D. Kalb, L. Milian, and S. P. Yim

Informal Report

Prepared for

URS |CH2M OAK RIDGE LLC

OAK RIDGE, TN

November 2012

\section{Environmental Sciences Department/Energy Research and Technology Division Brookhaven National Laboratory \\ P.O. Box 5000 \\ Upton, NY 11973-5000 \\ www.bnl.gov}

Notice: This manuscript has been authored by employees of Brookhaven Science Associates, LLC under Contract No. DE-AC0298CH10886 with the U.S. Department of Energy. The publisher by accepting the manuscript for publication acknowledges that the United States Government retains a non-exclusive, paid-up, irrevocable, world-wide license to publish or reproduce the published form of this manuscript, or allow others to do so, for United States Government purposes. 


\section{DISCLAIMER}

This report was prepared as an account of work sponsored by an agency of the United States Government. Neither the United States Government nor any agency thereof, nor any of their employees, nor any of their contractors, subcontractors, or their employees, makes any warranty, express or implied, or assumes any legal liability or responsibility for the accuracy, completeness, or any third party's use or the results of such use of any information, apparatus, product, or process disclosed, or represents that its use would not infringe privately owned rights. Reference herein to any specific commercial product, process, or service by trade name, trademark, manufacturer, or otherwise, does not necessarily constitute or imply its endorsement, recommendation, or favoring by the United States Government or any agency thereof or its contractors or subcontractors. The views and opinions of authors expressed herein do not necessarily state or reflect those of the United States Government or any agency thereof. 


\title{
Sulfur Polymer Stabilization/Solidification Treatability Study of Mercury Contaminated Soil from the Y-12 Site
}

\author{
P.D. Kalb, L. Milian, S.P. Yim
}

November 30, 2012

Prepared for:

URS | CH2M OAK RIDGE LLC

OAK RIDGE, TN

Prepared by:

EnVIRONMENTAL RESEARCH \& TECHNOLOGy Division

ENVIRONMENTAL SCIENCES Department

Brookhaven National Laboratory

UPTON, NY 11973 


\section{Executive Summary}

As a result of past operations, the Department of Energy's (DOE) Oak Ridge Y-12 National Security Complex (Y-12 Plant) has extensive mercury-contamination in building structures, soils, storm sewer sediments, and stream sediments, which are a source of pollution to the local ecosystem. Because of mercury's toxicity and potential impacts on human health and the environment, DOE continues to investigate and implement projects to support the remediation of the $\mathrm{Y}-12$ site.

URS | CH2M Oak Ridge LLC (UCOR) under its prime contract with DOE has cleanup responsibilities on the DOE Oak Ridge Reservation and is investigating potential mercury-contaminated soil treatment technologies through an agreement with Babcock and Wilcox (B\&W) Y-12, the $\mathrm{Y}-12$ operating contractor to DOE. As part of its investigations, UCOR has subcontracted with Brookhaven National Laboratory (BNL) to conduct laboratory-scale studies evaluating the applicability of the Sulfur Polymer Stabilization/Solidification (SPSS) process using surrogate and actual mixed waste Y-12 soils containing mercury $(\mathrm{Hg})$ at $135,2,000$, and 10,000 ppm .

SPSS uses a thermoplastic sulfur binder to convert $\mathrm{Hg}$ to stable mercury sulfide (HgS) and solidifies the chemically stable product in a monolithic solid final waste form to reduce dispersion and permeability. Formulations containing $40-60$ dry wt\% Y-12 soil were fabricated and samples were prepared in triplicate for Environmental Protection Agency Toxicity Characteristic Leaching Procedure (TCLP) testing by an independent laboratory. Those containing 50 and $60 \mathrm{wt} \%$ soil easily met the study criteria for maximum allowable $\mathrm{Hg}$ concentrations (47 and $1 \mathrm{ppb}$, respectively compared with the TCLP limit of 200 $\mathrm{ppb} \mathrm{Hg}$ ). The lowest waste loading of $40 \mathrm{wt} \%$ yielded TCLP Hg concentrations slightly higher (240 ppb) than the allowable limit. Since the $\mathrm{Y}-12$ soil tended to form clumps, the improved leaching at higher waste loadings was probably due to reduction in particle size from friction of the soil mixing, which creates more surface area for chemical conversion. This was corroborated by the fact that the same waste loading pre-treated by ball milling to reduce particle size prior to SPSS processing yielded TCLP concentrations almost 30 times lower, and at $8.5 \mathrm{ppb} \mathrm{Hg}$ was well below EPA limits. Pre-treatment by ball milling also allowed a reduction in the time required for stabilization, thus potentially reducing total process times by $30 \%$.

Additional performance testing was conducted including measurement of compressive strength to confirm mechanical integrity and immersion testing to determine the potential impacts of storage or disposal under saturated conditions. For both surrogate and actual Y-12 treated soils, waste form compressive strengths ranged between 2,300 and 6,500 psi, indicating very strong mechanical integrity (a minimum of $>40$ times greater than the NRC guidance for low-level radioactive waste). In general, compressive strength increases with waste loading as the soil acts as an aggregate in the sulfur concrete waste forms. No statistically significant loss in strength was recorded for the 30 and 40 wt\% surrogate waste samples and only a minor reduction in strength was measured for the $43 \mathrm{wt} \%$ waste forms. The 30 wt\% Y-12 soil did not show a significant loss in strength but the 50 wt\% samples were severely degraded in immersion due to swelling of the clay soil. The impact on $\mathrm{Hg}$ leaching, if any, was not determined. 
Mercury speciation testing revealed that before treatment, most (>90\%) of the Hg was in the elemental form and only a small fraction (2\%) was present as stable HgS. Following SPSS treatment, waste forms containing 50 wt\% 10,000 ppm Hg contaminated soil, 92\% and 95\% of the $\mathrm{Hg}$ for the baseline and pretreated SPSS processes, respectively were converted to stable $\mathrm{HgS}$. These data substantiate the mechanism responsible for the low $\mathrm{Hg}$ leaching results. $\mathrm{Hg}$ is highly volatile but analysis of the off-gas system at the end of the study revealed that $99.999 \%$ of the $\mathrm{Hg}$ was retained in the final waste form. Laboratory analyses confirmed that neither excess sulfide nor the $\mathrm{pH}$ of SPSS waste forms will present problems in storage and disposal. 


\section{Table of Contents}

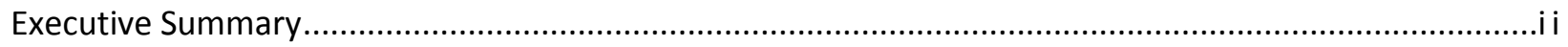

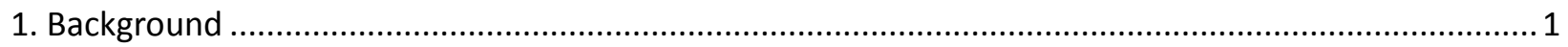

2. Sulfur Polymer Stabilization/Solidification: .................................................................................. 1

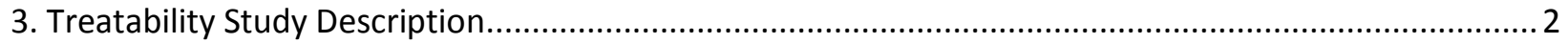

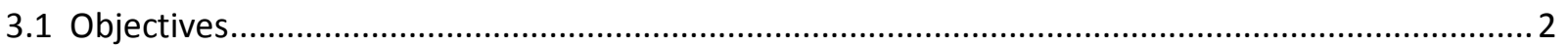

3.2 Overview of Treatment Study Elements ...................................................................................... 2

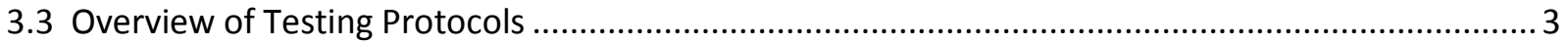

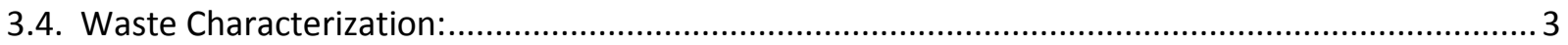

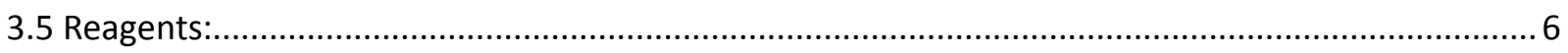

3.6 Equipment:

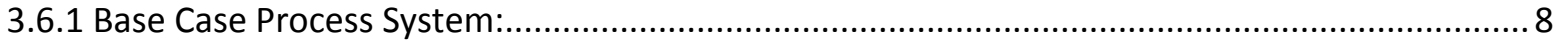

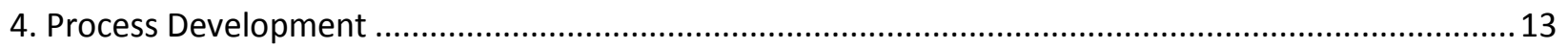

4.1 Baseline SPSS Sample Preparation and Processing................................................................... 13

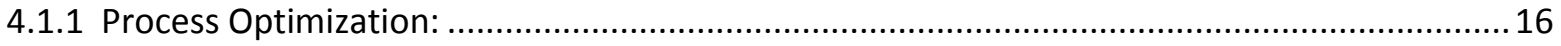

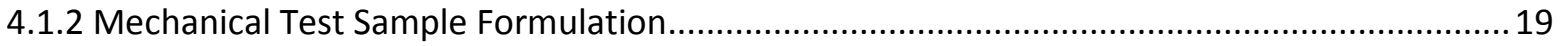

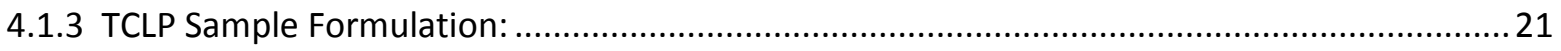

4.2 Pre-treatment Sample Preparation and Processing: .................................................................. 22

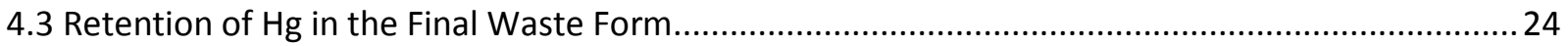

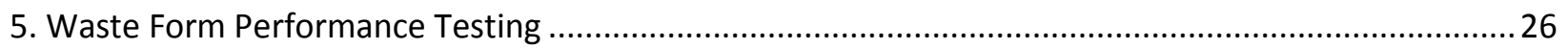

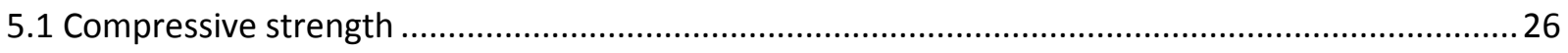

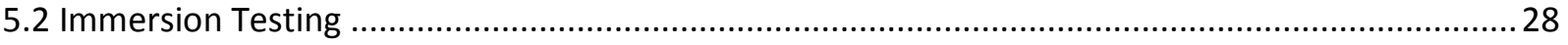

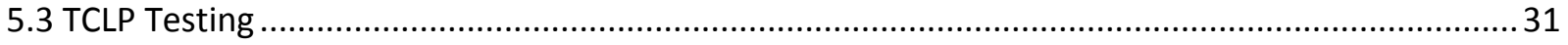

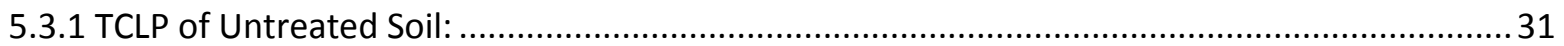

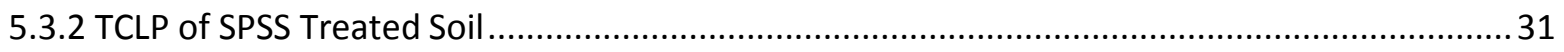

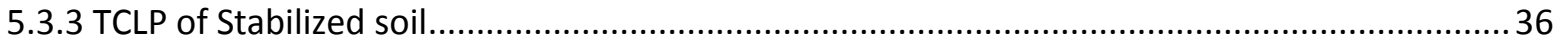

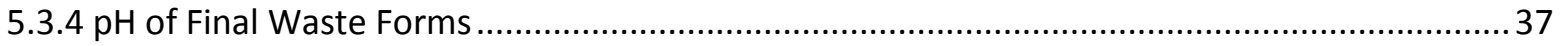

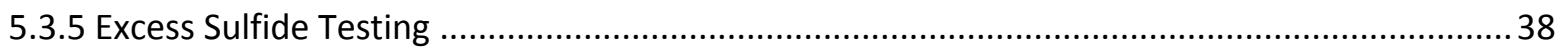

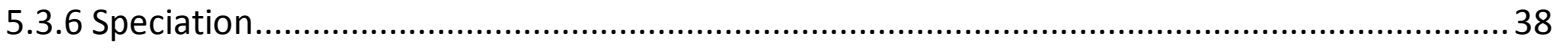

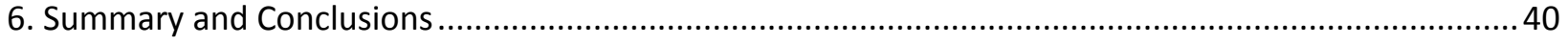

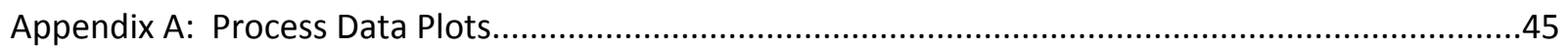

Appendix B: Compressive Strength and Immersion Test Data.......................................................55 


\section{List of Tables}

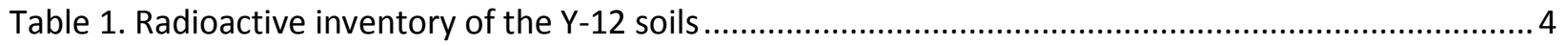

Table 2. Bulk Density Measurements for Y-12 Soil ........................................................................... 5

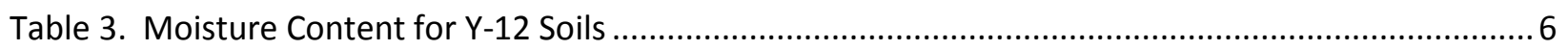

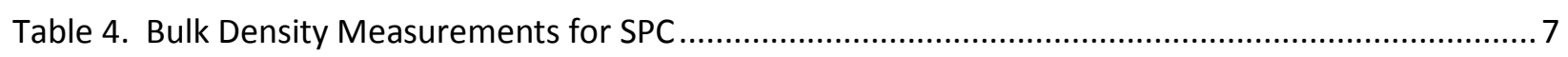

Table 5. Bulk Density of SPC as a function of Vibration Time ............................................................... 7

Table 6. Specifications for the planetary ball mill (Retsch PM 100) ..................................................... 12

Table 7. Observed SPC Melt Temperature............................................................................................ 14

Table 8. Clean Oak Ridge Soil Surrogate Mechanical Test Sample Weights, Dimensions and Densities ... 20

Table 9. Unspiked Y-12 Soil Mechanical Test Sample Weights, Dimensions and Densities ......................21

Table 10. Pre-treatment parameters for 40 and $50 \mathrm{wt} \% \mathrm{Y}-12$ soil loadings prior to SPSS processing ........23

Table 11. Pre-treatment parameters for $50 \mathrm{wt} \%$ Y-12 soil loadings without SPSS processing ..................24

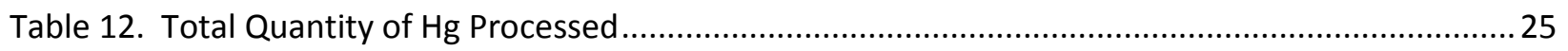

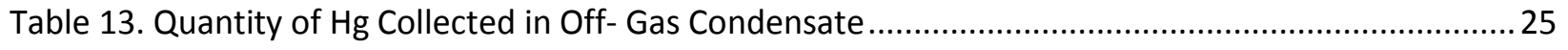

Table 14. Quantity of Hg Collected in Off-Gas Carbon Filter ...................................................................2 25

Table 15. Compressive Strength of SPSS Treated Oak Ridge Surrogate Soil Before and After Immersion 29

Table 16. Compressive Strength of SPSS Treated Y-12 Soil Before and After Immersion .........................29

Table 17. Average TCLP Data for Baseline and Pre-Treated SPSS Processing ..........................................32

Table 18. TCLP of 50 wt\% 10,000 ppm Hg Stabilized Soil (without solidification)......................................37

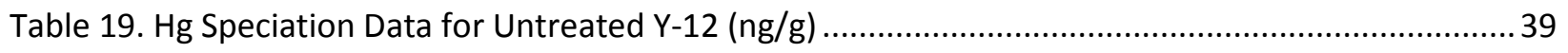

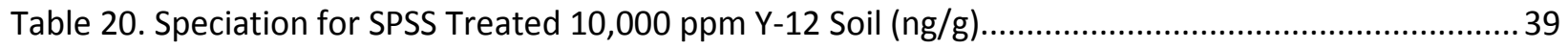

Table 21. Speciation for Pre-Treated SPSS 10,000 ppm Y-12 Soil (ng/g) ................................................ 39 


\section{List of Figures}

Figure 1. Visible beads of $\mathrm{Hg}$ seen in samples of $10,000 \mathrm{ppm} \mathrm{Y-12} \mathrm{soil} \mathrm{..............................................} 4$

Figure 2. Clean surrogate soil from Oak Ridge................................................................................. 5

Figure 3. Sartorius moisture balance (left) for measuring soil moisture of Y-12 soil (right) ..................... 6

Figure 4. Overview of the bench-scale SPSS processing system........................................................... 9

Figure 5. Heated, dual planetary orbital mixer (left), filled with soil and SPC binder (right) .................... 9

Figure 6 Oil Bath heater (left) and system installation (right) ........................................................... 10

Figure 7. Off-gas treatment system (left) with close-up of condensate collection (right) ....................... 10

Figure 8. Using Jerome Analyzer (left, center) and air filter (right) to monitor Hg Vapor......................... 11

Figure 9. Data logger (left) and real-time display of temperature and pressure data ............................11

Figure 10. Heated vessel for pouring waste forms .............................................................................. 12

Figure 11. Laboratory ball mill for pre-treating $\mathrm{Hg}$ contaminated soils ...............................................13

Figure 12. Molten mixture containing $40 \mathrm{wt} \%$ surrogate soil being poured (left) and cooling in cylindrical

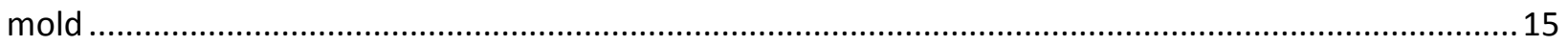

Figure 13. Diamond tipped wet saw (left) for cutting cylindrical test samples (right) ............................15

Figure 14 Preparing TCLP pellets by pouring into Teflon molds ........................................................... 16

Figure 15 TCLP pellets being prepared (left) and ready for testing (right) ............................................ 16

Figure 16 . Example of Process Data thermal profile for 60 wt\% High Hg $(10,000$ ppm) Hg Y-12 soil .......18

Figure 17. Mechanical test samples with clean surrogate soil (left) and unspiked Y-12 soil (right)......... 19

Figure 18. Comparison of melt viscosity for 40 (left), 50 (center) and 60 wt\% (right) loadings................. 22

Figure 19. Ball mill pre-treatment of $\mathrm{Y}-12$ soil before (left) and after (right) processing. Balls shown in

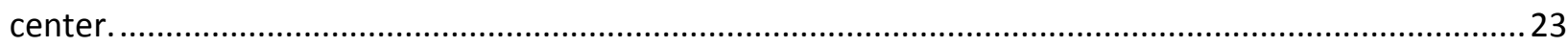

Figure 20. Instron Model 5582 Compression Tester (left) and Computer Control/Output (right)............26

Figure 21. Compression Test Stress-Strain Curve for SPSS Treated 30 wt\% Y-12 Soil ............................. 27

Figure 22. SPSS Treated 43 wt\% Y-12 Soil Samples Following 65 days in Water Immersion .....................30

Figure 23. 50 wt\% Y-12 Soil in Immersion after 18 hrs (left), 7 days (center), and 11 days (right) ............ 30

Figure 24. TCLP Data vs. Waste Loading for 2,000 ppm Hg Contaminated Y-12 Soil, Baseline SPSS

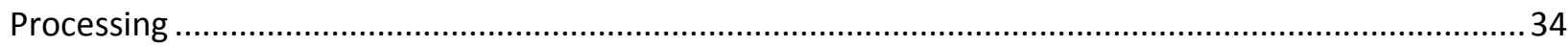

Figure 25. TCLP Data vs. Waste Loading for 10,000 ppm Hg Contaminated Y-12 Soil, Baseline Processing

Figure 26. TCLP Data vs. Waste Loading for 10,000 ppm Hg Contaminated Y-12 Soil with Ball Mill Pre-

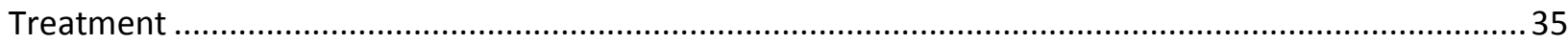

Figure 27. Time trials for soil stabilization of $50 \mathrm{wt} \%$ SPSS treated $\mathrm{Y}-12$ soil containing 10,000 ppm Hg... 37 


\section{Background}

Mercury contamination in soil and ground water at the Y-12 National Security Complex in Oak Ridge, TN has been a major environmental challenge for the past 50 years. Up to 11 million $\mathrm{kg}$ of elemental mercury $(\mathrm{Hg})$ was used for a lithium isotope separation technology in which the mercury was washed with process water containing dilute nitric acid. The effluents were subsequently discharged to the East Fork Poplar Creek which originates at the Y-12 plant and up to $3 \%(330,000 \mathrm{~kg})$ of the $\mathrm{Hg}$ was estimated to have been deposited in the soil beneath the facility.[1,2] Despite the fact that the large scale releases were curtailed in the early 1960s, much of the $\mathrm{Hg}$ remains and continues to serve as a source term for conversion to highly toxic organic mercuric compounds.

URS | CH2M Oak Ridge LLC (UCOR) under its prime contract with the Department of Energy (DOE) is responsible for the cleanup of major facilities at the Oak Ridge East Tennessee Technology Park and other DOE Environmental Management Program activities at the Oak Ridge National Laboratory and the Y-12 National Security Complex. Babcock and Wilcox (B\&W) Y-12, the DOE Contractor for operation of the Y-12 Plant, has contracted with UCOR to perform several projects related to the treatment and disposition of $\mathrm{Y}-12$ mercury-contaminated media including this treatability study of $\mathrm{Y}-12$ soils. Two other treatment technologies were tested in parallel by other vendors.

\section{Sulfur Polymer Stabilization/Solidification:}

Mercury exists in nature as cinnabar, a stable mercury sulfide (HgS) element in solid form. BNL's patented Sulfur Polymer Stabilization/Solidification (SPSS) process is a two stage treatment process that chemically stabilizes mercury to form HgS powder and then physically encapsulates it into a solid form that resembles cinnabar for long-term disposal.[3] The stabilization phase reduces the vapor pressure (lowers $\mathrm{Hg}$ volatility) and greatly reduces solubility to lower $\mathrm{Hg}$ leachability. The solidification step, based on an earlier BNL technology for microencapsulation of waste using Sulfur Polymer Cement (SPC) eliminates the potential for dispersion and further reduces leaching by reducing permeability.[4] SPC is a thermoplastic binder that melts at $119^{\circ} \mathrm{C}$ to form a low viscosity liquid that can be easily combined

with waste, homogenized, and cooled to form a durable, solid monolith. These properties are critical to ensure that contaminants are physically retained and not released to the environment. Thus the properties of low solubility from chemical stabilization and low permeability from solidification combine to enhance performance of SPSS treated waste.

The SPSS process has been demonstrated successfully at bench- and pilot-scale for treatment of pure elemental $\mathrm{Hg}$ and $\mathrm{Hg}$ contaminated soils, sludge, and debris.[5,6,7] In one study, two 55-gallon drums of mixed-waste soil containing $\sim 5,000 \mathrm{ppm}$ of mercury and about $62 \mathrm{~kg}$ of radioactively contaminated elemental mercury from a RCRA soil remediation effort at BNL were successfully treated. Waste 
loadings of $60 \mathrm{wt} \%$ were achieved for the soil without resulting in any increase in waste volume, while elemental mercury was solidified at a waste loading of $33 \mathrm{wt} \% \mathrm{Hg}$.[5] A commercial license has been issued for use of the SPSS process in treating $\mathrm{Hg}$ residuals from the mining industry.[8]

This work addressed feasibility of the SPSS process for site-specific $\mathrm{Hg}$ contaminated soil from Y-12 with $\mathrm{Hg}$ concentrations as high as $10,000 \mathrm{ppm}$, approximately twice the highest $\mathrm{Hg}$ soil concentration processed by SPSS to date. In addition, a new ball mill pre-treatment step was tested for technical and economic feasibility.

\section{Treatability Study Description}

\subsection{Objectives}

Treatability study objectives included:

- determination of feasibility of the SPSS process for application to Y-12 Hg contaminated mixed waste soils,

- identification of process parameters that lead to the most efficient and effective final waste forms,

- testing the performance of the waste forms to estimate long-term durability, and

- evaluating performance against U.S. Environmental Protection Agency (EPA) regulatory requirements for leaching and other metrics.

\subsection{Overview of Treatment Study Elements}

The objectives for this study were accomplished using four sets of soils. One was a clean Oak Ridge soil used to simulate the $\mathrm{Y}-12$ soil for preliminary set up and testing. One was a composite of $\mathrm{Y}-12$ soil with a nominal $\mathrm{Hg}$ concentration of $135 \mathrm{ppm}$ taken from various soil cores and used in this study for mechanical property testing. The remaining two soils were produced from the same Y-12 soil but were enhanced with additional elemental $\mathrm{Hg}$ at nominal concentrations of 2,000 and $10,000 \mathrm{mg} / \mathrm{kg}(\mathrm{ppm}) \mathrm{Hg}$ that were used for leach testing and other performance tests.

In addition to the four types of soils, the study investigated several processing options including the baseline Sulfur Polymer Stabilization/Solidification process and a modified process that incorporates pre-treatment of the waste-binder mixture by ball milling followed by baseline treatment. The baseline SPSS process was used to treat both of the enhanced Hg concentration soils and the ball mill pretreatment/SPSS process was used to treat the 10,000 ppm soil. 


\subsection{Overview of Testing Protocols}

The principle performance test for a hazardous or mixed waste is its ability to resist leaching. Wastes that are stored or disposed in shallow land disposal sites are subject to interaction with water permeating the site that can dissolve the contaminant and transport it through ground water, creating a pathway for human exposure. Through the Resource Conservation and Recovery Act (RCRA), the U.S. EPA regulates allowable concentrations of hazardous and toxic constituents through implementation of the Toxicity Characteristic Leaching Procedure (TCLP).[9] The rationale for TCLP was an assumption that potentially toxic waste could find its way into municipal solid waste landfills, so the leachant used for this test is dilute acetic acid that would typically be found under landfill conditions. TCLP is conducted on material that passes through a $9.5 \mathrm{~mm}$ sieve and is in contact with the leachant for 18 hours with constant agitation. Each toxic element has a unique concentration limit for untreated land disposal based on risks associated with potential health impacts. For this study, UCOR established that the maximum allowable $\mathrm{Hg}$ concentration by TCLP was $0.2 \mathrm{mg} / \mathrm{l}$ (0.2 ppm or $200 \mathrm{ppb}$ ).

The overall $\mathrm{pH}$ of the waste or final waste form is measured to determine if it will impact leaching or have deleterious impacts on the environment. For this study, samples were prepared and tested according to the EPA SW-846 9045D.[10] The sample is mixed with reagent water, and the $\mathrm{pH}$ of the resulting aqueous solution is measured. Treatment technologies that use sulfide (including SPSS) are subject to release of excess sulfide into the environment, which can impact $\mathrm{pH}$ and other soil conditions. Potentially excess sulfide concentration in samples that contain $0.2 \mathrm{mg} / \mathrm{kg}$ to $50 \mathrm{mg} / \mathrm{kg}$ of sulfide is measured according to EPA SW-846 9034.[11] Since leaching performance is closely tied to the solubility of $\mathrm{HgS}$, samples of the final waste form products were analyzed for $\mathrm{Hg}$ speciation.[12]

\subsection{Waste Characterization:}

Soil was supplied by UCOR from a drum that consisted of cores taken at multiple depths and locations within an area under investigation for remediation at the Y-12 Building 81-10 area. Once the original sample soils were homogenized, the mixture was divided into three lots - one for each of the three treatability study vendors. BNL's portion was subdivided again into three samples; one contained asreceived soil with a nominal $\mathrm{Hg}$ concentration of $135 \mathrm{ppm}$; one was spiked with elemental $\mathrm{Hg}$ to a nominal concentration of 2,000 ppm $\mathrm{Hg}$; and the third was spiked with additional elemental $\mathrm{Hg}$ to a nominal concentration of $10,000 \mathrm{ppm} \mathrm{Hg}$. Materials and Chemistry Laboratory, Inc. (MCL) performed the homogenization of the original Y-12 remediation soils, enhanced the soil with elemental mercury, and prepared the samples for shipment to the three treatability study vendors, including BNL.

The Y-12 soil contained very low concentrations of radioactivity as shown in Table 1 . The radioactivity was very difficult to detect during routine operations but based on DOE's "no-radioactivity added" policy, the soils were considered as radioactively contaminated material. For the spiked soils with $\mathrm{Hg}$ concentrations above the EPA Toxicity Characterization Leaching Procedure (TCLP) limits for $\mathrm{Hg}$, the material was treated as mixed waste. 
Table 1. Radioactive inventory of the Y-12 soils

\begin{tabular}{|c|c|}
\hline Isotope & Activity, $\mathbf{n C i} / \mathbf{g}$ \\
\hline Eu-155 & 4.54 \\
\hline Tc-99 & 17.4 \\
\hline Th-228 & 41.62 \\
\hline Th-230 & 21.16 \\
\hline Th-232 & 43.78 \\
\hline U-235 & 3.27 \\
\hline U-238 & 55.68 \\
\hline
\end{tabular}

Soils were enhanced with additional mercury to test the efficacy of the treatment process over a range of $\mathrm{Hg}$ concentrations. In order to distribute the additional elemental $\mathrm{Hg}$ evenly and produce homogeneous samples, it was applied using a pressurized air brush ( 200 psi nitrogen carrier gas) which atomized the $\mathrm{Hg}$ into an aerosol of tiny droplets that were sprayed on the soil. The spiked $\mathrm{Hg}$ soil was then blended into the larger aliquot by hand mixing. The soil enhanced to $2,000 \mathrm{ppm} \mathrm{Hg}$ appeared to be evenly coated with no visible $\mathrm{Hg}$ beads observable. The $10,000 \mathrm{ppm}$ soil however, had small visible droplets of $\mathrm{Hg}$ distributed throughout the soil. These can be seen in the photos taken of the soil at BNL in Figure 1.
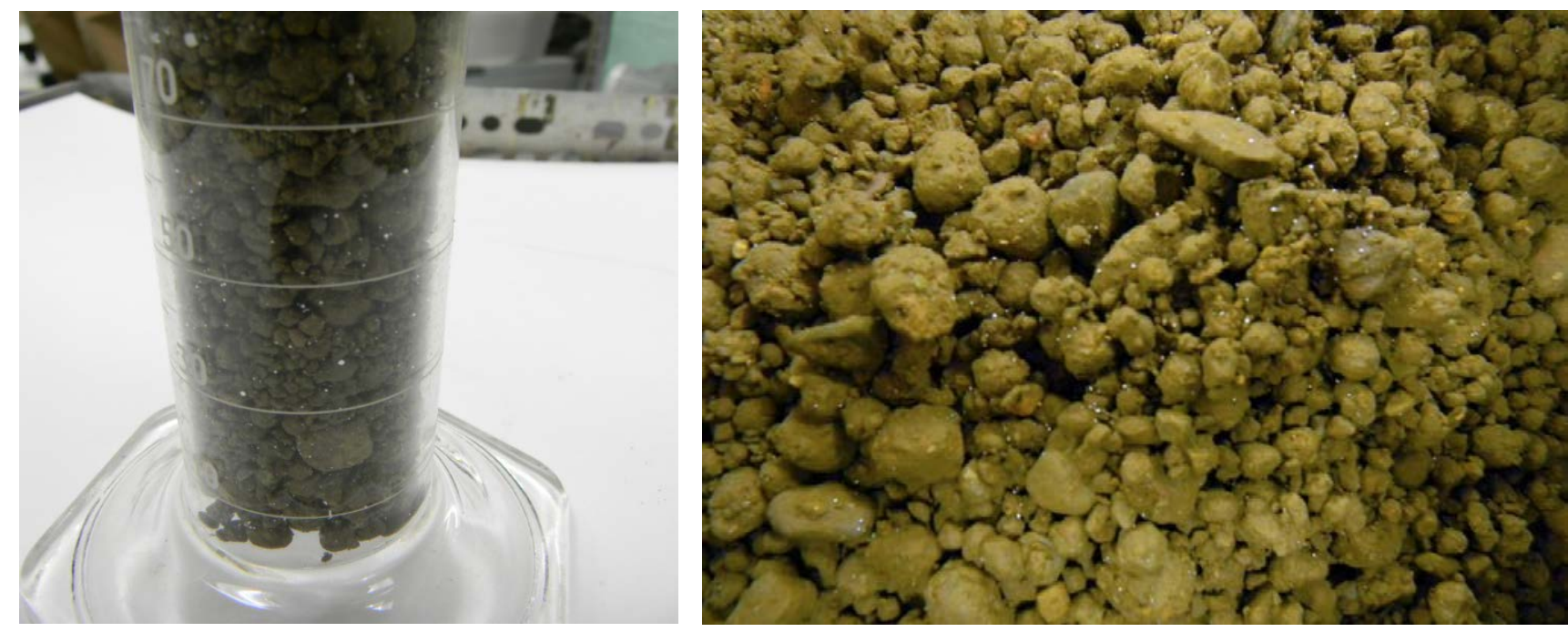

Figure 1. Visible beads of $\mathrm{Hg}$ seen in samples of $10,000 \mathrm{ppm} \mathrm{Y-12} \mathrm{soil}$ 


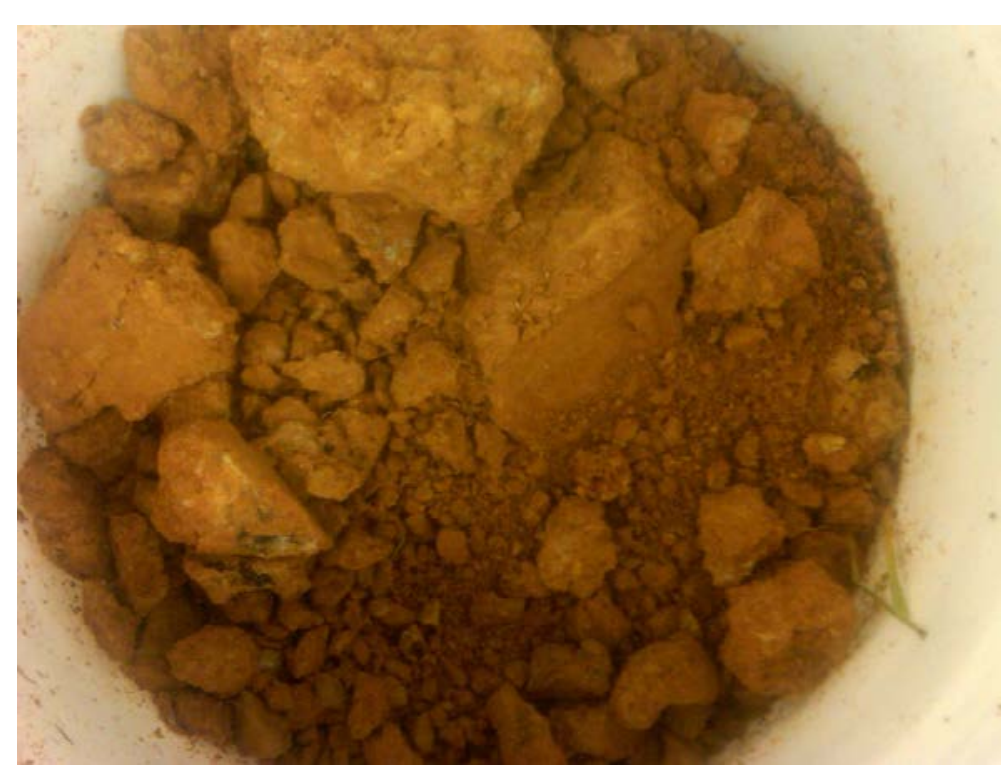

Figure 2. Clean surrogate soil from Oak Ridge

In addition, BNL received a drum of uncontaminated soil taken outside of but near the main Y-12 Site to simulate the actual $\mathrm{Y}-12$ soils for preliminary formulation and testing. The clean soil was a reddish-orange clay with chert fragments and is the weathered in place soil typically found overlying the limestone bedrock on Chestnut Ridge. [13] Figure 2 is a photo of the clean surrogate soil.

Basic soil properties including bulk density and moisture content were measured at BNL. Bulk density was measured by placing a known mass of soil in a graduated cylinder and vibrating for $15 \mathrm{sec}$. on a vibration table. As seen in Table 2, the bulk densities increased slightly with $\mathrm{Hg}$ concentration, attributable to the increased concentrations of the very dense elemental $\mathrm{Hg}$ as well as increased mixing which reduces voids in the soil.

Table 2. Bulk Density Measurements for Y-12 Soil

\begin{tabular}{|l|l|l|l|l|l|l|l|}
\hline Sample ID & $\begin{array}{l}\text { Soil } \\
\text { Mass, g }\end{array}$ & $\begin{array}{l}\text { Initial } \\
\text { Soil } \\
\text { Volume, } \\
\mathrm{cm}^{3}\end{array}$ & $\begin{array}{l}\text { Final } \\
\text { Soil } \\
\text { Volume, } \\
\mathrm{cm}^{3}\end{array}$ & $\begin{array}{l}\text { Bulk } \\
\text { Density, } \\
\mathrm{g} / \mathrm{cm}^{3(1)}\end{array}$ & $\begin{array}{l}\text { Mean } \\
\text { Bulk } \\
\text { Density, } \\
\mathrm{g} / \mathrm{cm}^{3}\end{array}$ & Std Dev & $\begin{array}{l}\text { Percent } \\
\text { Error }\end{array}$ \\
\hline BD-130-1 & 200.2 & 200 & 186 & 1.08 & & & \\
\hline BD-130-2 & 200.3 & 190 & 180 & 1.11 & $\mathbf{1 . 0 9}$ & $\mathbf{0 . 0 2}$ & $\mathbf{1 . 8 3 \%}$ \\
\hline BD-130-3 & 200.8 & 196 & 185 & 1.09 & & & \\
\hline BD-2000-1 & 200.6 & 190 & 174 & 1.15 & & & \\
\hline BD-2000-2 & 200.3 & 188 & 176 & 1.14 & $\mathbf{1 . 1 5}$ & $\mathbf{0 . 0 1}$ & $\mathbf{0 . 8 7 \%}$ \\
\hline BD-2000-3 & 200.9 & 192 & 174 & 1.15 & & & \\
\hline BD-10000-1 & 200.3 & 182 & 172 & 1.16 & & & \\
\hline BD-10000-2 & 200.1 & 182 & 174 & 1.15 & $\mathbf{1 . 1 8}$ & $\mathbf{0 . 0 4}$ & $\mathbf{3 . 3 9 \%}$ \\
\hline BD-10000-3 & 200.4 & 174 & 164 & 1.22 & & & \\
\hline
\end{tabular}

1) Measured after $15 \mathrm{sec}$ on a vibration table

Moisture contents were measured using a Sartorius moisture balance shown in Figure 3. The results for the three $\mathrm{Y}-12$ soils are given in Table 3. Using the bulk density of the unspiked soil of $1.09 \mathrm{~g} / \mathrm{cm}^{3}$ and the average moisture content of $15.1 \%$, the soil contains $10.22 \mathrm{lbs}$ moisture $/ \mathrm{ft} 3$ soil or $1.23 \mathrm{gal} / \mathrm{ft}^{3}$ soil. 

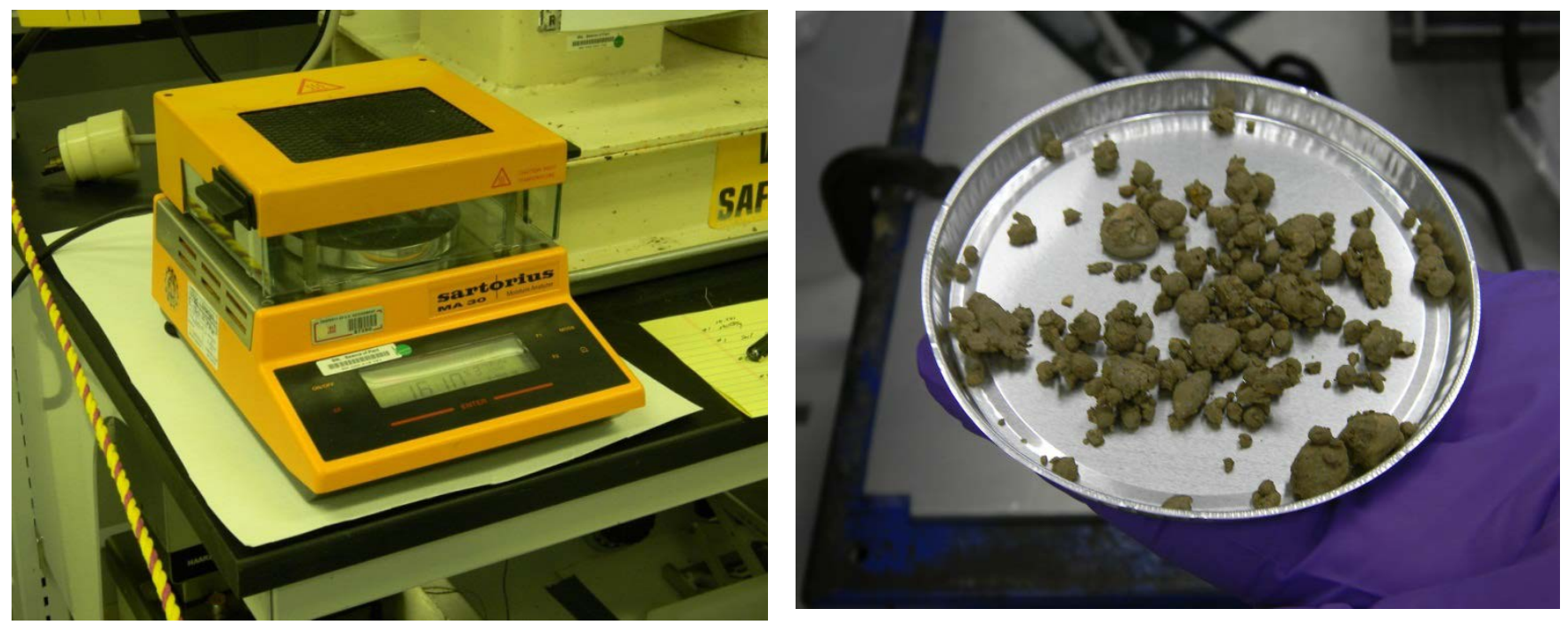

Figure 3. Sartorius moisture balance (left) for measuring soil moisture of $Y-12$ soil (right)

Table 3. Moisture Content for Y-12 Soils

\begin{tabular}{|c|c|c|c|c|c|}
\hline \multicolumn{2}{|c|}{135 ppm Hg } & \multicolumn{2}{|c|}{ 2,000 ppm Hg } & \multicolumn{2}{|c|}{10,000 ppm Hg } \\
\hline Sample ID & Moisture , \% & Sample ID & Moisture, \% & Sample ID & Moisture, \% \\
\hline M-1A-1 & 15.09 & M-1B-1 & 14.97 & M-3-1 & 13.55 \\
\hline$M-1 A-2$ & 16.1 & M-1B-2 & 14.75 & $M-3-2$ & 14.12 \\
\hline$M-1 A-3$ & 14.65 & M-1B-3 & 15.27 & $M-3-3$ & 14.05 \\
\hline$M-1 A-4$ & 15.33 & Mean & 15.00 & Mean & 13.91 \\
\hline$M-1 A-5$ & 14.55 & Std Dev. & 0.261 & Std Dev. & 0.311 \\
\hline M-1A-6 & 15.02 & $\%$ error & $1.74 \%$ & $\%$ error & $2.24 \%$ \\
\hline$M-1 A-7$ & 15.39 & & & & \\
\hline$M-1 A-8$ & 14.64 & & & & \\
\hline Mean & 15.10 & & & & \\
\hline Std Dev. & 0.515 & & & & \\
\hline$\%$ error & $3.41 \%$ & & & & \\
\hline
\end{tabular}

\subsection{Reagents:}

The SPSS process uses sulfur polymer cement (SPC) as both the chemical stabilization and physical encapsulation agent. SPC is a thermoplastic material with a melt temperature of $119^{\circ} \mathrm{C}$. It contains $95 \%$ elemental sulfur reacted with $5 \mathrm{wt} \%$ organic modifier (dicyclopentadiene) to suppress the solid phase change that occurs when elemental sulfur cools resulting in reduced mechanical stability. Commercially 
available SPC, in flake form (Chement 2000, Martin Resources, Inc.), is ground to a fine powder to increase surface area and increase the reaction kinetics of the stabilization reaction. The mean bulk density of three replicates of SPC powder measured in the same manner used for the soil was 0.92 $\mathrm{g} / \mathrm{cm}^{3} \pm 1.6 \%$ (Table 4). However, higher bulk densities can be achieved by longer vibration times which reduce the voids between particles. The variability of bulk density for SPC as a function of vibration time is shown in Table 5, with a maximum bulk density measured at $1.10 \mathrm{~g} / \mathrm{cm}^{3}$ with $180 \mathrm{sec}$. of vibration.

A small amount of sodium sulfide additive (technical grade, $\mathrm{Na}_{2} \mathrm{~S} 9 \mathrm{H}_{2} \mathrm{O}$ ) is used to enhance the chemical stabilization. The quantity of sulfide additive is dependent on the $\mathrm{Hg}$ content of the soil. For this study, twice the stoichiometric quantity of sulfide additive needed to react with the total mass of $\mathrm{Hg}$ was used since the soil contains other cations (e.g., iron) that compete with $\mathrm{Hg}$ in reacting with sulfide. The quantity ranged from $0.2 \%$ sulfide for the lowest waste loading of $2,000 \mathrm{ppm} \mathrm{Hg}$ soil to $1.7 \%$ sulfide for the highest waste loading of $10,000 \mathrm{ppm} \mathrm{Hg}$ soil. The sulfide component of the formulation is included with SPC when reporting the sulfur binder percentage.

Table 4. Bulk Density Measurements for SPC

\begin{tabular}{|l|c|c|c|c|}
\hline \multicolumn{1}{|c|}{ Sample ID } & $\begin{array}{c}\text { SPC } \\
\text { Mass, } \mathrm{g}\end{array}$ & $\begin{array}{c}\text { Initial SPC } \\
\text { Volume, cc }\end{array}$ & $\begin{array}{c}\text { Final SPC } \\
\text { Volume, cc }\end{array}$ & $\begin{array}{c}\text { Bulk Density, } \\
\mathrm{g} / \mathrm{cc}^{1}\end{array}$ \\
\hline BD-SPC-1 & 200 & 232 & 220 & 0.91 \\
\hline BD-SPC-2 & 200 & 232 & 220 & 0.91 \\
\hline BD-SPC-3 & 200 & 230 & 214 & 0.93 \\
\hline Mean & & & & 0.92 \\
\hline Std Dev & & & & 0.0147 \\
\hline \% Error & & & & $1.6 \%$ \\
\hline
\end{tabular}

1) Measured after 15 sec on a vibration table

Table 5. Bulk Density of SPC as a function of Vibration Time

\begin{tabular}{|c|c|c|c|c|}
\hline Mass, $\mathrm{g}$ & $\begin{array}{c}\text { Initial } \\
\text { Volume, } \mathrm{cm}\end{array}$ & $\begin{array}{c}\text { Final } \\
\text { Volume, } \mathrm{cm}\end{array}$ & $\begin{array}{c}\text { Total Vibrating } \\
\text { Time, } \mathrm{sec}\end{array}$ & $\begin{array}{c}\text { Bulk Density*, } \\
\mathrm{g} / \mathrm{cm}^{3}\end{array}$ \\
\hline 200 & 230 & 214 & 15 & 0.93 \\
\hline 200 & 230 & 204 & 30 & 0.98 \\
\hline 200 & 230 & 196 & 45 & 1.02 \\
\hline 200 & 230 & 190 & 60 & 1.05 \\
\hline 200 & 230 & 186 & 90 & 1.08 \\
\hline 200 & 230 & 182 & 120 & 1.10 \\
\hline 200 & 230 & 182 & 180 & 1.10 \\
\hline
\end{tabular}

*Note: based on measurement of Sample BD-SPC-3 


\subsection{Equipment:}

3.6.1 Base Case Process System: The base case for this study was based on the SPSS process system previously developed and patented at BNL and was conducted using a bench-scale SPSS treatment system shown in Figure 4. The system is based on a one-gallon capacity heated, dual planetary orbital mixer (Ross Mixers, Inc.) shown in Figure 5. The process vessel is heated by a circulating hot oil bath (Haake, Model N3) with digital set point thermal control shown in Figure 6. Moisture and Hg emissions are captured in the off-gas system that includes two serpentine coil condensers, condensate collection vessels, a circulating cold water chiller, an activated carbon filter, and vacuum pump (Figure 7). Potential $\mathrm{Hg}$ vapors that may escape during the waste handling and loading operations were removed via a vent hood installed over the mixer and several large ventilation duct trunks that were positioned as needed during operations (Figures 4 and 8 ). Worker safety was ensured by monitoring for $\mathrm{Hg}$ vapors in real time using a Jerome Analyzer (Figure 8 ) and by air samples taken over an 8 hour day. Temperatures of the heat transfer fluid, materials in the process vessel, and off-gas chiller are monitored by thermocouples, and pressure in the vessel is monitored by a direct reading gauge and pressure transducer. All parameters are recorded and updated every second and reported as one min. averages by a Campbell Model 3000 data logger with a real-time display for the operator (Figure 9). 


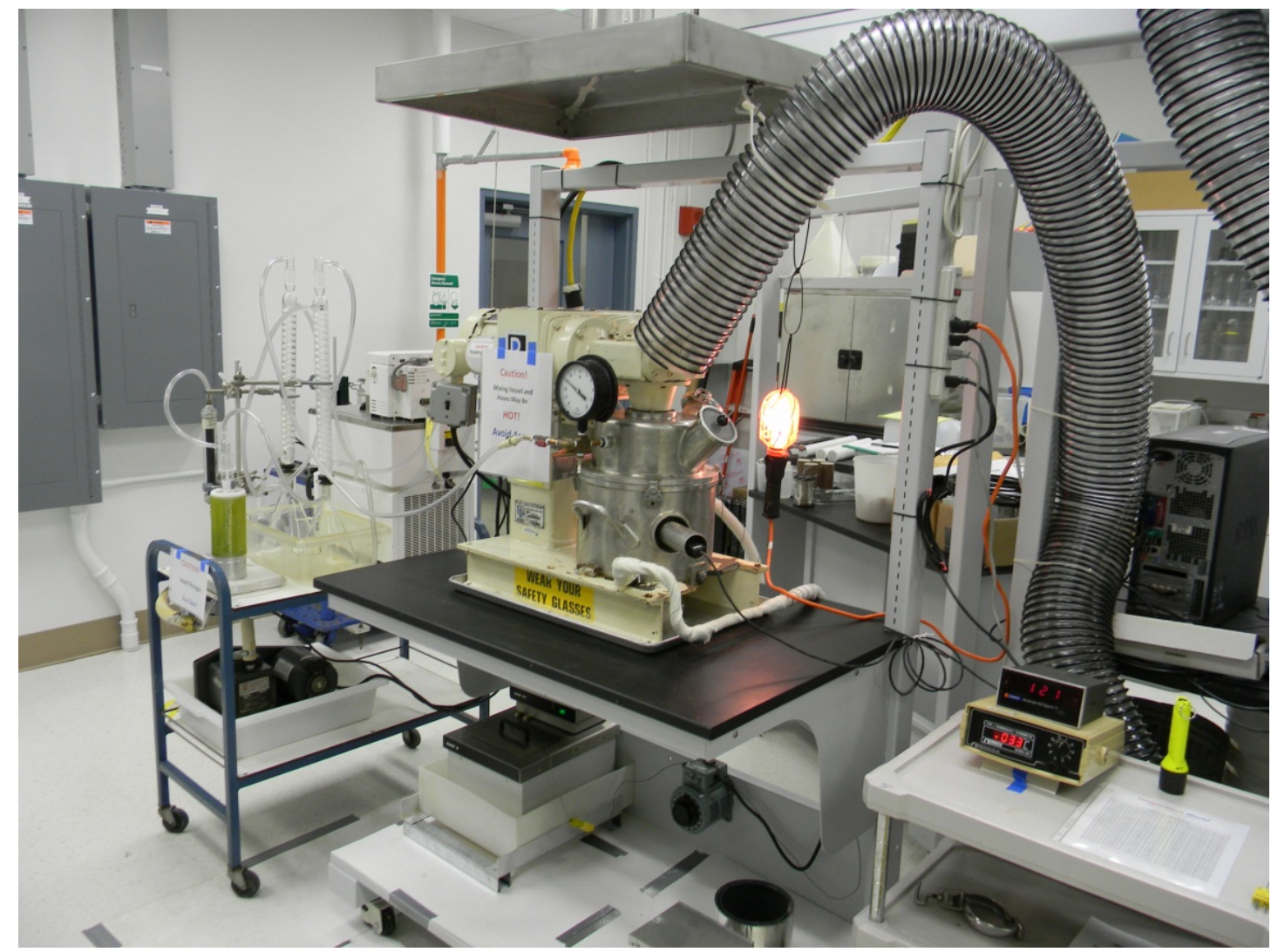

Figure 4. Overview of the bench-scale SPSS processing system
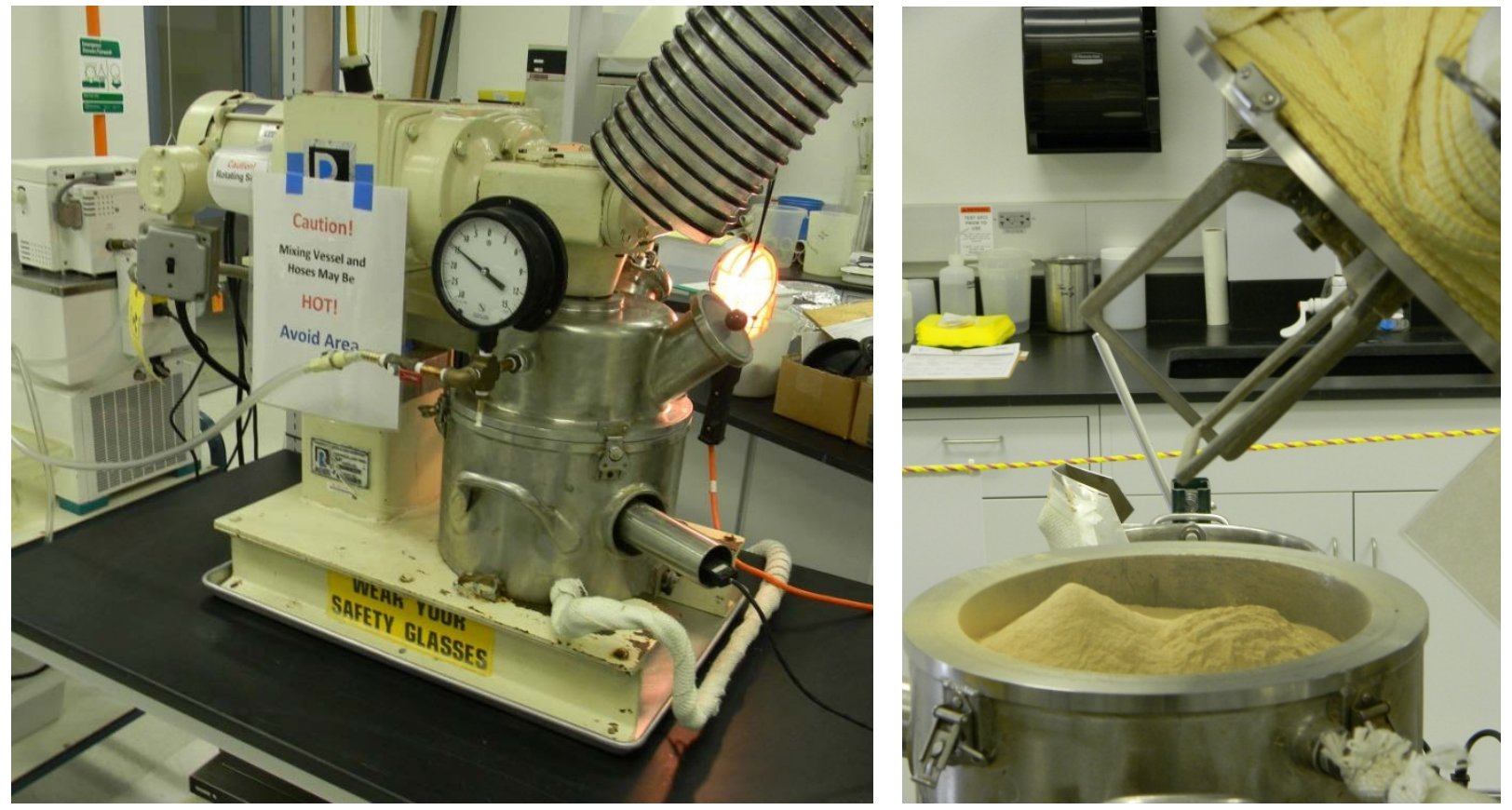

Figure 5. Heated, dual planetary orbital mixer (left), filled with soil and SPC binder (right) 

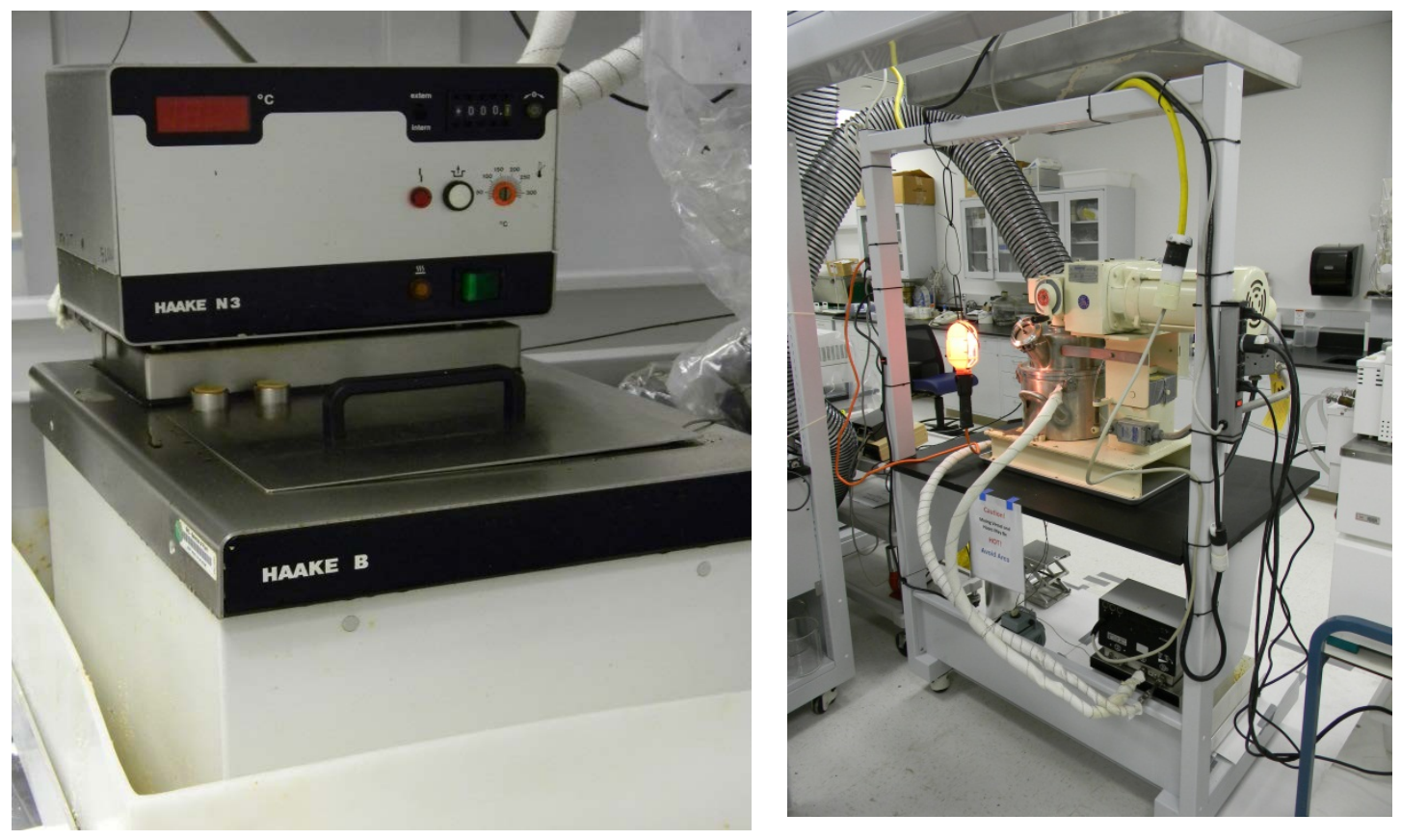

Figure 6 Oil Bath heater (left) and system installation (right)
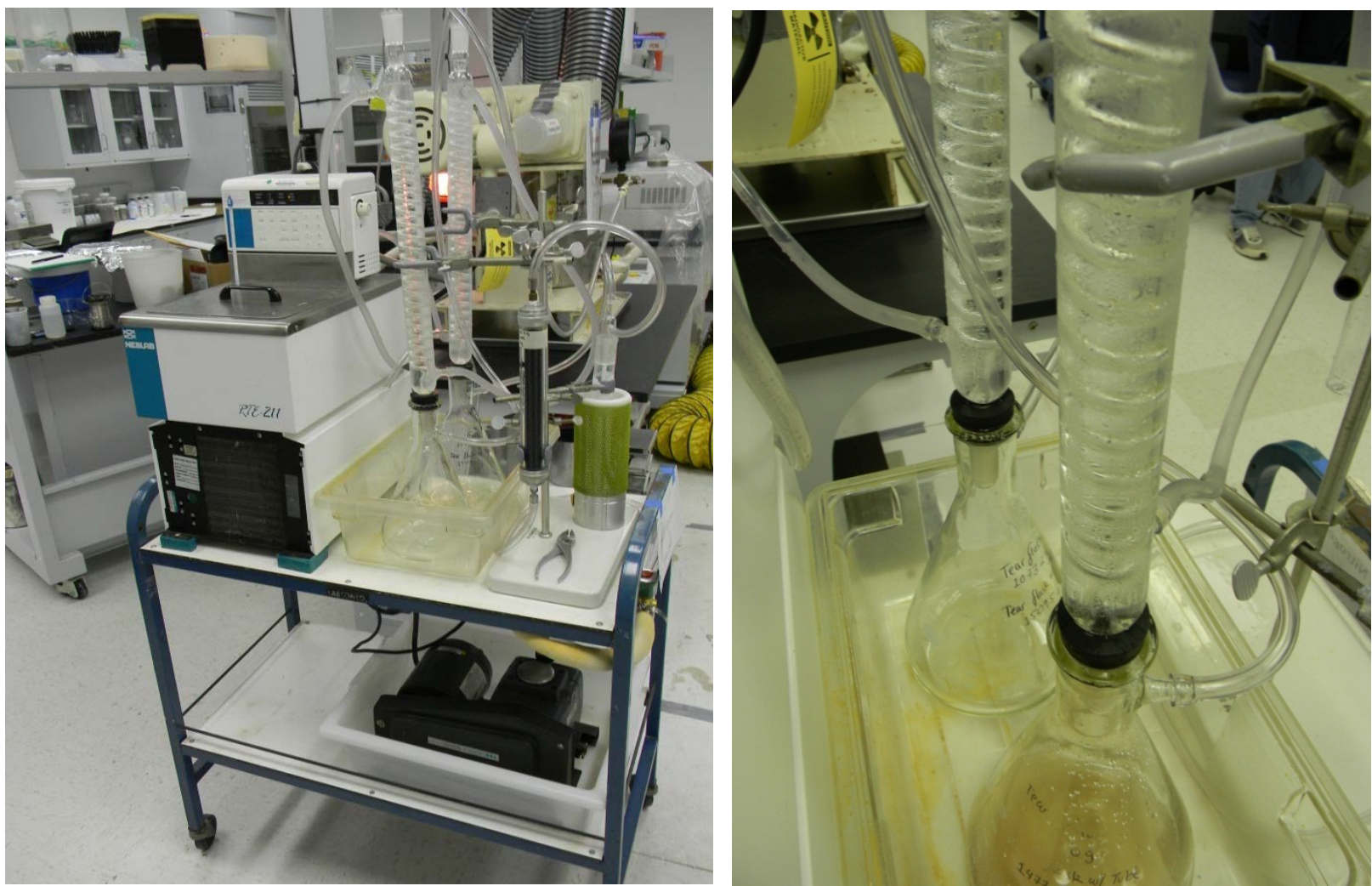

Figure 7. Off-gas treatment system (left) with close-up of condensate collection (right) 

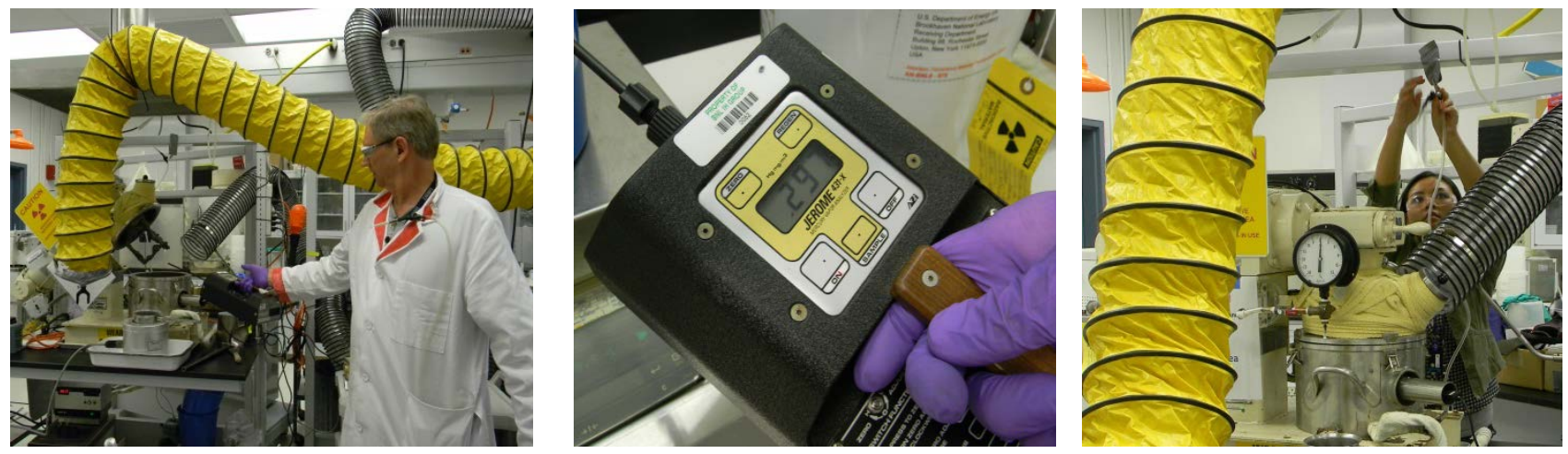

Figure 8. Using Jerome Analyzer (left, center) and air filter (right) to monitor Hg Vapor
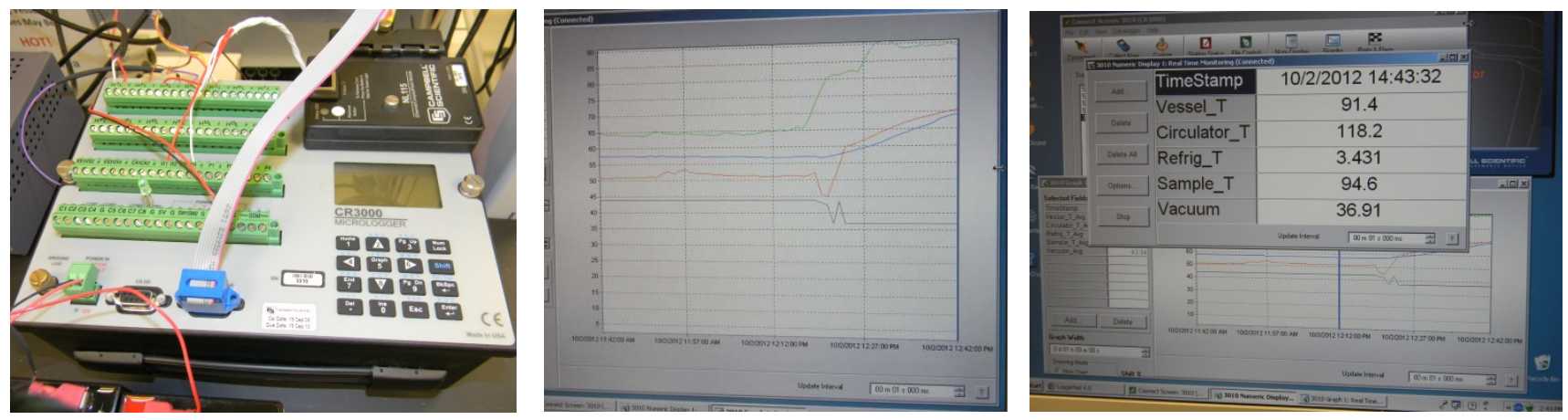

Figure 9. Data logger (left) and real-time display of temperature and pressure data

For most of the Y-12 soil formulations treated by SPSS, the viscosity of the final mix did not allow direct discharge from the $5 \mathrm{~cm}$ heated ball valve located beneath the planetary mixer's flat bottom base (BNL's pilot-scale mixer has a tapered cone design with a $15 \mathrm{~cm}$ discharge ball valve which would likely allow for easy direct discharge). To facilitate pouring of final waste forms in the bench-scale study, a heated transfer vessel was designed and built (Figure 10). The molten mixture was transferred by scooping from the mixer into the transfer pot which could pivot to facilitate discharge into the molds. 

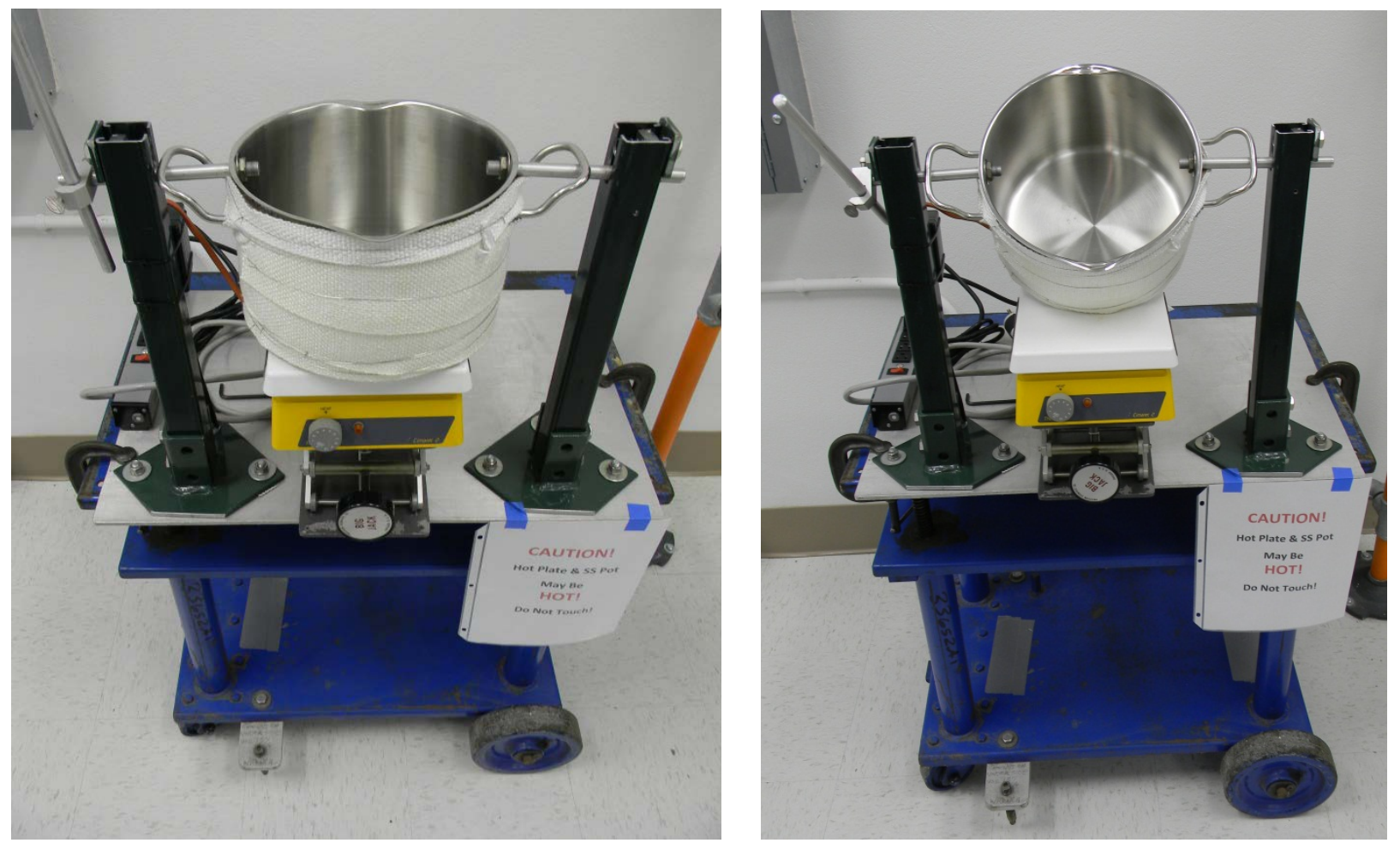

Figure 10. Heated vessel for pouring waste forms

3.6.2 Pre-Treatment System: In addition to the base case study, a pre-treatment system was tested using a ball-mill to size reduce the soil and binder mixture and aggressively mix the materials to enhance the reaction to HgS. This process modification was based on work done by Spanish scientists investigating techniques for SPSS processing of elemental $\mathrm{Hg}$ that showed the energetic mixing associated with a ball mill helped convert the elemental $\mathrm{Hg}$ to cinnabar or metacinnabar, two forms of stable HgS. [14,15]. A planetary ball mill (Retsch PM 100) shown in Figure 11, was used for the study. Its specifications are shown in Table 6.

Planetary ball mill mixing is based on the relative rotational movement of the grinding jar attached to the sun wheel of the mixer and the impact and friction generated by steel balls combined with the constituents in the grinding vessel. With this kinetic energy, the particle size of material is reduced and its surface area increases. Ball mills are used for mixing, homogenizing and mechanical alloying.

Table 6. Specifications for the planetary ball mill (Retsch PM 100)

\begin{tabular}{|l|c|}
\hline Milling speed (Sun wheel) & $100-650 \mathrm{rpm}$ \\
\hline Speed ratio (Sun wheel to grinding jar) & $1: 2$ \\
\hline Maximum speed of the jar & $1300 \mathrm{rpm}$ \\
\hline Effective sun wheel diameter & $141 \mathrm{~mm}$ \\
\hline Feed size & $<10 \mathrm{~mm}$ \\
\hline Batch/Sample volume & Max. $220 \mathrm{~mL}$ \\
\hline Power consumption & Approx. $1250 \mathrm{~W}$ \\
\hline
\end{tabular}




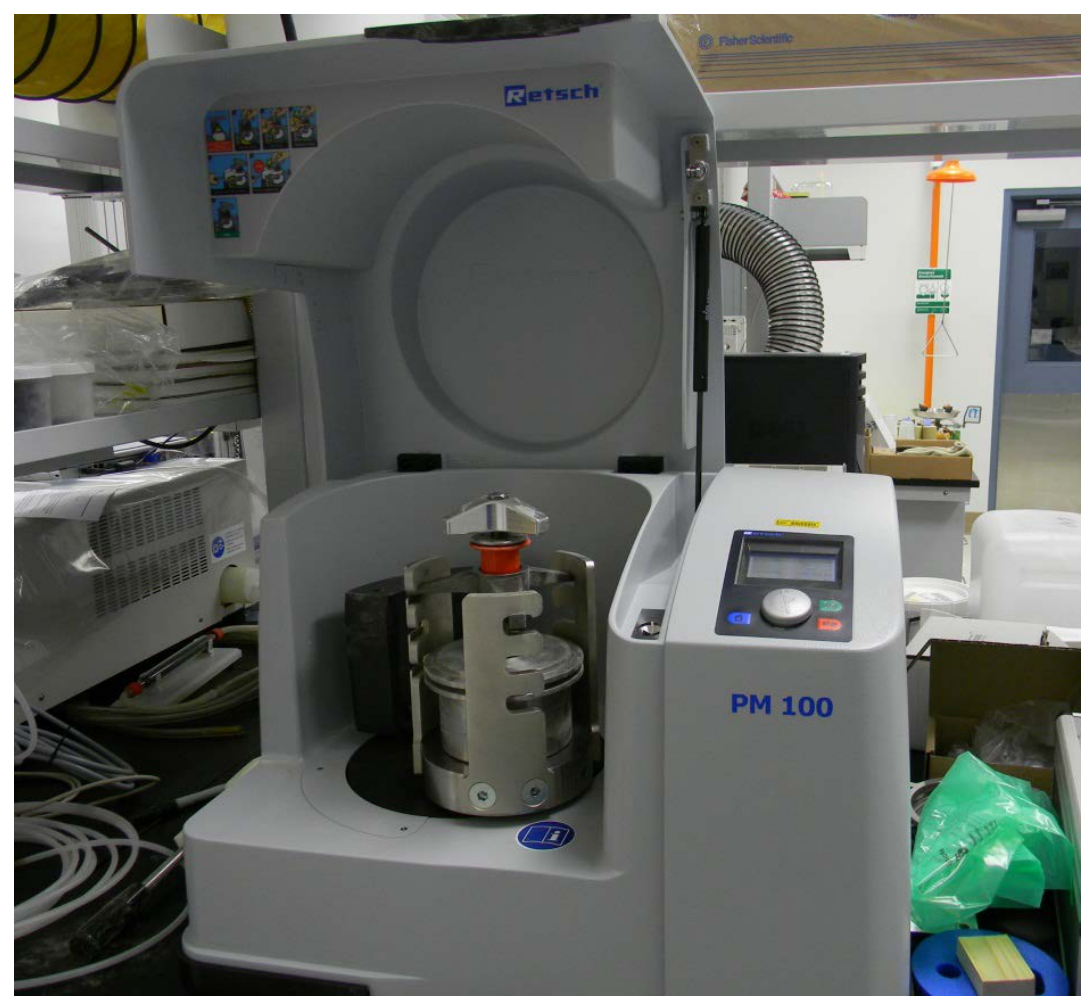

Figure 11. Laboratory ball mill for pre-treating $\mathrm{Hg}$ contaminated soils

\section{Process Development}

\subsection{Baseline SPSS Sample Preparation and Processing}

The SPSS process for $\mathrm{Hg}$ contaminated soil is conducted in three stages. In the first stage, sulfur in the SPC and sulfide additive reacts with $\mathrm{Hg}$ in the soil to form $\mathrm{HgS}$ which lowers the $\mathrm{Hg}$ vapor pressure and solubility. After combining reagents in a heated, dual planetary mixer, the process vessel is purged of oxygen by flushing with an inert cover gas (nitrogen) to reduce the formation of $\mathrm{Hg}$ oxides and is sealed. The soil and reagents in the closed system are then heated to $40-60^{\circ} \mathrm{C}$ to accelerate the reaction to $\mathrm{HgS}$. Once the stabilization reaction is complete the off-gas system is engaged and the remainder of the process occurs under negative pressure.

The speed of rotation of the orbital mixing arm in the planetary mixer was 27 RPM and the mixing blades rotated 2.35 times per rotation of the orbital arm for a total of rotational blade speed of 63.5 RPM. The rotational speed is adjustable through the gearbox, but is usually set for a given mix and not adjusted further.

In the second stage of processing, the temperature is raised and the soil mixture is heated under vacuum to remove the moisture. The temperature is ramped from $60^{\circ} \mathrm{C}$ to between 85 and $95^{\circ} \mathrm{C}$, below 
the melt temperature of the SPC. This allows the moisture in the soil to be driven off and condensed in the off-gas system and ensures that any fugitive $\mathrm{Hg}$ vapors are captured before entering the atmosphere. The majority of the $\mathrm{Hg}$ is retained in the mix however, due to the reduction in $\mathrm{Hg}$ vapor pressure associated with conversion to the sulfide form. Since the encapsulation process occurs above the boiling point of water, moisture removal eliminates foaming from trapped moisture vapor that would result in: 1) voids in the waste form leading to increased porosity and leaching, and 2) lower density and decreased process efficiency.

Once the moisture is removed, the temperature of the mixture is increased from about $95^{\circ} \mathrm{C}$ to between $125-130^{\circ} \mathrm{C}$ to thoroughly melt the SPC in the mixture for the final pouring/molding stage. At ambient pressure, melting occurs at $119^{\circ} \mathrm{C}$ but as shown in Table 7, under vacuum the SPC was observed on average to melt at just over $100{ }^{\circ} \mathrm{C}$. The stabilized $\mathrm{Hg}$ soil and molten SPC mixture is stirred for about 30 min. to form a homogeneous mixture.

Table 7. Observed SPC Melt Temperature

\begin{tabular}{|c|c|c|c|}
\hline $\begin{array}{c}\text { Mercury Soil } \\
\text { Concentration, } \\
\text { (ppm) }\end{array}$ & $\begin{array}{c}\text { Weight \% } \\
\text { Dry Soil }\end{array}$ & $\begin{array}{c}\text { Vacuum } \\
\text { (in. } \mathbf{~ H g})\end{array}$ & $\begin{array}{c}\text { Observed Melt } \\
\text { Temperature, } \\
\left({ }^{\circ} \mathbf{C}\right)\end{array}$ \\
\hline 135 & 50 & 20.00 & 102.0 \\
\hline \multirow{3}{*}{2,000} & 40 & 13.00 & 100.0 \\
\cline { 2 - 4 } & 50 & 16.50 & 101.5 \\
\cline { 2 - 4 } & 60 & 17.00 & 100.0 \\
\hline \multirow{5}{*}{10,000} & 40 & 16.00 & 97.5 \\
\cline { 2 - 4 } & 50 & 17.00 & 97.5 \\
\cline { 2 - 4 } & 60 & 17.00 & 102.0 \\
\cline { 2 - 4 } & 40 (Ball Mill) & 16.75 & 101.0 \\
\cline { 2 - 4 } & 50 (Ball Mill) & 18.00 & 105.0 \\
\hline & Mean & 16.8 & 100.7 \\
\cline { 2 - 4 } & Std Dev & 1.8 & 2.3 \\
\cline { 2 - 4 } & \% Error & $10.9 \%$ & $2.3 \%$ \\
\cline { 2 - 4 } & & & \\
\hline
\end{tabular}

In the final step, the molten mixture is then poured into a mold where it cools to form a solid monolithic waste form. For this study, two types of waste form molds were used to facilitate performance testing: 1) $5 \mathrm{~cm}$. diameter PVC pipe, approx. $60 \mathrm{~cm}$ in length for preparation of $5 \times 10 \mathrm{~cm}$ cylindrical mechanical testing samples, and 2) $9 \mathrm{~mm}$ thick Teflon molds for preparation of "miniature waste form" pellets that meet EPA particle size criteria for TCLP tests. Pouring of sample mixtures into cylindrical molds is shown in Figure 12. The size and shape of the final waste form can be varied but the larger the size, the longer the time required for cooling. For that reason, pouring over a large area at a relatively shallow depth, i.e., in shallow lifts, is preferable to maximize the surface area for cooling. 
After cooling, the cylindrical molds were cut to lengths of $10 \mathrm{~cm}$. using a diamond tipped wet saw. The saw and representative mechanical test samples are shown in Figure13. After cutting to the specified length, the PVC mold is scored and the waste form removed. A small amount of shrinkage resulting in a surface void occurs on cooling depending on waste loading, so the top $5-10 \mathrm{~cm}$ of the molds were discarded.

The EPA requires that samples for TCLP pass through a $9.5 \mathrm{~mm}$ sieve. Rather than break up encapsulated waste form samples, TCLP samples are cast as pellets in Teflon molds that meet EPA size requirements. The TCLP molds and sample preparation are shown in Figures 14 and 15.
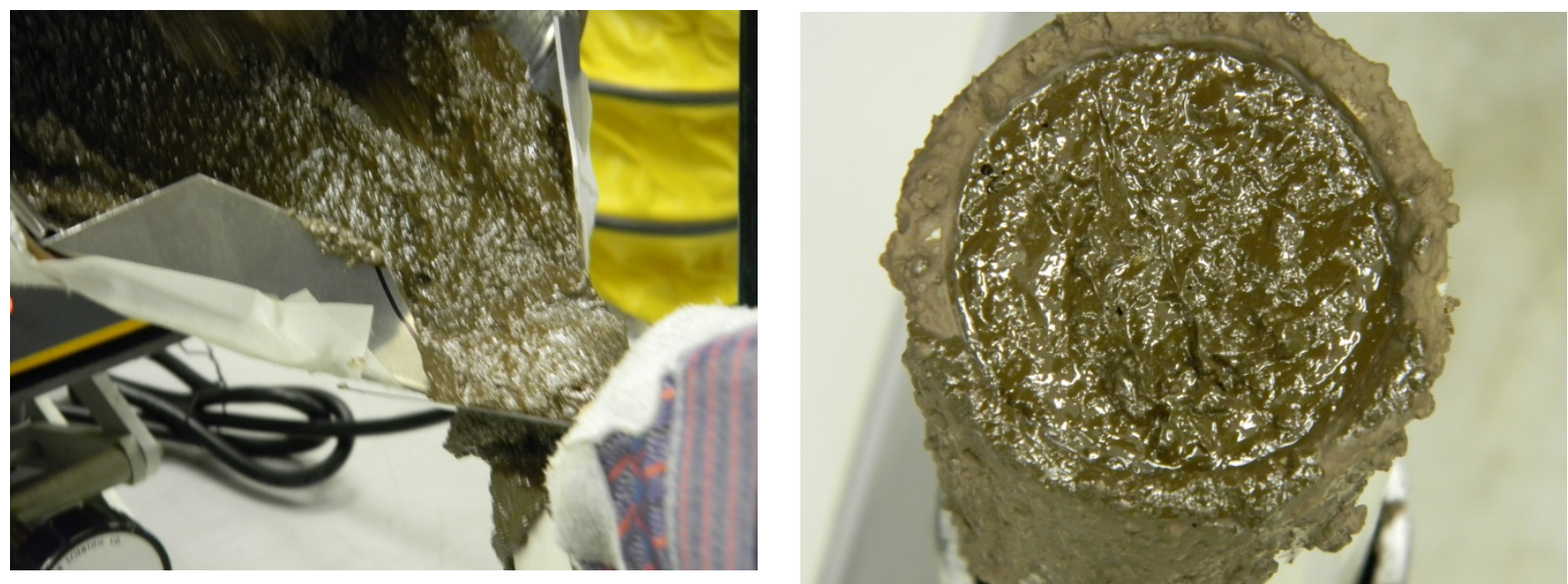

Figure 12. Molten mixture containing $40 \mathrm{wt} \%$ surrogate soil being poured (left) and cooling in cylindrical mold
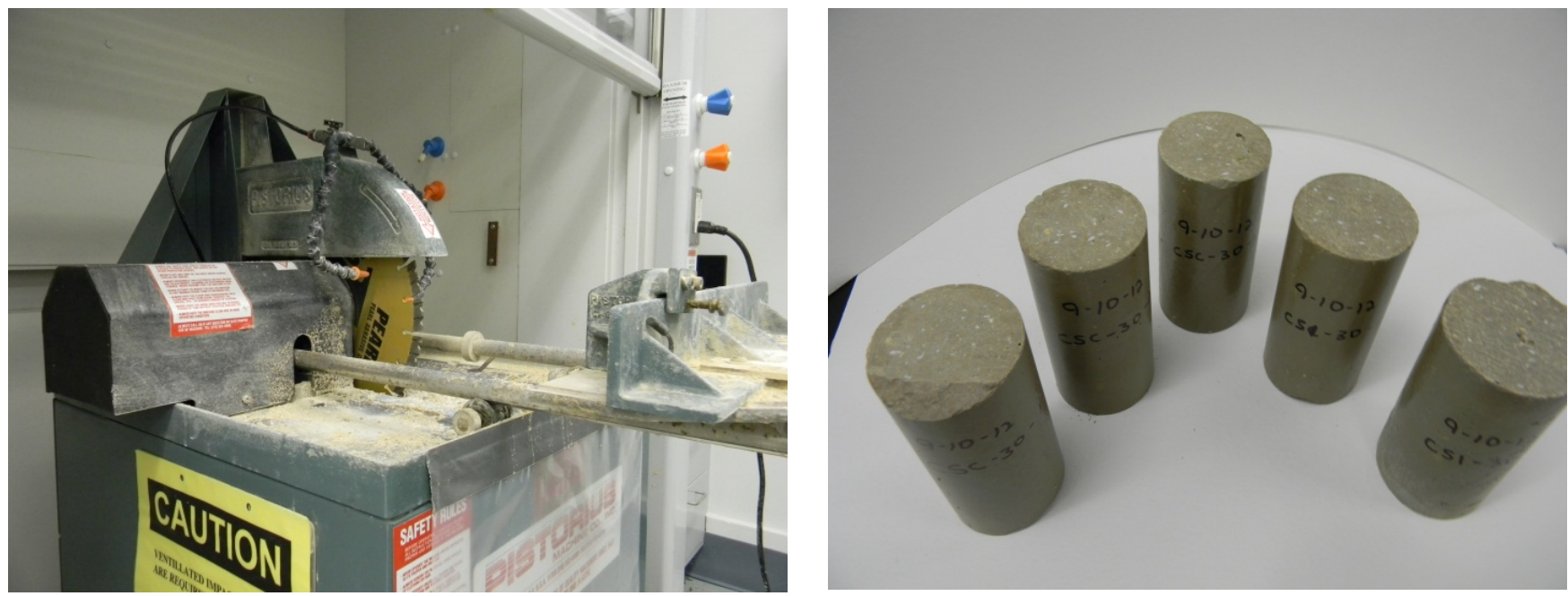

Figure 13. Diamond tipped wet saw (left) for cutting cylindrical test samples (right) 

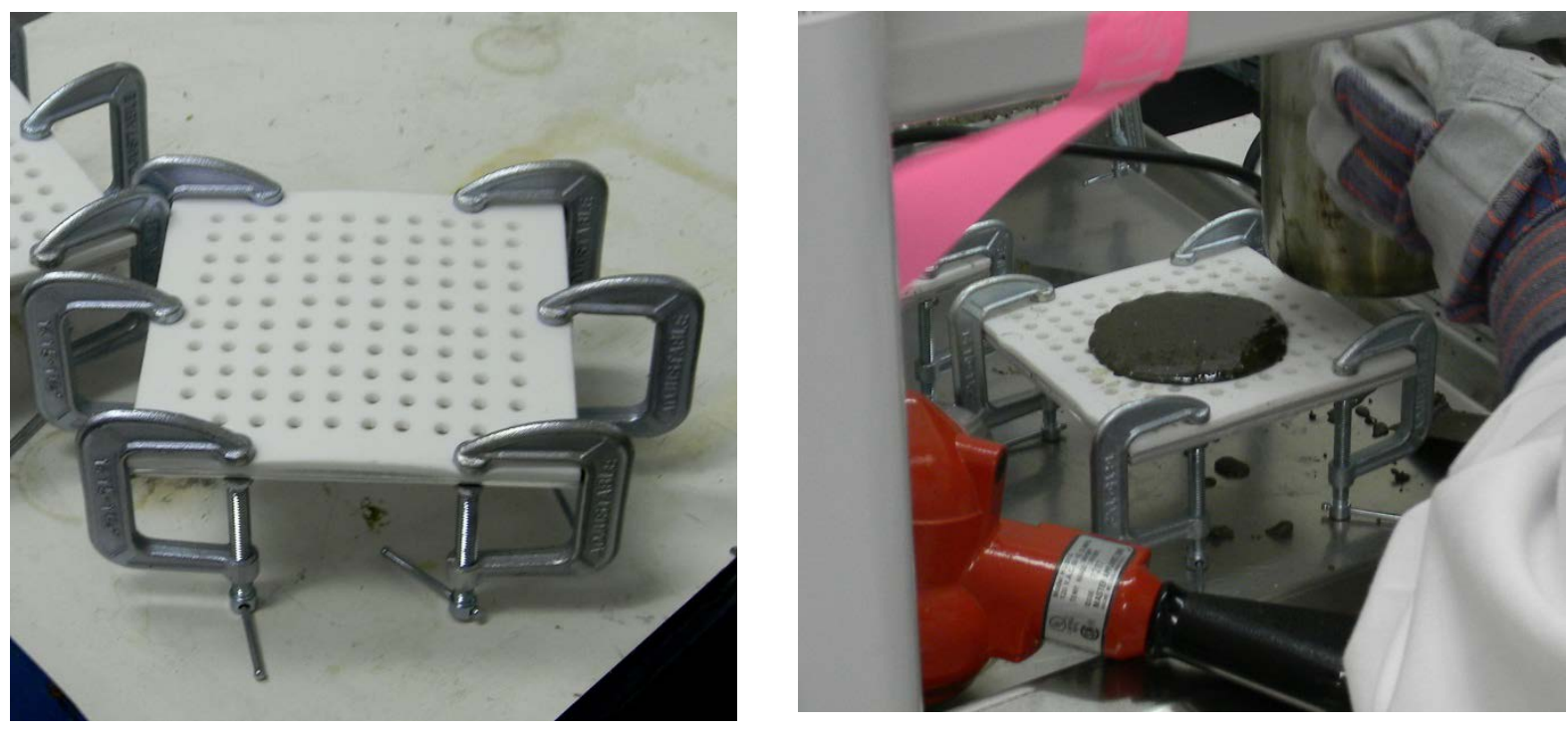

Figure 14 Preparing TCLP pellets by pouring into Teflon molds
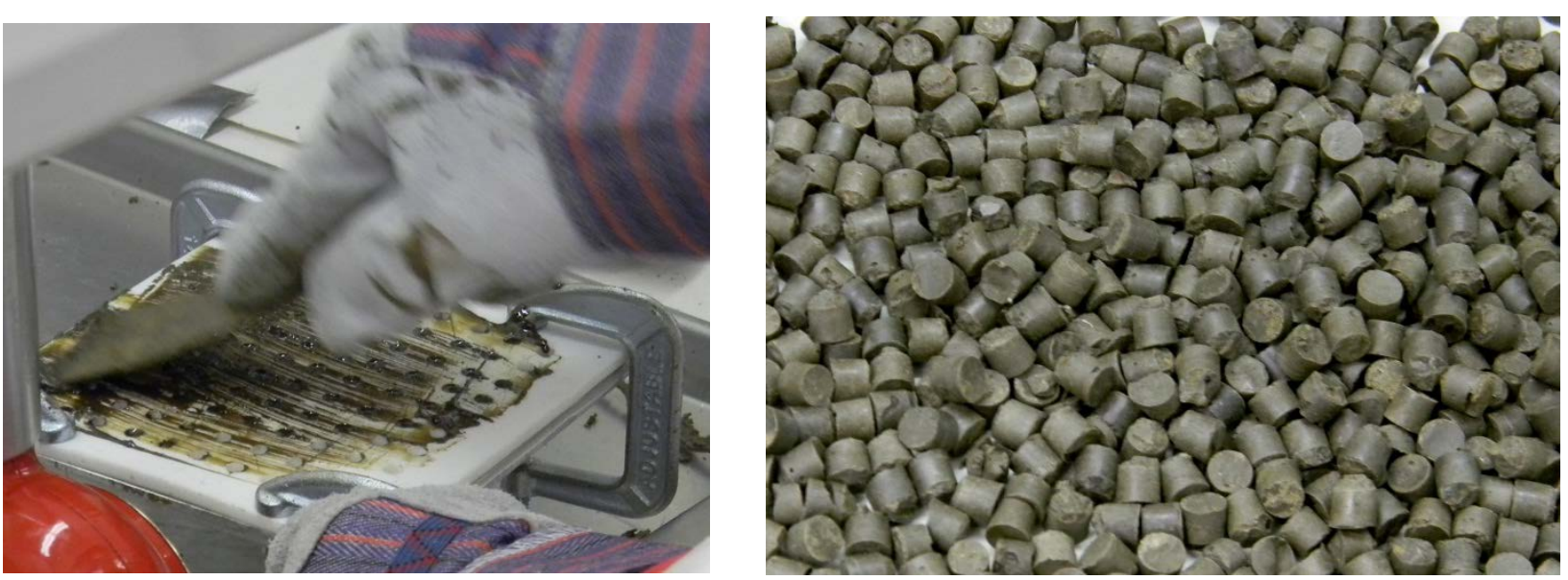

Figure 15 TCLP pellets being prepared (left) and ready for testing (right) 


\subsubsection{Process Optimization:}

Samples with varying amounts of $\mathrm{Y}-12$ soil were processed by the baseline SPSS process to determine maximum waste loadings and prepare test specimens for performance testing. The total mass of each batch was either $6 \mathrm{~kg}$ (for preparation of mechanical test samples) or $4 \mathrm{~kg}$ (for preparation of TCLP and other performance test samples). The constituents in each formulation are reported in terms of dry weight percent contained in the waste form so the quantity of as-received moist soil needed for each formulation was calculated considering the moisture content of the soil and assuming all of the moisture is removed during processing. Moist soil was weighed and placed in the mixer. Powdered SPC and sulfide additive were weighed and placed on top of the soil. For the $6 \mathrm{~kg}$ batches, the volume filled the mixer but once the sulfur melts, the total volume decreased as the molten sulfur displaces void space in the mix. While changes in waste volume before and after processing were not directly measured in this study, previous results treating $\mathrm{Hg}$ contaminated soil from the BNL site showed that for a waste loading of $50 \mathrm{wt} \%$, the volume of the final waste form was the same as the volume of the soil prior to treatment, i.e., no volume increase. Once the materials were charged, the mixer was then closed and sealed.

The speed of rotation of the orbital mixing arm in the planetary mixer was 27 RPM and the mixing blades rotated 2.35 times per rotation of the orbital arm for a total of 63.5 RPM. The rotational speed is adjustable through the gearbox, but is usually set for a given mix and not adjusted further.

The temperature profile history for a typical process run is shown in Figure 16. In this case, the process run was for a $50 \mathrm{wt} \%$ soil loading of the $10,000 \mathrm{ppm} \mathrm{Hg}$ soil. Profiles for the remaining process runs are included in the appendix. Temperature of the system is controlled by setting the digital control on the oil bath heater. For this system the digital setting does not represent the actual temperature of the bath so the reported settings are relative in nature. For example, setting the heater to $110^{\circ} \mathrm{C}$ results in a steady-state oil bath temperature of about $68^{\circ} \mathrm{C}$. The specific temperature settings varied slightly based on waste loading, moisture content, etc., but in general the oil bath heater digital set point was initially set above $100^{\circ} \mathrm{C}$ to provide a quick ramp up in temperature of the mix to the desired stabilization temperature range of $40-60^{\circ} \mathrm{C}$ and was lowered to maintain the mixture within the stabilization temperature zone. At equilibrium these settings raised the temperature of the heat transfer fluid approximately $3-10^{\circ} \mathrm{C}$ above the desired mix temperature. The amount of time required to stabilize the soil varies based on the $\mathrm{Hg}$ concentration, waste loading, etc. but for a typical run the stabilization time was two hours.

After the stabilization to $\mathrm{HgS}$ is complete, the oil bath set point was increased incrementally to $150^{\circ} \mathrm{C}$. This resulted in increasing the oil bath temperature of the mixing vessel to between $90-105^{\circ} \mathrm{C}$, which in turn, increased the mixture temperature to between $80-95^{\circ} \mathrm{C}$. The system was held at this temperature and with a vacuum of about $18 \mathrm{in.} \mathrm{Hg}$, for approximately two hours, until all the moisture was removed. This was determined by observing the condensate production in the off-gas system.

For the final phase, the temperature setting is raised to about $200^{\circ} \mathrm{C}$ and the temperature of the oil bath raised to about $150^{\circ} \mathrm{C}$. Once the mixture begins to melt, it is mixed for another 30 minutes to ensure a homogeneous molten mixture and the final processing temperature of $125-130^{\circ} \mathrm{C}$ is achieved before 
discharge to the final waste form mold. The final mix temperature prior to pouring into molds was between $120-125^{\circ} \mathrm{C}$.

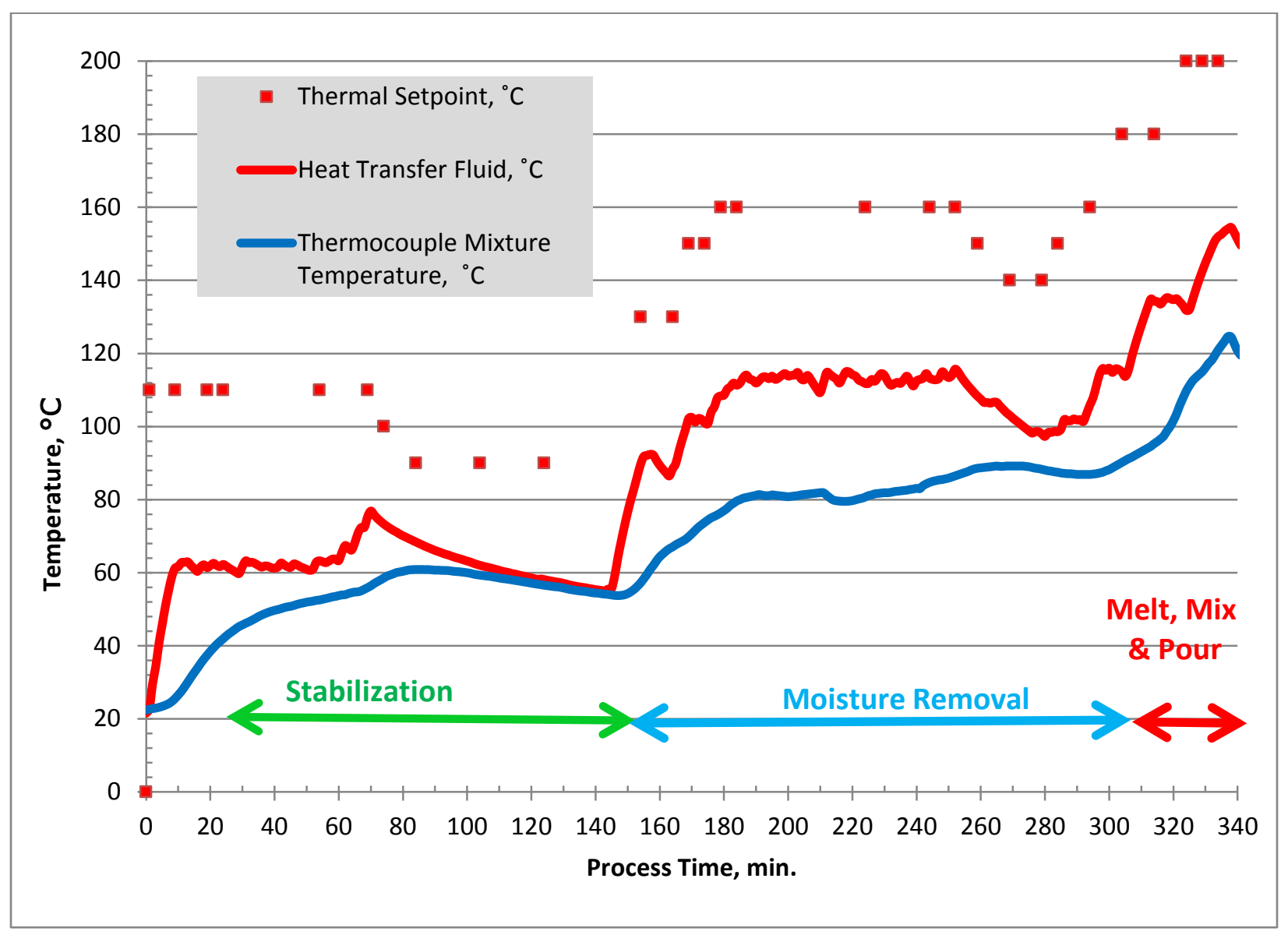

Figure 16 . Example of Process Data thermal profile for 60 wt\% High Hg $(10,000$ ppm) Hg Y-12 soil

Total process times shown in the set of Process Data thermal profiles included in the appendix, ranged from 245 - 394 minutes but averaged just under 5.5 hours ( $327 \pm 14 \%$ ). The longest run (baseline processing of $50 \mathrm{wt} \% 10,000 \mathrm{ppm}$ soil) was due to a clog in the off-gas condensate line that slowed moisture removal. The shortest run (pre-treatment run at $40 \mathrm{wt} \%$ ) was conducted to examine whether process time could be reduced based on the use of pre-treatment. By pre-treating, the stabilization step can be shortened or skipped. The $40 \mathrm{wt} \%$ pre-treated run $(245 \mathrm{~min}$.) reduced total process time by about $30 \%$ compared with the same waste loading using the baseline SPSS process (337 $\mathrm{min}$ ). 


\subsubsection{Mechanical Test Sample Formulation}

Mechanical test samples were fabricated using the baseline SPSS process with Oak Ridge surrogate soil and the unspiked ( $135 \mathrm{ppm} \mathrm{Hg}$ ) Y-12 soil. A total of 25 test specimens were produced for compressive strength and water immersion testing. Weights, dimensions and densities for these test samples are provided in Tables 8 and 9 for the Oak Ridge clean surrogate soil and Y-12 unspiked soil, respectively. Representative SPSS treated mechanical test samples are shown in Figure 17.

In general, the higher the waste loading (i.e., more soil per unit volume), the greater the density of the waste form. The one exception is for the $50 \mathrm{wt} \%$ clean Oak Ridge surrogate soil. In this case, the average density $\left(2.03 \mathrm{~g} / \mathrm{cm}^{3} \pm 2.9 \%\right)$ was lower than the $43 \mathrm{wt} \%$ sample $\left(2.06 \mathrm{~g} / \mathrm{cm}^{3} \pm 0.5 \%\right)$. The viscosity of the molten mixture for this loading with high clay content soil resisted flow and efficient packing in the cylindrical molds and the density variation is probably a result of the presence of small voids. One density measurement in particular (CSI-50-2) appeared to be anomalous and if removed from consideration the average density is $2.06 \pm 1.2 \%$.

Based on the viscosity of the surrogate soil mixtures, target waste loadings for $\mathrm{Y}$-12 soil were adjusted to bracket $30-50 \mathrm{wt} \%$. Density measurements for the actual Y-12 soils did not show evidence of voids. The average densities for the $30 \mathrm{wt} \%$ and $50 \mathrm{wt} \%$ samples were $2.09 \pm 1.1 \%$ and $2.22 \pm 0.2 \%$, respectively. Testing of these samples was conducted at BNL as described in Section 5.
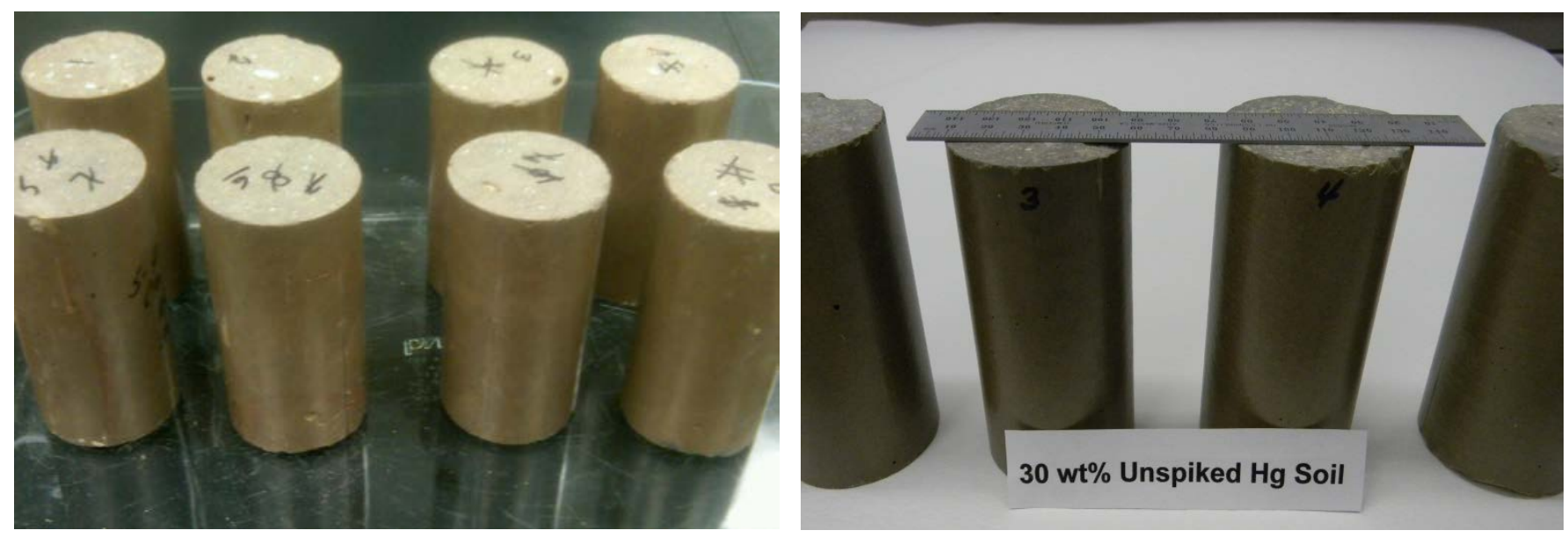

Figure 17. Mechanical test samples with clean surrogate soil (left) and unspiked Y-12 soil (right) 
Table 8. Clean Oak Ridge Soil Surrogate Mechanical Test Sample Weights, Dimensions and Densities

\begin{tabular}{|c|c|c|c|c|c|}
\hline Sample ID & $\begin{array}{l}\text { Mass, } \\
\text { (g) }\end{array}$ & $\begin{array}{l}\text { Length, } \\
\text { (cm) }\end{array}$ & $\begin{array}{l}\text { Diameter, } \\
\text { (cm) }\end{array}$ & $\begin{array}{l}\text { Volume, } \\
\text { (cc) }\end{array}$ & $\begin{array}{r}\text { Density } \\
\text { (g/cc) }\end{array}$ \\
\hline \multicolumn{6}{|c|}{40 wt\% Clean Surrogate Soil Loading: } \\
\hline CSC-40-1 & 441.93 & 10.10 & 5.27 & 220.31 & 2.01 \\
\hline CSC-40-2 & 450.65 & 10.22 & 5.27 & 222.93 & 2.02 \\
\hline CSI-40-1 & 449.61 & 10.12 & 5.28 & 221.58 & 2.03 \\
\hline CSI-40-2 & 450.51 & 10.16 & 5.27 & 221.62 & 2.03 \\
\hline Mean & 448.18 & 10.15 & 5.27 & 221.61 & 2.02 \\
\hline Std Dev & 4.19 & 0.05 & 0.01 & 1.07 & 0.01 \\
\hline \% Error & $0.93 \%$ & $0.52 \%$ & $0.09 \%$ & $0.48 \%$ & $0.59 \%$ \\
\hline \multicolumn{6}{|c|}{43 wt\% Clean Surrogate Soil Loading: } \\
\hline CSC-43-1 & 457.27 & 10.18 & 5.29 & 223.74 & 2.04 \\
\hline CSC-43-2 & 455.82 & 10.12 & 5.28 & 221.58 & 2.06 \\
\hline CSI-43-1 & 460.25 & 10.20 & 5.27 & 222.49 & 2.07 \\
\hline CSI-43-2 & 458.00 & 10.18 & 5.27 & 222.05 & 2.06 \\
\hline Mean & 457.84 & 10.17 & 5.28 & 222.47 & 2.06 \\
\hline Std Dev & 1.85 & 0.03 & 0.01 & 0.93 & 0.01 \\
\hline \% Error & $0.40 \%$ & $0.34 \%$ & $0.18 \%$ & $0.42 \%$ & $0.52 \%$ \\
\hline \multicolumn{6}{|c|}{50 wt\% Clean Surrogate Soil Loading: } \\
\hline CSC-50-1 & 459.40 & 10.13 & 5.29 & 222.64 & 2.06 \\
\hline CSC-50-2 & 454.90 & 10.19 & 5.28 & 223.12 & 2.04 \\
\hline CSC-50-3 & 466.90 & 10.15 & 5.29 & 223.08 & 2.09 \\
\hline CSI-50-1 & 458.60 & 10.20 & 5.30 & 225.03 & 2.04 \\
\hline CSI-50-2 & 432.60 & 10.13 & 5.30 & 223.49 & 1.94 \\
\hline Mean & 454.48 & 10.16 & 5.29 & 223.47 & 2.03 \\
\hline Std Dev & 12.98 & 0.03 & 0.01 & 0.92 & 0.06 \\
\hline \% Error & $2.86 \%$ & $0.33 \%$ & $0.16 \%$ & $0.41 \%$ & $2.91 \%$ \\
\hline
\end{tabular}


Table 9. Unspiked Y-12 Soil Mechanical Test Sample Weights, Dimensions and Densities

\begin{tabular}{|c|c|c|c|c|c|}
\hline Sample ID & Mass, ( g) & $\begin{array}{c}\text { Length, } \\
(\mathrm{cm})\end{array}$ & Diameter, $(\mathrm{cm})$ & Volume, (cc) & Density, (g/cc) \\
\hline \multicolumn{6}{|c|}{30 wt\% Unspiked Y-12 Soil Loading: } \\
\hline C-1A-30-1 & 446.53 & 10.00 & 5.20 & 212.37 & 2.10 \\
\hline$C-1 A-30-2$ & 460.92 & 10.11 & 5.20 & 214.71 & 2.15 \\
\hline$C-1 A-30-3$ & 444.38 & 10.01 & 5.20 & 212.58 & 2.09 \\
\hline $\mathrm{I}-1 \mathrm{~A}-30-1$ & 443.70 & 10.03 & 5.20 & 213.01 & 2.08 \\
\hline $\mathrm{I}-1 \mathrm{~A}-30-2$ & 435.39 & 9.95 & 5.19 & 210.50 & 2.07 \\
\hline $\mathrm{I}-1 \mathrm{~A}-30-3$ & 424.77 & 9.91 & 5.19 & 209.65 & 2.03 \\
\hline Mean & 442.62 & 10.00 & 5.20 & 212.14 & 2.09 \\
\hline Std Dev & 12.04 & 0.07 & 0.01 & 1.82 & 0.04 \\
\hline \% Error & 2.72 & 0.69 & 0.10 & 0.86 & 1.90 \\
\hline \multicolumn{6}{|c|}{50 wt\% Unspiked Y-12 Soil Loading: } \\
\hline$C-1 A-50-1$ & 482.35 & 10.10 & 5.23 & 216.98 & 2.22 \\
\hline$C-1 A-50-2$ & 480.73 & 10.07 & 5.24 & 217.16 & 2.21 \\
\hline$C-1 A-50-3$ & 482.73 & 10.12 & 5.23 & 217.41 & 2.22 \\
\hline $\mathrm{I}-1 \mathrm{~A}-50-1$ & 482.28 & 10.11 & 5.23 & 217.19 & 2.22 \\
\hline $\mathrm{I}-1 \mathrm{~A}-50-2$ & 478.07 & 10.01 & 5.23 & 215.04 & 2.22 \\
\hline $\mathrm{I}-1 \mathrm{~A}-50-3$ & 480.28 & 10.03 & 5.23 & 215.47 & 2.23 \\
\hline Mean & 481.07 & 10.07 & 5.23 & 216.54 & 2.22 \\
\hline Std Dev & 1.77 & 0.05 & 0.00 & 1.01 & 0.00 \\
\hline \% Error & 0.37 & 0.45 & 0.08 & 0.47 & 0.22 \\
\hline
\end{tabular}

\subsubsection{TCLP Sample Formulation:}

TCLP pellets and other performance test samples were fabricated using the baseline SPSS process with the medium $(2,000 \mathrm{ppm} \mathrm{Hg})$ and high $(10,000 \mathrm{ppm} \mathrm{Hg})$ concentration Y-12 soils. Processing of the actual Y-12 soil revealed significantly lower melt viscosities than were experienced with the clean Oak Ridge surrogate soil. After observing lower melt viscosities while formulating the Y-12 mechanical samples, target waste loadings were thus increased to $40-60 \mathrm{wt} \%$ for the remainder of performance test samples. Maximum waste loadings were constrained by the viscosity of the molten mixture; at 50 wt\% for the surrogate soil and $60 \mathrm{wt} \%$ for the $\mathrm{Y}-12$ soil, the consistency of the mix resembled cake batter and did not readily flow. Figure 18 is a photo comparing the SPSS melt viscosity of 40, 50, and 60 wt $\%$ mixtures of $\mathrm{Y}-12$ soils. BNL's pilot-scale system has a tapered cone geometry and considerably larger ( 3 in.) dia. discharge valve so improved discharge is anticipated from pilot- and scale process equipment. Mechanical test samples were poured using the modified transfer system described in Section 3.6.1. TCLP samples were poured into Teflon molds and spread by spatula.

The TCLP test requires test samples of 100g. A minimum of $300 \mathrm{~g}$ of TCLP pellets per process run were fabricated so that three $100 \mathrm{~g}$ replicate samples of each formulation could be tested. Additional final 
waste form pellet samples were fabricated for $\mathrm{pH}$, speciation, and excess sulfide testing. Three waste loadings, i.e., 40, 50, and $60 \mathrm{wt} \%$ were processed for each of the two Hg soil concentrations. Thus, a total of (3) waste loadings $\times(2)$ soil concentrations $\times(3)$ replicates, or (18) sets of 100g of TCLP samples were prepared. In addition, (2) replicate samples of $5 \mathrm{~g}$ of the $50 \mathrm{wt} \%$ baseline SPSS and pre-treated 10,000 ppm Hg Y-12 soil were prepared for speciation testing; (2) replicate samples of 20g each of the 50 wt\% baseline SPSS 10,000 ppm Hg Y-12 soil were prepared for waste form pH ; and (3) replicates of $10 \mathrm{~g}$ each of the $50 \mathrm{wt} \%$ baseline SPSS $10,000 \mathrm{ppm} \mathrm{Hg} \mathrm{Y}-12$ soil were prepared for excess sulfide measurement.
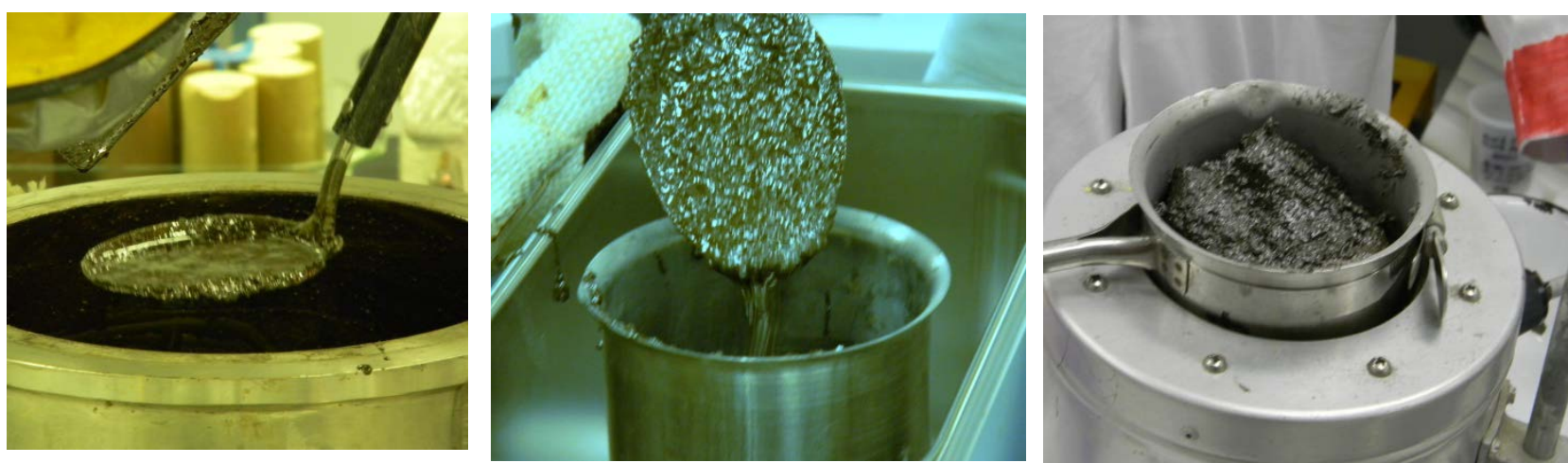

Figure 18. Comparison of melt viscosity for 40 (left), 50 (center) and $60 \mathrm{wt} \%$ (right) loadings

In addition to the TCLP test samples of stabilized and solidified SPSS treated Y-12 soils, a number of samples of stabilized soil (without solidification) were analyzed for comparison. These included high $(10,000 \mathrm{ppm})$ concentration $\mathrm{Hg}$ soil at $50 \mathrm{wt} \%$ loading processed in the same manner as the solidified samples and a series of samples taken after $15,30,60,120$, and $180 \mathrm{~min}$. of processing.

All samples were accompanied by Chain of Custody paperwork and shipped by overnight delivery to GEL Laboratories, except for the speciation samples, which were analyzed by Brooks Rand Laboratories.

\subsection{Pre-treatment Sample Preparation and Processing:}

The planetary ball mill was used to pre-treat high $(10,000 \mathrm{ppm}) \mathrm{Hg}$ concentration $\mathrm{Y}-12$ soils at both 40 and $50 \mathrm{wt} \%$ loadings. The bench-scale mill uses a $500 \mathrm{ml}$ stainless steel grinding jar with a maximum sample capacity of $220 \mathrm{ml}$. Three $40 \mathrm{~mm}$ diameter stainless steel balls were used for milling and several combinations of mix time and speed were tested. Figure 19 is a photo of the ball mill grinding jar with soil and following pre-treatment processing. The grinding jar was securely fastened to the planetary sun wheel for milling and the process time and rotational speed pre-set. Multiple treatment lots were run to obtain the $4 \mathrm{~kg}$ batch size for each baseline process run. After milling, the sample produced stuck to the wall and the bottom of the jar and was scraped out from the jar using a modified spatula. Following the ball mill pre-treatment the mix was transferred to the baseline process mixer for completion of the SPSS processing. The pre-treated (particle size reduced) soil caused an increase in viscosity of the molten mix, requiring a reduction in maximum waste loading to $50 \mathrm{wt} \%$. For the $40 \mathrm{wt} \% \mathrm{run}$, the stabilization step was skipped in the baseline process to test whether the process times could be shortened by pre-treatment (results discussed in Section 5.3.2. 

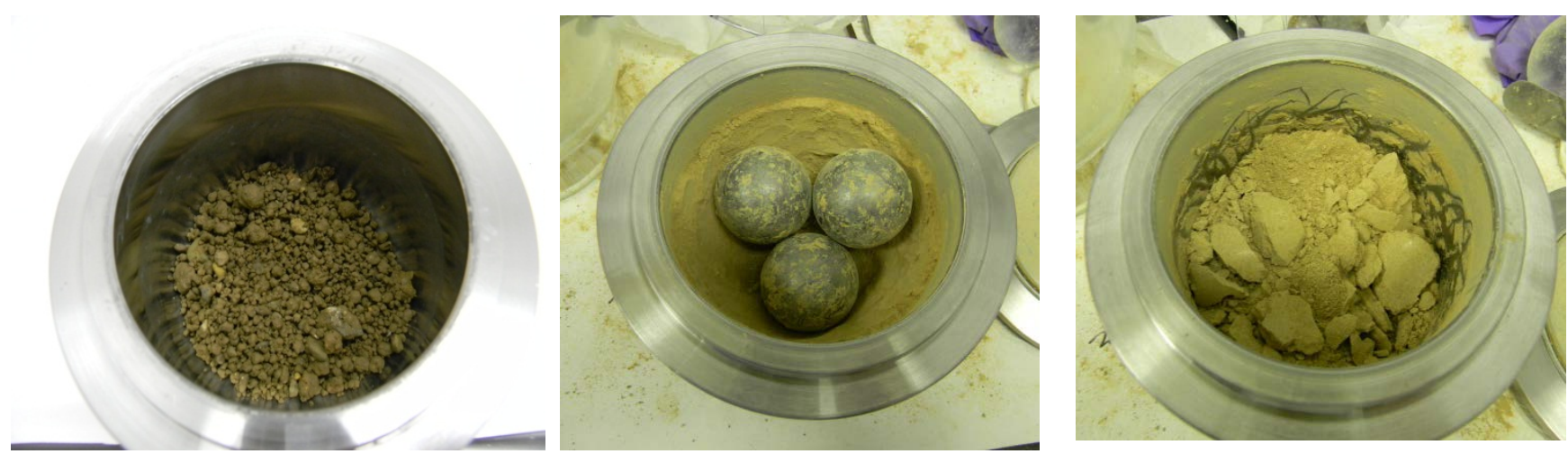

Figure 19. Ball mill pre-treatment of $\mathrm{Y}-12$ soil before (left) and after (right) processing. Balls shown in center.

The $40 \mathrm{wt} \%$ samples were pre-treated at $400 \mathrm{rpm}$ for 2 minutes. The $50 \mathrm{wt} \%$ samples were pre-treated at 400 RPM for 10 minutes. Following the pre-treatment mixing, the soil mixture was caked along the inside walls but was easily dislodged by gentle scraping. After milling, the temperature of the 50 wt\% samples measured by infrared thermometer, (Exergen, Model DX501), was about $50{ }^{\circ} \mathrm{C}$. The color of the constituents was slightly darker than that of the sample for $40 \mathrm{wt} \%$ loading indicating a possible conversion to metacinnabar. The mercury vapor in the head space of the jar was below detection limits of the mercury vapor detector, (Jerome Analyzer, Model J431X), of less than $0.001 \mathrm{mg} / \mathrm{m}^{3}$. The operational conditions for ball mill pre-treatment are summarized in Table 10.

Table 10. Pre-treatment parameters for 40 and 50 wt\% Y-12 soil loadings prior to SPSS processing

\begin{tabular}{|l|l|l|}
\hline Pre-Treatment Parameters & $40 \mathrm{wt} \% \mathrm{Y}-12$ Soil & $50 \mathrm{wt} \% \mathrm{Y}-12$ Soil \\
\hline Milling speed (Sun wheel) & $400 \mathrm{rpm}$ & $400 \mathrm{rpm}$ \\
\hline Milling time & 2 minutes & 10 minutes \\
\hline Volume of Jar & $500 \mathrm{~mL}$ & $500 \mathrm{~mL}$ \\
\hline Weight of Soil, SPC and Na2S per each batch: & & \\
$\bullet \quad$ Soil & $87.3 \mathrm{~g}$ & $107.4 \mathrm{~g}$ \\
$\bullet \quad$ SPC & $110.6 \mathrm{~g}$ & $90.0 \mathrm{~g}$ \\
$\bullet \quad 2.1 \mathrm{~g}$ & $2.6 \mathrm{~g}$ \\
\hline Total Weight of sample per batch & $200 \mathrm{~g}$ & $200 \mathrm{~g}$ \\
\hline
\end{tabular}

In addition to the solidified SPSS samples using pre-treated $\mathrm{Y}-12$ soils, samples of ball mill stabilized but unsolidified Y-12 soils were sent for TCLP testing. Two sets of 10,000 ppm Hg Y-12 soils were pretreated as shown in Table 11. The major differences between these two trials were the batch size $(200 \mathrm{~g}$ vs. $50 \mathrm{~g}$ ), rotational mixing speed (400 rpm vs.600 rpm) and mixing time (10 min vs. $8 \mathrm{~min}$.) for Trials 1 and 2, respectively. In addition, the mixing chamber was purged with nitrogen gas to remove the oxygen from the jar in Trial 2. After milling, the temperature of the Trial 2 sample measured by the infrared thermometer was about $80^{\circ} \mathrm{C}$ and the mercury vapor in the head space of the jar was not detected by the mercury vapor detector. About one third of the sample produced was a free flowing powder and the remainder was attached on the wall and the bottom of the jar, however, could be easily scrapped out using a modified spatula. The color of sample was dark gray to black. 
Table 11. Pre-treatment parameters for 50 wt\% Y-12 soil loadings without SPSS processing

\begin{tabular}{|l|c|c|}
\hline Pre-Treatment Parameters & $50 \mathrm{wt} \%$ Y-12 Soil, Trial 1* & $50 \mathrm{wt} \%$ Y-12 Soil, Trial 2** \\
\hline Milling speed (Sun wheel) & $400 \mathrm{rpm}$ & 600 \\
\hline Milling time & 10 minutes & 8 minutes \\
\hline Volume of Jar & $500 \mathrm{~mL}$ & $500 \mathrm{~mL}$ \\
\hline Weight of Soil, SPC and Na2S per batch & & \\
$\bullet \quad$ Soil & $107.4 \mathrm{~g}$ & $26.9 \mathrm{~g}$ \\
$\bullet \quad$ SPC & $90.0 \mathrm{~g}$ & $22.5 \mathrm{~g}$ \\
$\bullet \quad$ Na2S & $2.6 \mathrm{~g}$ & $0.6 \mathrm{~g}$ \\
\hline Total Weight of sample per batch & $200 \mathrm{~g}$ & $50 \mathrm{~g}$ \\
\hline
\end{tabular}

* Samples designated SS-3-50

**Samples designated SSBM-3-50

\subsection{Retention of $\mathrm{Hg}$ in the Final Waste Form}

Since the SPSS process is a closed system, $\mathrm{Hg}$ is either retained in the final waste form or captured in the off-gas system. The efficacy of the SPSS process to retain $\mathrm{Hg}$ in the stabilized final waste form was evaluated by monitoring the amount of $\mathrm{Hg}$ collected in the off-gas treatment train and comparing it with the total amount of mercury processed. The very small quantity of $\mathrm{Hg}$ that may be lost as a vapor to the air while charging and discharging the system was monitored by a Jerome analyzer, but for this calculation is neglected. As shown in Table 12, a total of approximately $126.4 \mathrm{~g}$ of Hg $(126,411 \mathrm{mg})$ was processed for all of the $\mathrm{Y}-12$ soils combined. Mercury collected in the off-gas system was determined by analyzing the $\mathrm{Hg}$ concentrations in a composite of all of the liquid condensate collected (Table 13) plus the activated carbon filter (Table 14) and integrating over the mass of each. Using this approach, a total of $0.373 \mathrm{mg}$ of $\mathrm{Hg}$ was captured in the off-gas system over the life of the study. Thus $>99.999 \%$ of the $\mathrm{Hg}$ processed was retained in the SPSS final waste form and $0.0003 \%$ was volatilized and captured in the off-gas system. The emissions from the off-gas system were monitored for $\mathrm{Hg}$ vapor using a Jerome analyzer to ensure no fugitive $\mathrm{Hg}$ vapors were being discharged.

These calculations are based on nominal $\mathrm{Hg}$ concentrations of 2,000, and 10,000 ppm $\mathrm{Hg}$ for the two spiked Y-12 soil processed. Subsequent analysis of the untreated nominal 10,000 ppm $\mathrm{Hg}$ soil indicate the actual $\mathrm{Hg}$ concentrations in the $\mathrm{Y}-12$ soil may be closer to $7,000 \mathrm{ppm}$, although this may be a function of heterogeneities in the $\mathrm{Hg}$ concentration. However, a sensitivity calculation assuming the spiked $\mathrm{Hg}$ concentrations were 1500 and $7000 \mathrm{ppm}$, respectively showed the increase in the percentage of $\mathrm{Hg}$ in the off-gas system to be only an additional $0.00016 \%$ and the percentage of $\mathrm{Hg}$ retained in the waste form still remains $>99.999 \%$. Potential deposition on the interior surfaces of the off-gas system was considered insignificant and was not measured. However, even with the extremely conservative assumption that an equal quantity of $\mathrm{Hg}$ was deposited as was measured in the condensate and filter media (i.e., the mass of $\mathrm{Hg}$ is doubled), the percentage of $\mathrm{Hg}$ in the off-gas system is $0.0006 \%$ and $>99.999 \%$ is still retained in the waste form. 
Table 12. Total Quantity of $\mathrm{Hg}$ Processed

\begin{tabular}{|c|c|c|c|c|c|c|}
\hline Treatment & $\begin{array}{c}\text { Hg Concentration, } \\
\text { ppm }\end{array}$ & Waste Loading & Dry Soil, $\mathbf{g}$ & Wet Soil, $\mathrm{g}$ & $\begin{array}{l}\text { Hg in } \\
\text { Soil, } g\end{array}$ & $\begin{array}{l}\text { Total Hg in } \\
\text { Soil, } \mathrm{g}\end{array}$ \\
\hline \multirow{8}{*}{ Baseline SPSS } & 135 & $30 \mathrm{wt} \%$ & 1,800 & 2133 & 0.288 & \multirow{8}{*}{84.594} \\
\hline & 135 & $50 w t \%$ & 3,000 & 3534 & 0.477 & \\
\hline & 2000 & $40 w t \%$ & 1,600 & 1885 & 3.769 & \\
\hline & 2000 & 50 wt\% & 2,000 & 2356 & 4.711 & \\
\hline & 2000 & $60 \mathrm{wt} \%$ & 2,400 & 2827 & 5.654 & \\
\hline & 10000 & $40 w t \%$ & 1,600 & 1859 & 18.585 & \\
\hline & 10000 & 50 wt $\%$ & 2,000 & 2323 & 23.232 & \\
\hline & 10000 & $60 \mathrm{wt} \%$ & 2,400 & 2788 & 27.878 & \\
\hline \multirow{2}{*}{$\begin{array}{l}\text { Ball Mill Pre- } \\
\text { Treatment }\end{array}$} & 10000 & $40 \mathrm{wt} \%$ & 1,600 & 1859 & 18.585 & 18.585 \\
\hline & 10000 & $50 \mathrm{wt} \%$ & 2,000 & 2323 & 23.232 & 23.232 \\
\hline Total & & & & & & 126.411 \\
\hline
\end{tabular}

Table 13. Quantity of Hg Collected in Off- Gas Condensate

\begin{tabular}{|c|c|c|c|c|c|}
\hline Treatment & $\begin{array}{c}\text { Hg Concentration, } \\
\text { ppm }\end{array}$ & Condensate, g & $\begin{array}{c}\text { Composite } \\
\text { Condensate, } \mathrm{g}\end{array}$ & $\begin{array}{c}\text { Hg Concentration } \\
\text { in Condensate, } \\
\mathrm{mg} / \mathrm{l}\end{array}$ & $\begin{array}{c}\mathrm{Hg} \text { in } \\
\text { Condensate, } \\
\mathrm{mg}\end{array}$ \\
\hline \multirow{8}{*}{ Baseline SPSS } & 135 & 271 & \multirow{8}{*}{2667.88} & \multirow{8}{*}{0.00833} & \multirow{8}{*}{0.022} \\
\hline & 135 & 498.7 & & & \\
\hline & 2000 & 257.7 & & & \\
\hline & 2000 & 320.92 & & & \\
\hline & 2000 & 365.38 & & & \\
\hline & 10000 & 246.98 & & & \\
\hline & 10000 & 318.72 & & & \\
\hline & 10000 & 388.48 & & & \\
\hline \multirow{2}{*}{$\begin{array}{l}\text { Ball Mill Pre- } \\
\text { Treatment }\end{array}$} & 10000 & 250.6 & 250.6 & 0.0692 & 0.017 \\
\hline & 10000 & 217.8 & 217.8 & 0.0538 & 0.012 \\
\hline Total & & & & & 0.051 \\
\hline
\end{tabular}

Table 14. Quantity of Hg Collected in Off-Gas Carbon Filter

\begin{tabular}{|c|c|c|c|c|}
\hline Treatment & $\begin{array}{c}\text { Hg Concentration, } \\
\text { ppm }\end{array}$ & Carbon Filter, $\mathrm{g}$ & $\begin{array}{l}\text { Hg Concentration in } \\
\text { Filter, } \mathrm{mg} / \mathrm{kg}\end{array}$ & $\begin{array}{c}\mathrm{Hg} \text { in Carbon Filter, } \\
\mathrm{mg}\end{array}$ \\
\hline \multirow{8}{*}{ Baseline SPSS } & 135 & \multirow{10}{*}{70.1} & \multirow{10}{*}{4.59} & \multirow{10}{*}{0.322} \\
\hline & 135 & & & \\
\hline & 2000 & & & \\
\hline & 2000 & & & \\
\hline & 2000 & & & \\
\hline & 10000 & & & \\
\hline & 10000 & & & \\
\hline & 10000 & & & \\
\hline \multirow{2}{*}{$\begin{array}{l}\text { Ball Mill Pre- } \\
\text { Treatment } \\
\end{array}$} & 10000 & & & \\
\hline & 10000 & & & \\
\hline Total & & & & 0.322 \\
\hline
\end{tabular}




\section{Waste Form Performance Testing}

Results of waste form performance testing are presented and discussed in this section. These include mechanical integrity tests (compressive strength and immersion testing), TCLP, Hg speciation, excess sulfide, and $\mathrm{pH}$.

\subsection{Compressive strength}

Compressive strength was measured as a means of assessing long-term mechanical integrity of the final waste forms. The U.S. Nuclear Regulatory Commission, (NRC) recommends a minimum compressive strength of 60 psi for low-level radioactive wastes that are being disposed by shallow land burial. [16] This minimal strength is the amount needed to withstand typical soil over burden in disposal. Compressive strength of the final waste forms was measured according to ASTM C-39, Standard Test Method for Compressive Strength of Cylindrical Concrete Specimens.[17] Testing was conducted at BNL using a calibrated Instron Model 5582 Materials Tester (Figure 20). Stress-strain curves were generated (example in Figure 21) and maximum strength at failure was calculated for each specimen. Two or three replicate samples were tested at each waste loading and average compressive strength is given in Tables 15 and 16 , for the surrogate and $Y-12$ soils, respectively.
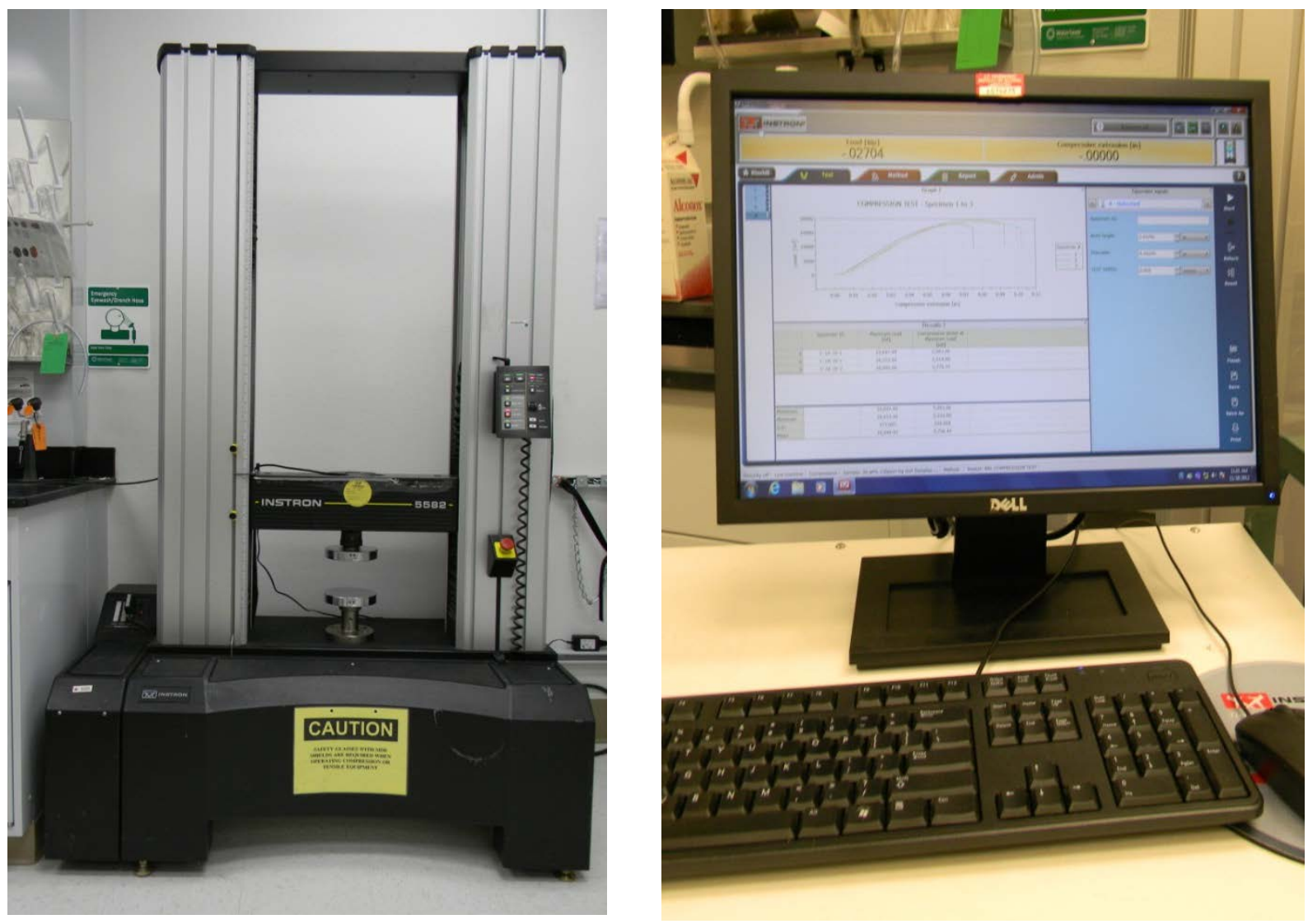

Figure 20. Instron Model 5582 Compression Tester (left) and Computer Control/Output (right) 


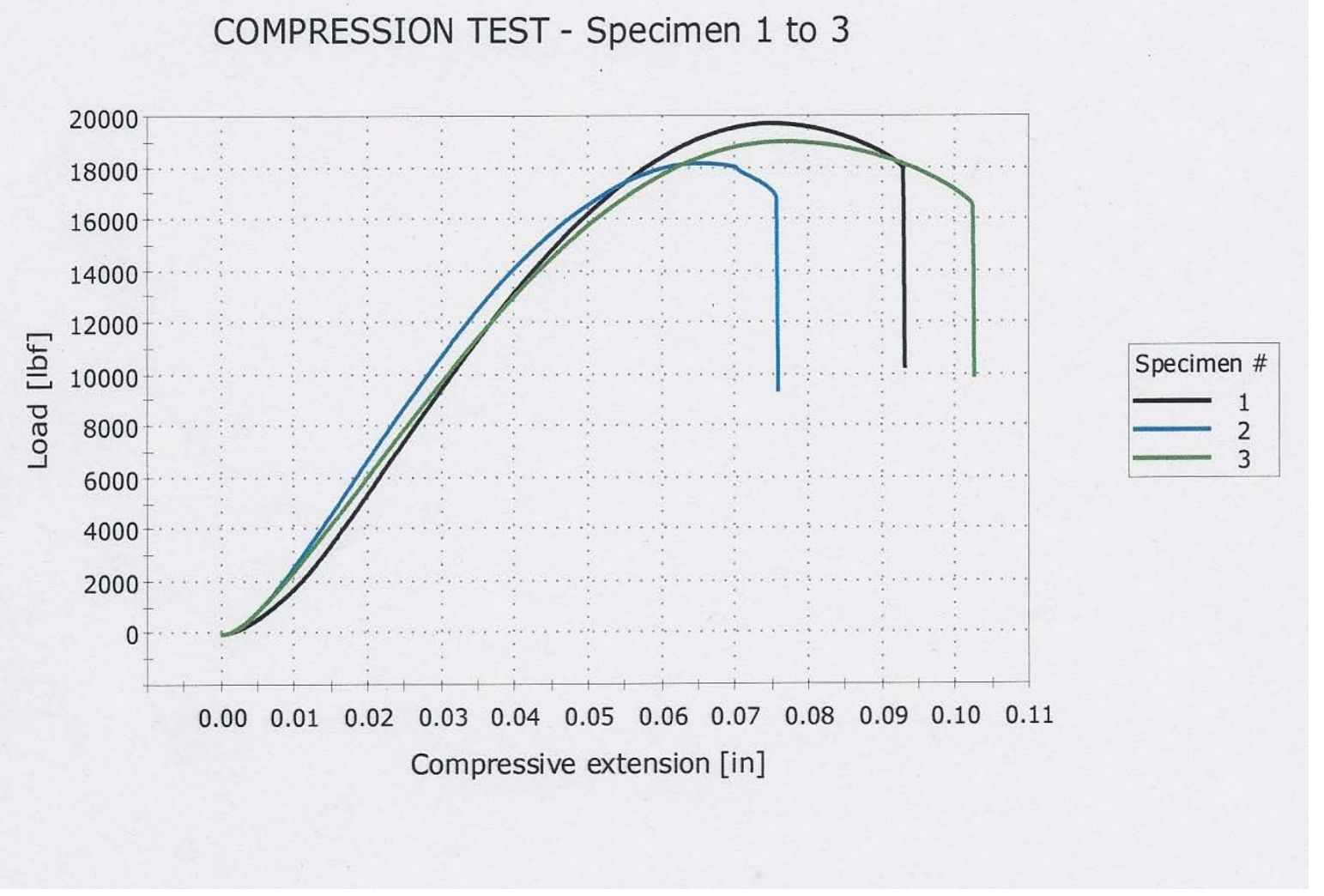

Figure 21. Compression Test Stress-Strain Curve for SPSS Treated 30 wt\% Y-12 Soil

For both surrogate and actual $\mathrm{Y}-12$ treated soils, waste form compressive strengths ranged between 2,300 and 6,500 psi, indicating very strong mechanical integrity (a minimum of $>40$ times greater than the NRC guidance for low-level radioactive waste). In general, compressive strength increases with waste loading as the soil acts as an aggregate in the sulfur concrete waste forms. The one exception in these tests were the highest waste loading ( $50 \mathrm{wt} \%$ ) clean Oak Ridge surrogate soil which had the lowest strength. This is probably due to the presence of voids in the sample molds due to poor compaction of the viscous mixture. The equivalent waste loading of $Y-12$ soil demonstrated the highest mechanical strength; the viscosity of this mixture allowed for improved packing in the molds. 


\subsection{Immersion Testing}

The U.S. NRC recommends 90 day water immersion testing of waste forms to simulate conditions that would be experienced under saturated disposal conditions. [8] Waste forms are observed for changes in physical condition (e.g., swelling or cracking) and are then compression tested to determine if there is any loss in integrity compared with samples that did not undergo immersion. Because of the time constraints for completion of this study, samples could not be tested for the full 90 days. The surrogate samples which were processed first were tested for 56 - 65 days in immersion, while the Y-12 soil samples were tested for 21 days in immersion.

Despite the fact that the Oak Ridge surrogate soil had a high clay content, as seen in Table 15, no statistically significant loss in strength was recorded for the 30 and $40 \mathrm{wt} \%$ samples and only a minor reduction in strength was measured for the 43 wt\% waste forms. Figure 22 is a photo of the 43 wt\% surrogate soil waste forms after 65 days in immersion. Note there are no apparent physical changes in the waste form. The $50 \mathrm{wt} \%$ surrogate soil waste forms however, did suffer a significant (77\%) loss in strength after 56 days. As seen in Table 16, the $30 \mathrm{wt} \%$ Y-12 soil did not show a significant loss in strength but the $50 \mathrm{wt} \%$ samples were severely degraded in immersion. For these immersion samples, cracking was evident after just 18 hours, severe swelling and cracking by 7 days, and after 11 days the samples had swelled to the point where all mechanical integrity was lost (Figure 23).

These water immersion test data emphasize the potential impact of non-hazardous constituents in the waste soil on the long-term durability of the waste form. Specifically, clay-bearing soils and high salt content materials are known to be problematic for solidification regardless of the binder. Their shrinking and swelling properties create large osmotic pressures within the waste form that can result in cracks and/or structural failure. The NRC 90 day immersion test is a good indicator of how the waste form will behave over longer periods. However, BNL has shown that failures usually occur in significantly less time so that if little deterioration is observed or measured after several weeks in immersion, the waste form will likely maintain structural integrity over extended periods under saturated conditions. For the Oak Ridge surrogate soil, SPSS waste forms had sufficient tensile strength to resist osmotic pressures at a loading of $43 \mathrm{wt} \%$ but degraded at $50 \mathrm{wt} \%$. In previous work, BNL demonstrated that the use of additives (e.g., glass fibers) can improve tensile strength of the waste forms so that swelling forces of expanding waste under saturated conditions can be withstood without cracking or loss of mechanical integrity.[2] Since the $\mathrm{Y}-12$ soils were unaffected at $30 \mathrm{wt} \%$ and also failed at $50 \mathrm{wt} \%$, it is reasonable to assume loadings of $40-43 w t \%$ would resist degradation under saturated conditions.

Implications for the loss of mechanical integrity under saturated conditions should be evaluated in context. For simple encapsulation of contaminants (e.g., radioactive elements) loss of waste form integrity can lead to higher leach rates due to increased porosity. For SPSS, however, the Hg has been converted to stable cinnabar (HgS) which has a very low solubility and thus leaches at a very slow rate. Since this conversion was confirmed through speciation testing (discussed in Section 5.3.6), leaching even after loss of mechanical integrity is not expected to be significant. 
Table 15. Compressive Strength of SPSS Treated Oak Ridge Surrogate Soil Before and After Immersion

\begin{tabular}{|c|r|r|}
\hline \multirow{2}{*}{$\begin{array}{c}\text { Waste Loading, } \\
\text { wt\% }\end{array}$} & \multicolumn{3}{|c|}{ Average Compressive Stress at Maximum Load } \\
\cline { 2 - 4 } & Before Immersion & Following Immersion* \\
\hline 30 & $5,677 \pm 23.6 \%$ & $4,740 \pm 4.9 \%$ \\
\hline 40 & $3,043 \pm 33.6 \%$ & $3,066 \pm 2.1 \%$ \\
\hline 43 & $6,376 \pm 1.7 \%$ & $4,407 \pm 0.7 \%$ \\
\hline 50 & $2,321 \pm 10.2 \%$ & $531 \pm 20.0 \%$ \\
\hline
\end{tabular}

*All samples were immersed for 65 days except the 50 wt\% (56 days)

Table 16. Compressive Strength of SPSS Treated Y-12 Soil Before and After Immersion

\begin{tabular}{|c|r|c|}
\hline \multirow{2}{*}{$\begin{array}{c}\text { Waste } \\
\text { Loading, } \\
\text { wt\% }\end{array}$} & \multicolumn{2}{|c|}{ Average Compressive Stress at Maximum Load } \\
\cline { 2 - 3 } & Before Immersion & Following Immersion* \\
\hline 30 & $5,757 \pm 4.1 \%$ & $5,287 \pm 14.59$ \\
\hline 50 & $6,459 \pm 9.0 \%$ & sample failures \\
\hline
\end{tabular}

*Samples immersed for 21 days; sample failures in 50 wt\% samples after 7 days 


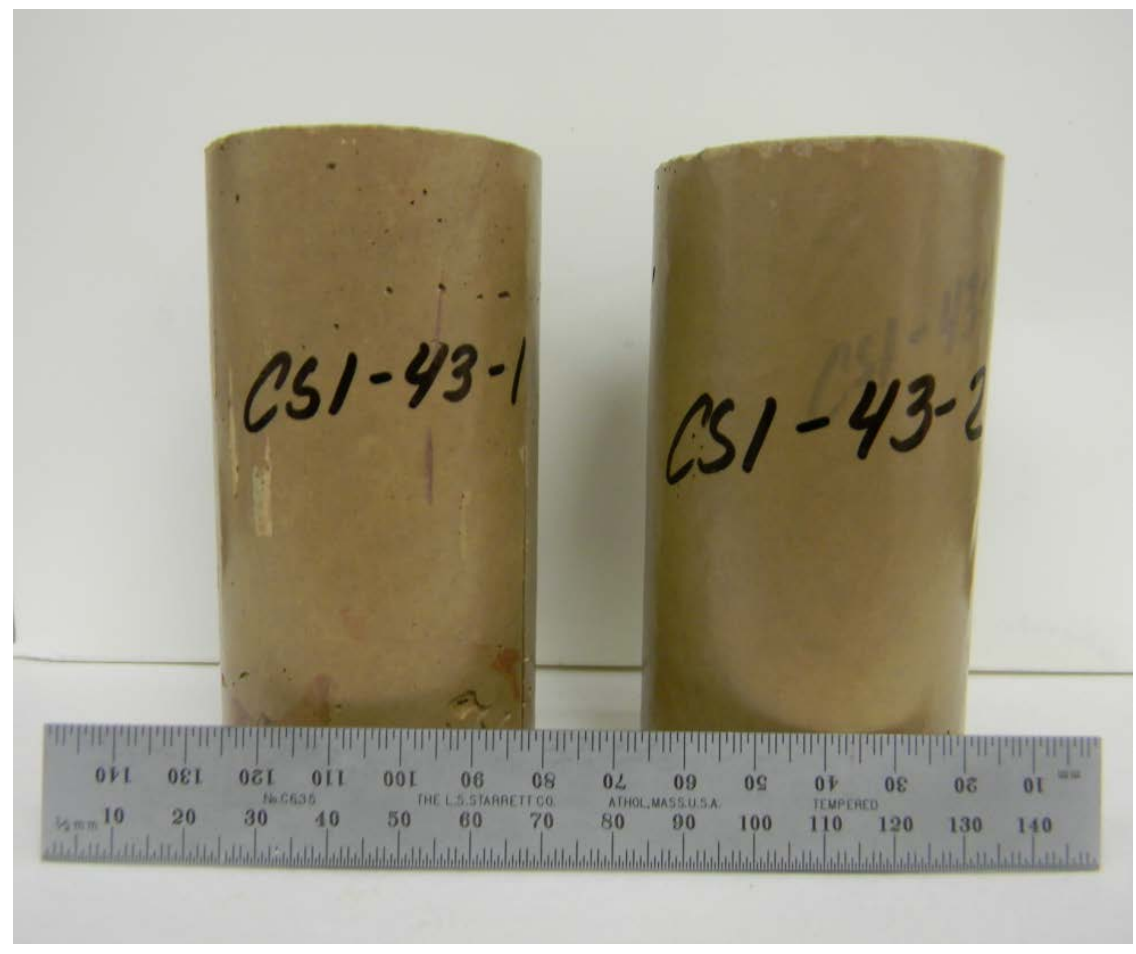

Figure 22. SPSS Treated 43 wt $\%$ Y-12 Soil Samples Following 65 days in Water Immersion
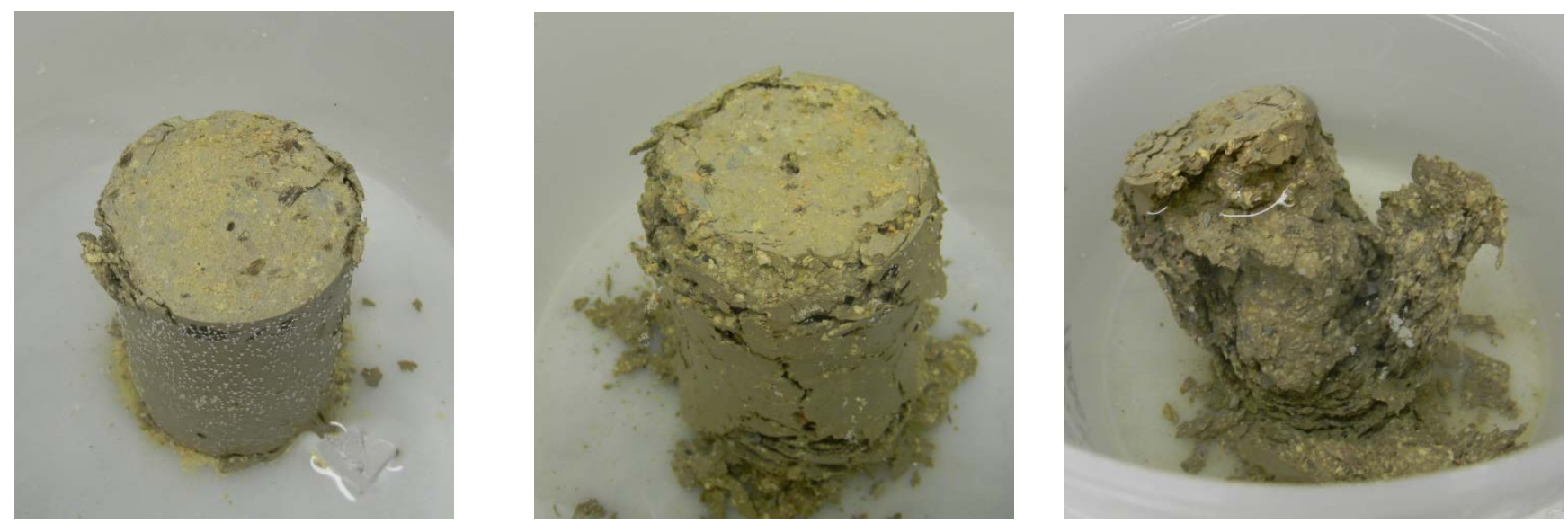

Figure 23. 50 wt\% Y-12 Soil in Immersion after 18 hrs (left), 7 days (center), and 11 days (right) 


\subsection{TCLP Testing}

A total of seventeen sets of TCLP test specimens were prepared for analysis. This included samples of the two untreated spiked Y-12 soils, three waste loadings of 2,000 ppm Hg Y-12 soil, three waste loadings of $10,000 \mathrm{ppm} \mathrm{Hg}$ contaminated Y-12 soils, two waste loadings of the pre-treatment SPSS formulations, and seven sets of soil for stabilization without solidification. Each set contained three replicate 100g samples for a total of 51 samples shipped to the independent analytical lab (GEL Labs) selected by UCOR.

\subsubsection{TCLP of Untreated Soil:}

BNL took (3) replicate $100 \mathrm{~g}$ samples of each of the two untreated spiked Y-12 soils for TCLP analysis by GEL Laboratories. Untreated Y-12 soils spiked to 2,000 and $10,000 \mathrm{ppm}$ Hg failed TCLP and thus are EPA characteristic hazardous waste. Considering the radiological contamination these soils are considered mixed waste. The mean TCLP of S-1B soil (2000 ppm Hg soil) is 6,596 $\pm 9 \%$ ppb, 33 times higher than TCLP limit of 200 ppb. The mean TCLP for S-2 soil (10,000 ppm Hg soil) is $11,947 \pm 19 \%$ ppb, 60 times higher than TCLP limit of 200 ppb. Two of the three replicates were tightly grouped $(13,400$ and 13,100$)$ and one was considerably lower $(9,340 \mathrm{ppb})$. This increased the variability in the measurement (higher percent error) and is an indication of the difficulty in homogenizing soils containing high concentrations of elemental Hg. The TCLP leaching performance of the untreated soil is a useful metric for comparison with the treated soil performance in evaluating how well the treatment technology performed.

\subsubsection{TCLP of SPSS Treated Soil}

Average leach test results from GEL Laboratories for the three sets of treated samples (baseline SPSS with 2,000 ppm Hg, baseline SPSS with 10,000 ppm Hg, and pre-treated SPSS with $10,000 \mathrm{ppm} \mathrm{Hg}$ ) are summarized in Tables 17. The untreated soil data are indicated as zero waste loading. Raw data for individual test samples and statistics are included in the appendix. Leach data for SPSS treated soils do not consider the quantity of waste contained so comparison with the untreated waste is not precisely equivalent. A conservative method of normalizing the data for comparison is to adjust treated soil results so they represent the same amount of soil and therefore, the same quantity of $\mathrm{Hg}$. This normalization is presented for comparison to better indicate the ability of the treatment process for immobilization of $\mathrm{Hg}$ and demonstrate results are not simply due to dilution. Thus SPSS leach data is presented as the actual concentration reported by the analytical laboratory and normalized to represent the same quantity of soil in each formulation (e.g., a factor of two for the $50 \mathrm{wt} \%$ samples). From a regulatory perspective, however as long as the treatment is not based solely on dilution, the raw TCLP data apply. 
Table 17. Average TCLP Data for Baseline and Pre-Treated SPSS Processing vs. Untreated Soils

\begin{tabular}{|r|r|r|}
\hline $\begin{array}{c}\text { Waste Loading, } \\
\text { wt\% }\end{array}$ & $\begin{array}{c}\text { TCLP*, } \\
\mathrm{ppb}\end{array}$ & $\begin{array}{c}\text { Normalized TCLP, } \\
\mathrm{ppb}\end{array}$ \\
\hline \multicolumn{3}{|c|}{ 2,000 ppm Y-12 Soil, Baseline SPSS Process } \\
\hline 0 & 6596.7 & 6596.67 \\
\hline 40 & 14.8 & 37.00 \\
\hline 50 & 2.4 & 4.58 \\
\hline 60 & 1.1 & 1.82 \\
\hline $10,000 p p m$ Y-12 Soil, Baseline SPSS Process & 11946.7 \\
\hline 0 & 11946.67 & 600.83 \\
\hline 40 & 240.3 & 93.87 \\
\hline 50 & 46.9 & 2.12 \\
\hline 60 & 1.3 & 11946.7 \\
\hline $10,000 p p m$ Y-12 Soil, Pre-Treatment Process \\
\hline 0
\end{tabular}

*RCRA criteria for Hg leachability under TCLP is $200 \mathrm{ppb}$

In general, the TCLP results for SPSS treatment were very favorable for both the 2,000 and 10,000 ppm $\mathrm{Hg} \mathrm{Y}-12$ soils with just one sample that did not meet EPA limits for $\mathrm{Hg}$. In this case it was slightly above the allowable TCLP limit (240 ppb compared with limit of $200 \mathrm{ppb).} \mathrm{Leaching} \mathrm{for} 40 \mathrm{wt} \% \mathrm{Y}-12$ soils (both 2,000 and 10,000 ppm $\mathrm{Hg}$ ) yielded the highest $\mathrm{Hg}$ concentrations while the $60 \mathrm{wt} \%$ samples yielded the lowest. This can be seen graphically in Figures $24-26$. The higher the waste loading the more $\mathrm{Hg}$ is contained, so this inverse relationship between waste loading and TCLP Hg was unexpected. Several possible explanations are postulated:

- The viscosity of the molten SPSS product may have played a role. The $40 \mathrm{wt} \%$ loading mixture exhibited some liquid-solid separation at the conclusion of processing. The relatively large sand particles were not well held in suspension by the SPC and tended to settle toward the bottom of the mixture after mixing was completed, so the upper level was "soupy" in consistency and the lower level was more "granular". This separation would lead to variability in the $\mathrm{Hg}$ concentration. If the mixture for preparing TCLP pellets was scooped from the bottom of the container it might have contained a disproportionate quantity of $\mathrm{Hg}$, which could account for higher TCLP levels, despite the smaller quantity of soil in the mix. However, after reviewing procedures this seems unlikely.

- The most likely explanation is related to particle size which, in turn, has a strong impact on the effectiveness of $\mathrm{Hg}$ stabilization. The higher waste loadings experienced higher internal frictional load while mixing due to the presence of more soil. The action of the particles interacting with other particles as well as the mixer blades occurs more frequently when more particles are present. This may have reduced the agglomerated particles in the clay soil to a 
larger extent for the higher waste loadings than for the lower waste loadings. Any free $\mathrm{Hg}$ droplets present (these were observed for the 10,000 ppm soil) would be subject to size reduction by mechanical agitation, making more $\mathrm{Hg}$ surface available for stabilization. Because the SPSS process reacts with both free $\mathrm{Hg}$ and $\mathrm{Hg}$ contained on the surface of soil particles, breaking down soil clumps and beads of liquid $\mathrm{Hg}$ into smaller particle size would enhance the stabilization process.

These hypotheses are substantiated by the fact the ball mill pre-treatment reduced the particle size of the soil significantly and the much finer soil following pre-treatment was better entrained in the molten SPC. The differences in the mix viscosity were dramatic and in fact, the thixotropic effect of the fine grained, size-reduced soil increased mix viscosity and required the maximum waste loading be reduced from 60 to $50 \mathrm{wt} \%$. With improved homogeneity in the pre-treated mixture, the $\mathrm{Hg}$ would have been more evenly distributed, thus avoiding hot spots of concentrated $\mathrm{Hg}$ that could increase TCLP results. And with smaller particle sizes the soil would better react to form HgS. In fact, use of the ball mill pretreatment did reduce leachability in the $40 \mathrm{wt} \%$ samples more than 28 times lower than the baseline process and well below the allowable TCLP limits.

One of the objectives of the study was to evaluate the potential improvements of using the pretreatment for processing Y-12 soils. As discussed, a significantly lower TCLP can be achieved for the 40 wt\% loading at high $\mathrm{Hg}$ concentrations, but for all other loadings at either 2,000 or $10,000 \mathrm{ppm} \mathrm{Hg}$, the baseline process was equally effective. Thus, from the perspective of effective treatment, ball milling of the $\mathrm{Y}-12$ soil is not required. For higher $\mathrm{Hg}$ concentrations and especially for liquid elemental $\mathrm{Hg}$, the ball mill (or equivalent) pre-treatment process would likely provide more dramatic improvement in leaching than demonstrated in this study.

The $40 \mathrm{wt} \%$ ball mill sample was not processed through the normal stabilization phase in SPSS; this $2 \mathrm{hr}$ step was bypassed and the temperature was ramped steeply to go directly to de-watering (remained in the "stabilization zone" temperature of $40-60^{\circ} \mathrm{C}$ for just $20 \mathrm{~min}$. rather than $120 \mathrm{~min}$.) Leaching of the $40 \mathrm{wt} \%$ ball mill sample yielded a slightly higher $\mathrm{Hg}$ concentration of $8.5 \mathrm{ppb}$ vs. $3.1 \mathrm{ppb}$ for the $50 \mathrm{wt} \%$ samples or $21 \mathrm{ppb}$ vs. $6 \mathrm{ppb}$ if normalized for soil loading. This small difference indicates that although ball milling or other size reduction pre-treatment may not be required, it can speed up the overall processing time without sacrificing the leach performance of the final waste form. 


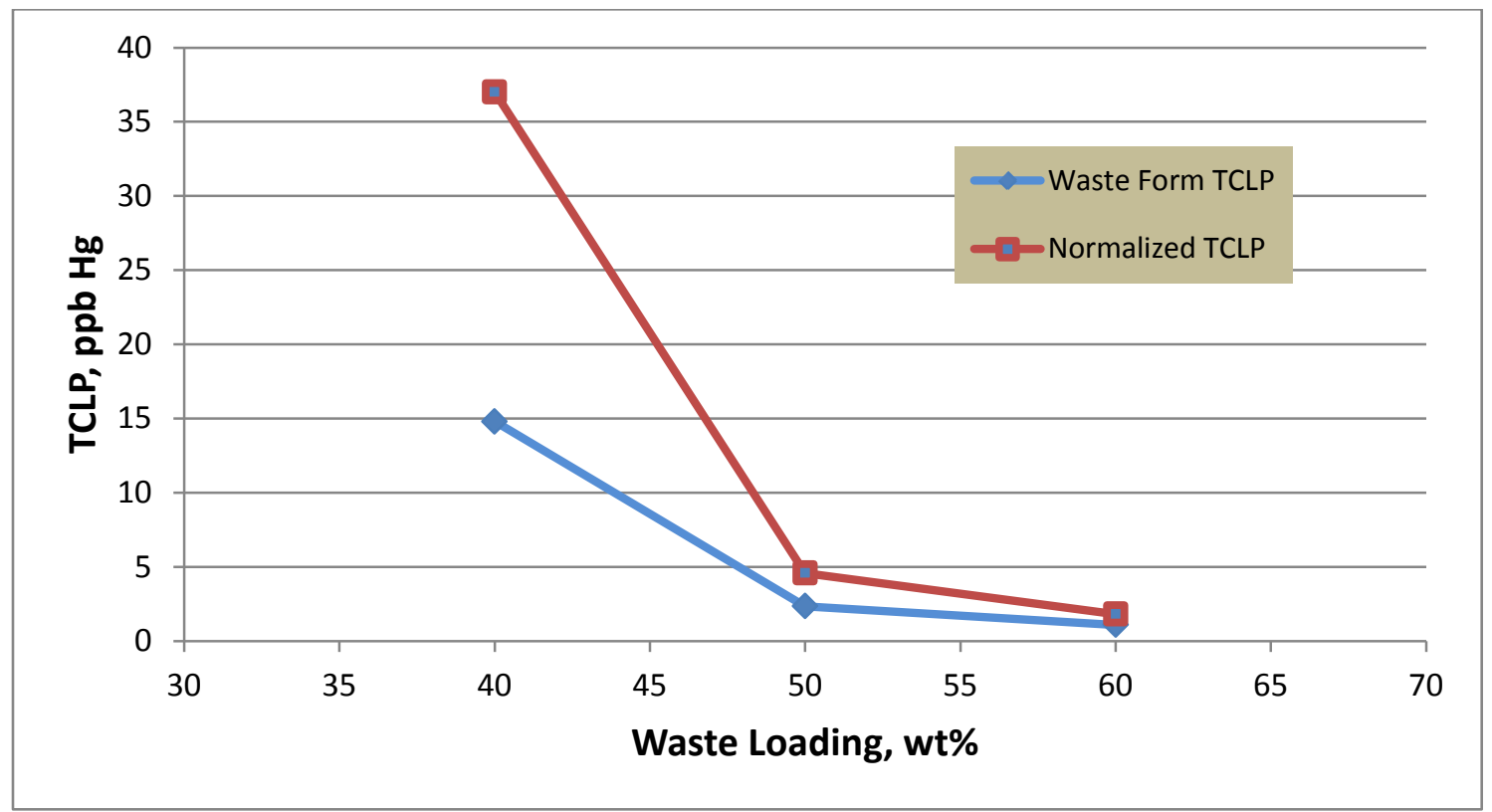

Figure 24. TCLP Data vs. Waste Loading for 2,000 ppm Hg Contaminated Y-12 Soil, Baseline SPSS Processing

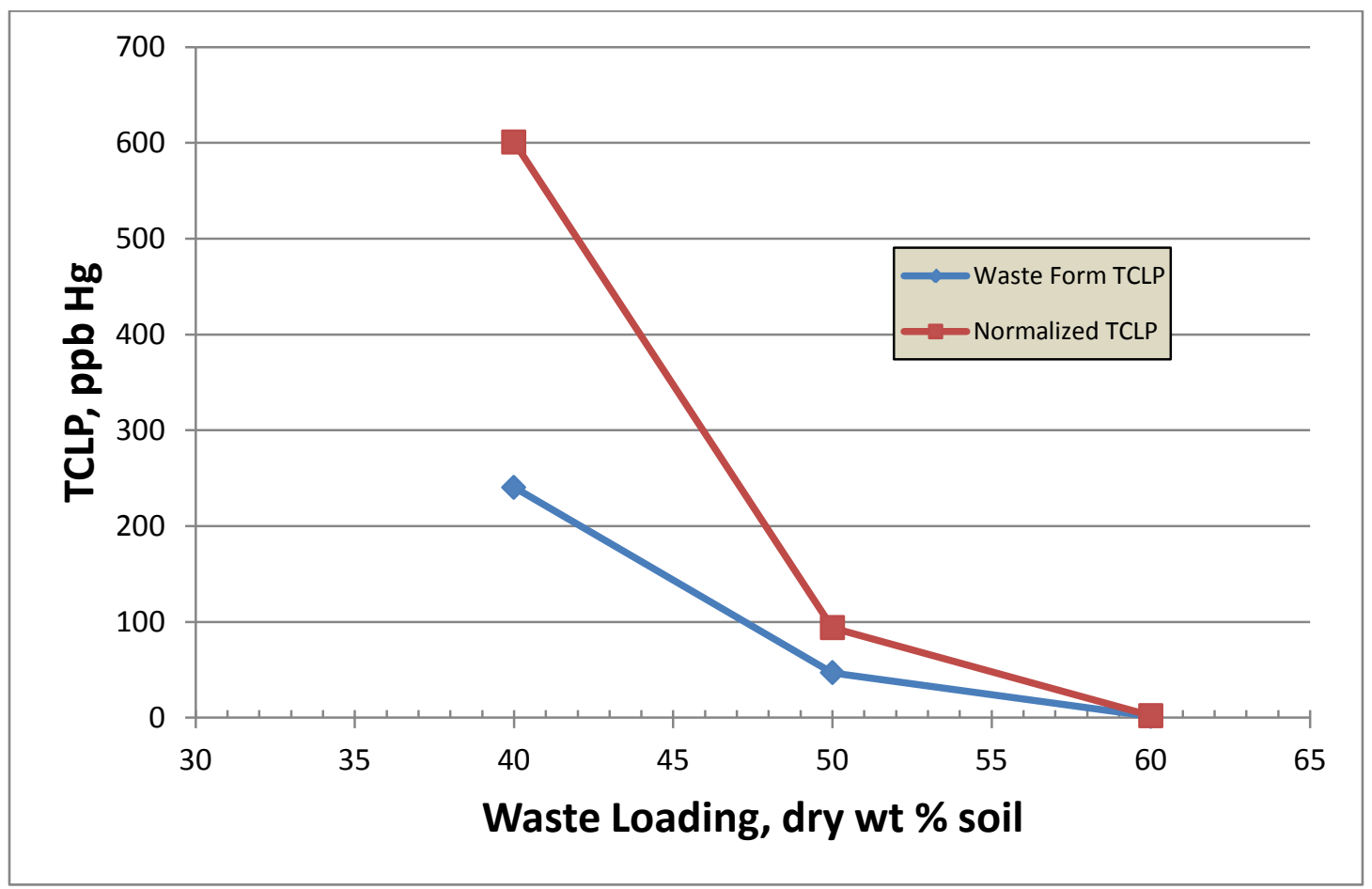

Figure 25. TCLP Data vs. Waste Loading for 10,000 ppm Hg Contaminated Y-12 Soil, Baseline Processing 


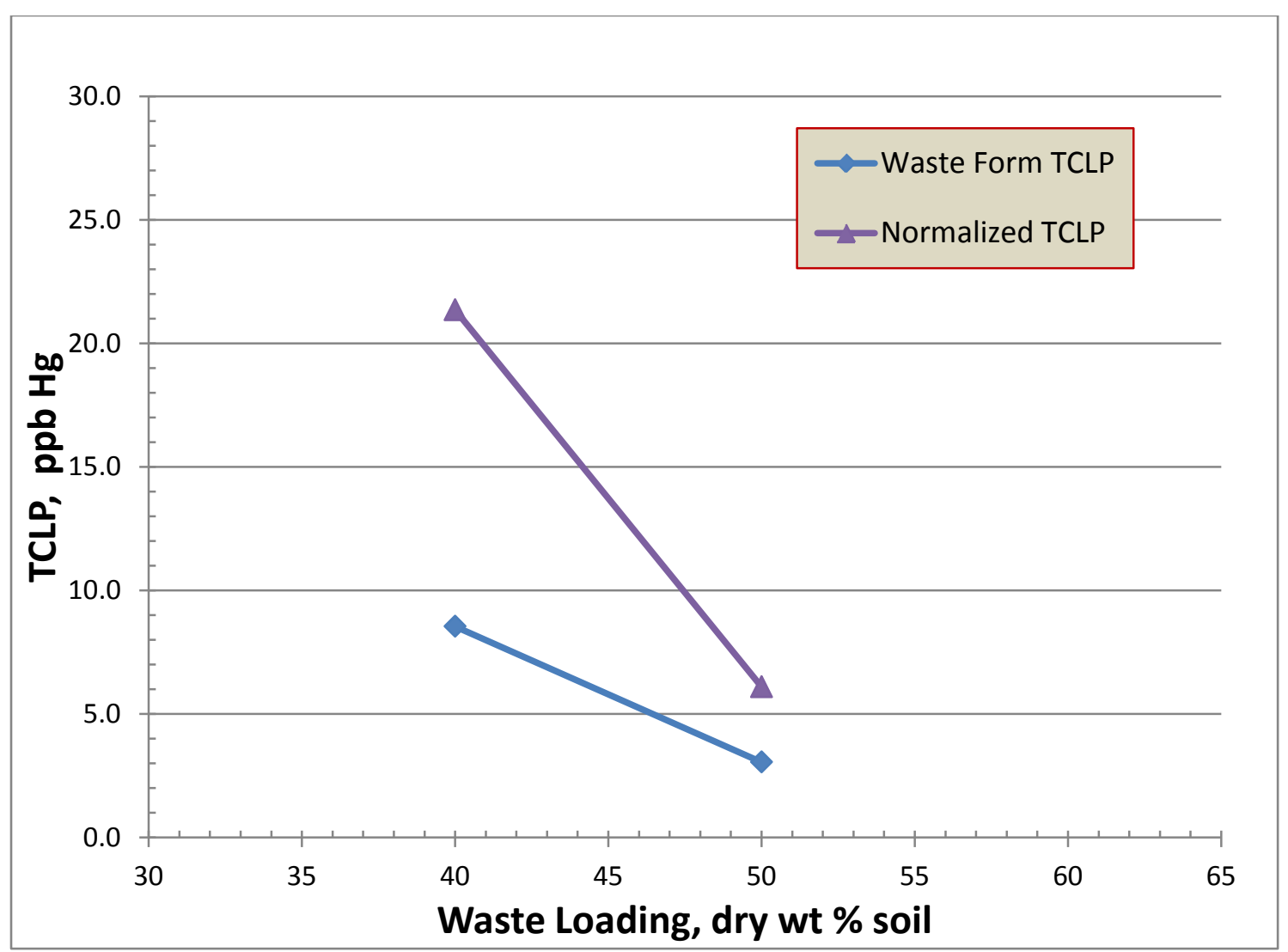

Figure 26. TCLP Data vs. Waste Loading for 10,000 ppm Hg Contaminated Y-12 Soil with Ball Mill Pre-Treatment 


\subsubsection{TCLP of Stabilized Soil}

Samples of soil were taken following the stabilization phase of the SPSS process in order to compare leaching performance with stabilized and solidified SPSS final waste forms. One set of three $100 \mathrm{~g}$ replicates of treated soil (SS-2-50) were taken during the production of SPSS waste form samples. In this case they were from a batch totaling $4 \mathrm{~kg}$ and were taken after the soil was stabilized between $40-$ $60^{\circ} \mathrm{C}$ for two hours. A Jerome analyzer reading above the soil mix recorded $0.000 \mathrm{mg} / \mathrm{m}^{3}$ of $\mathrm{Hg}$ vapor. The system was then closed, purged with inert gas, and the process to dewater, melt, mix and pour the waste form samples continued. TCLP of this set of samples was relatively low, i.e., at $172 \mathrm{ppb}$, it was below TCLP allowable limits. Another set of treated soil samples was collected later to try and evaluate the optimal length of time for the stabilization phase. In this case a smaller batch size $(2 \mathrm{~kg})$ was used since production of SPSS waste form TCLP pellets was not needed. Samples were taken at 15, 30, 60, 120 , and $180 \mathrm{~min}$. and after each set of soil samples were removed, the vessel was closed and purged. Results are summarized in Table 18.

The data show that after operating under normal conditions and processing times the soil can be stabilized sufficiently to pass TCLP. However, compared with the full SPSS process (47 ppb for the baseline process and $3 \mathrm{ppb}$ for ball milled SPSS soil) the leachability can be reduced by an additional factor of 3.7 and 57, respectively. It is also important to consider the inherent advantages of solidification including prevention of dispersal of stabilized waste during transportation, storage or disposal and improved long-term durability.

Attempts to determine the optimal stabilization time were not successful. From the data in Table 18 and accompanying Figure 27, the most favorable leaching results were achieved at the shortest process time. Further, $\mathrm{Hg}$ vapor readings taken by Jerome analyzer directly above the mixture after opening the lid enough to insert the meter probe corroborate the shape of the leaching curve, i.e., lower vapor readings are indicative of better conversion to $\mathrm{HgS}$. However, these time trial data are counter intuitive and do not agree with the initial soil stabilization sample that was taken during the production of the 50 wt\% 10,000 ppm Y-12 soil TCLP test sample run (passed TCLP after $180 \mathrm{~min}$. of processing). The most likely explanation for this phenomenon is separation of $\mathrm{Hg}$ which is heavier and tends to settle to the bottom. The sequential sampling of soil only removed small quantities of $\mathrm{Hg}$ in the first set of samples and increasingly higher concentrations as the sampling process continued closer to the bottom of the mixing vessel. The time trials for $\mathrm{Hg}$ stabilization were conducted as the last experiment of the study and the majority of the soil had been consumed. It is possible that the $\mathrm{Hg}$ concentration for this final experiment was higher than earlier ones due to settling of the $\mathrm{Hg}$ in storage. This would explain higher numbers in general and especially in comparison with the first soil stabilization sampling that was conducted earlier. 
Table 18. TCLP of 50 wt\% 10,000 ppm Hg Stabilized Soil (without solidification)

\begin{tabular}{|c|c|c|c|}
\hline Time & TCLP, $\mathrm{ppb}^{*}$ & Normalized, $\mathrm{pb}$ & Hg vapor, $\mathrm{mg} / \mathrm{m}^{3}$ \\
\hline 0 & 11946.7 & 11946.7 & - \\
\hline 15 & 426.3 & 852.7 & 0.000 \\
\hline 30 & 1239.3 & 2478.7 & 0.004 \\
\hline 60 & 2666.7 & 5333.3 & 0.044 \\
\hline 120 & 1756.7 & 3513.3 & 0.050 \\
\hline 180 & 1283.3 & 2566.7 & 0.038 \\
\hline $180^{* *}$ & 172.8 & 345.6 & 0.000 \\
\hline
\end{tabular}

*RCRA criteria for Hg leachability under TCLP is $200 \mathrm{ppb}$

**Samples taken during process run for 50 wt\% SPSS TCLP sample production on 10/6/12; total mass $=4 \mathrm{~kg}$. Time trial samples taken on $10 / 18 / 12$; total mass $=2 \mathrm{~kg}$.

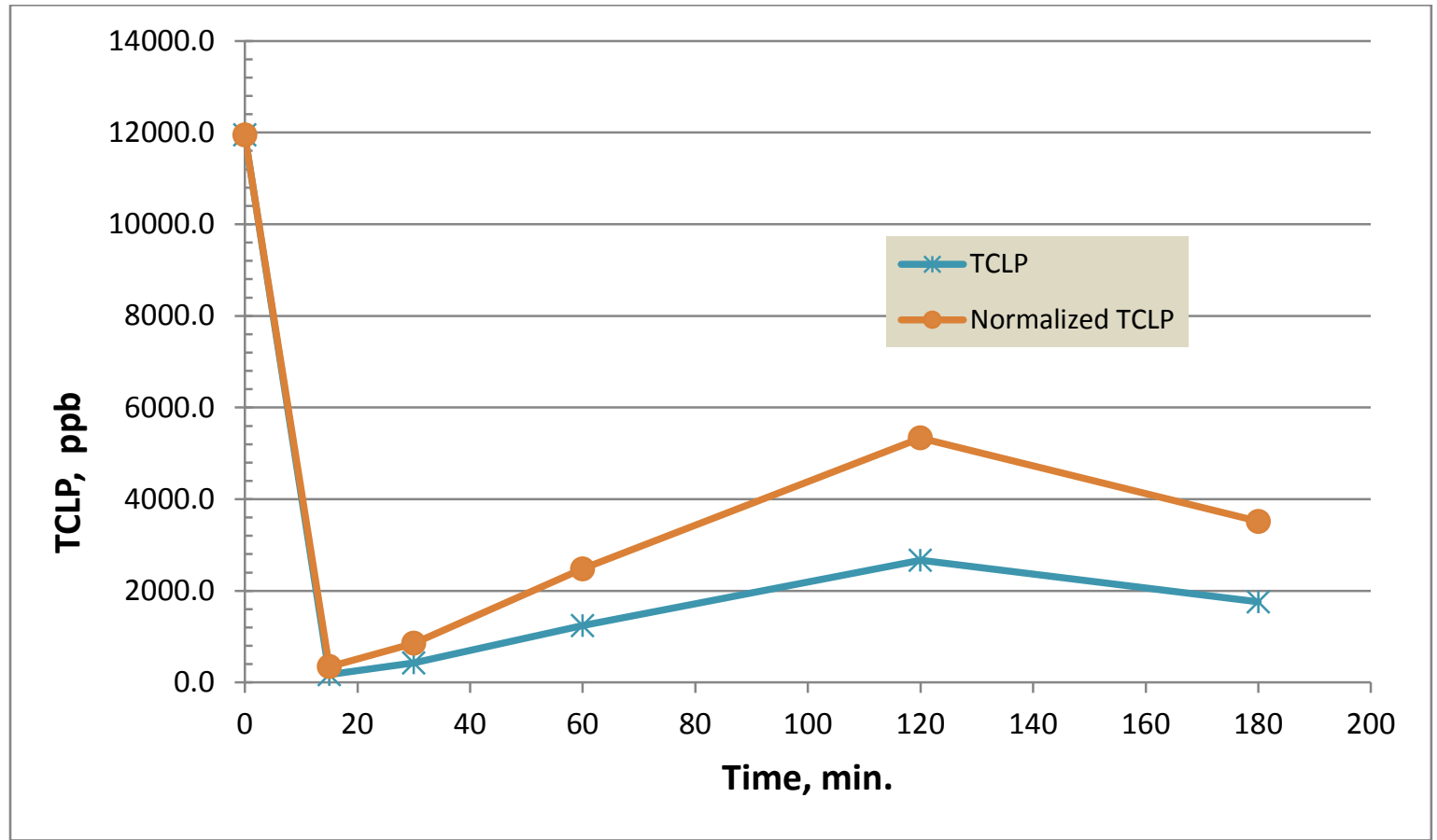

Figure 27. Time trials for soil stabilization of $50 \mathrm{wt} \%$ SPSS treated $Y-12$ soil containing $10,000 \mathrm{ppm} \mathrm{Hg}$

\section{$5.4 \mathrm{pH}$ of Final Waste Forms}

Laboratory testing of SPSS final waste forms for $\mathrm{pH}$ containing $50 \mathrm{wt} \% 10,000 \mathrm{ppm} \mathrm{Y-12}$ soil was conducted by GEL Laboratories according to EPA SW-846 9045D. Results for the two replicates were 9.98 and 9.88 (average $=9.93$ ). This compares with a pH of 7.3 and 7.41 for the untreated $Y-12$ soils $(2,000$ and $10,000 \mathrm{ppm}$, respectively) measured at BNL. This level of alkalinity in the final waste form is 
not expected to present significant concerns about corrosion in storage or disposal. For example, the $\mathrm{pH}$ of Portland concrete leachate tested by BNL measured 11.5 (with a more conservative dilution of 1:20 vs. 1:2 for the 9045D method).

\title{
5.5 Excess Sulfide Testing
}

Excess sulfide testing was conducted for three replicate samples containing 50 wt\% 10,000 ppm Y-12 soil. Results were $<500 \mathrm{mg} / \mathrm{kg}$ for two samples and $505 \mathrm{mg} / \mathrm{kg}$ for the third. Potential reactivity due to excess sulfide is not expected to be a concern for SPSS treatment of $\mathrm{Y}-12$ soils.

\subsection{Speciation}

SPSS processing was very successful in converting elemental $\mathrm{Hg}$ in the soil into stable HgS. The EPA Method SW- 846-3200, "Mercury Species Fractionation and Quantification by Microwave Assisted Extraction", which separates the species of Hg through a series of sequential extractions based on solubility of the Hg compounds was conducted by Brooks Rand Laboratories, Inc. Measurement of $\mathrm{Hg}$ headspace vapor is included as FO and results of the other fractions are associated with the following $\mathrm{Hg}$ species:

\author{
F1: $\mathrm{HgCl} 2, \mathrm{HgSO} 4$ \\ F2: $\mathrm{HgO}$ \\ F3: Hg-humic acid complexes, $\mathrm{Hg} 2 \mathrm{Cl} 2, \mathrm{CH} 3 \mathrm{Hg}$ \\ F4: Mineral lattice-bound $\mathrm{Hg} 2 \mathrm{Cl}$, Liquid $\mathrm{HgO}$ \\ F5: HgS (cinnabar), m-HgS (meta-cinnabar), HgSe, HgAu, amalgams
}

In addition, samples were analyzed for total $\mathrm{Hg}$ by EPA 1631 by digestion with aqua regia at room temperature and oxidation with $\mathrm{BrCl}$. Sample dissolution was incomplete so the data show poor correlation between the total $\mathrm{Hg}$ and the sum of the $\mathrm{Hg}$ fractions by sequential extraction. In some cases the total $\mathrm{Hg}$ is lower. Despite poor correlation with the total $\mathrm{Hg}$ analyses, the sequential extraction provides useful information on the relative partitioning of $\mathrm{Hg}$ species.

As seen in Table 19, the overwhelming majority (90\%) of the $\mathrm{Hg}$ in the untreated soil is present in the elemental form ( $\mathrm{F} 4$ fraction) and only a small percentage $(<2 \%)$ is present in the stable $\mathrm{HgS}$ mineral form (F5 fraction). As seen in Tables 20 and 21, those percentages are reversed in the SPSS treated wastes; most of the $\mathrm{Hg}$ present (92-95\%) is in stable sulfide form (F5 Fraction), with $2-2.5 \%$ in elemental form (F4 Fraction). The ball mill pre-treatment resulted in slightly better (95\% vs. $92 \%$ ) conversion to the stable sulfide form but this difference is not statistically significant. In the baseline processed samples, between $6-7 \% \mathrm{Hg}$ was present in organic form (F3 Fraction), approximately unchanged from the untreated soil, but in the pre-treated samples the organic fraction is reduced to $3 \%$.

These data are corroboration that the SPSS process is performing as designed. Reduction in TCLP leachability of SPSS final waste forms and lower $\mathrm{Hg}$ vapor pressures attributed to the conversion of 
elemental and other $\mathrm{Hg}$ compounds to $\mathrm{HgS}$ (cinnabar) with its significantly lower solubility and vapor pressure have been confirmed.

Table 19. Hg Speciation Data for Untreated Y-12 (ng/g)

\begin{tabular}{|c|r|r|r|r|}
\hline $\begin{array}{c}\text { Hg } \\
\text { Fraction }\end{array}$ & $\mathbf{1 2 4 0 0 1 6 - 0 1}$ & $\mathbf{1 2 4 0 0 1 6 - 0 2}$ & Average & $\begin{array}{r}\text { \% of } \\
\text { Sum }\end{array}$ \\
\hline F1 & 36200 & 29600 & 32900 & $0.6 \%$ \\
F2 & 74100 & 57900 & 66000 & $1.3 \%$ \\
F3 & 352000 & 271000 & 311500 & $6.0 \%$ \\
F4 & 5900000 & 3490000 & 4695000 & $90.3 \%$ \\
F5 & 96000 & 94100 & 95050 & $1.8 \%$ \\
\hline Sum & 6458300 & 3942600 & 5200450 & $100.0 \%$ \\
\hline
\end{tabular}

Table 20. Speciation for SPSS Treated 10,000 ppm Y-12 Soil (ng/g)

\begin{tabular}{|c|r|r|r|r|}
\hline Hg Fraction & SP-2-50-1 & SP-2-50-2 & Average & \% of Sum \\
\hline F0 & 89.9 & 101 & 95.45 & $0.002 \%$ \\
F1 & 443 & 559 & 501 & $0.009 \%$ \\
F2 & 1180 & 350 & 765 & $0.014 \%$ \\
F3 & 405000 & 364000 & 384500 & $6.827 \%$ \\
F4 & 126000 & 95600 & 110800 & $1.967 \%$ \\
F5 & 5160000 & 5110000 & 5135000 & $91.181 \%$ \\
\hline Sum & 5692712.9 & 5570610 & 5631661.45 & $100.0 \%$ \\
\hline
\end{tabular}

Table 21. Speciation for Pre-Treated SPSS 10,000 ppm Y-12 Soil (ng/g)

\begin{tabular}{|c|r|r|r|r|}
\hline Hg Fraction & SP-2-50-1 & SP-2-50-2 & Average & \% of Sum \\
\hline F0 & 70.8 & 47.7 & 59.25 & $0.002 \%$ \\
F1 & 131 & 329 & 230 & $0.006 \%$ \\
F2 & 2.8 & 203 & 102.9 & $0.003 \%$ \\
F3 & 111000 & 103000 & 107000 & $3.014 \%$ \\
F4 & 64900 & 111000 & 87950 & $2.477 \%$ \\
F5 & 2220000 & 4490000 & 3355000 & $94.498 \%$ \\
\hline Sum & 2396104.6 & 4704579.7 & 3550342.15 & $100.0 \%$ \\
\hline
\end{tabular}




\section{Summary and Conclusions}

This laboratory-scale treatability study examined the applicability of the BNL SPSS Hg treatment process for use in treating $\mathrm{Hg}$ contaminated soil at the Y-12 Plant. The patented BNL process has been successfully demonstrated for treating liquid elemental $\mathrm{Hg}$, and $\mathrm{Hg}$ contaminated soil, sludge, and debris.

Samples of surrogate and actual Y-12 Hg contaminated mixed waste soils were supplied by UCOR to conduct the bench-scale investigation. The soil initially contained a nominal $135 \mathrm{ppm} \mathrm{Hg}$ and was enhanced with additional $\mathrm{Hg}$ to nominal concentrations of 2,000 and $10,000 \mathrm{ppm} \mathrm{Hg}$. Bulk densities ranged between 1.09 and $1.18 \mathrm{~g} / \mathrm{cm}^{3}$ and moisture content ranged from $13.9 \pm 2 \%$ to $15.1 \pm 3 \%$.

The study was conducted in four phases including evaluation of: 1) mechanical integrity/durability of solidified waste forms, 2) leachability of the $2,000 \mathrm{ppm} \mathrm{Hg}$ soil treated by the baseline BNL process, 3 ) leachability of the $10,000 \mathrm{ppm} \mathrm{Hg}$ soil treated by the baseline SPSS process, and 4) leachability of the 10,000 ppm Hg soil pre-treated to reduce particle size and improve mixing by ball milling, followed by conventional SPSS processing.

Waste loading optimization was conducted and loadings of 40,50, and 60 dry wt\% Y-12 soil were achieved. Key process parameters including mixing speed, mixing times, temperature settings and resultant mixture temperatures for the process vessel and off-gas system, process times, vessel pressures, etc. were recorded by an automatic computerized data logger and reported. A temperature vs. time plot was prepared to document the temperature profile parameters for each run.

SPSS includes chemical stabilization to convert $\mathrm{Hg}$ to the stable $\mathrm{HgS}$ form (cinnabar) and physical encapsulation of the stabilized $\mathrm{Hg}$ by solidifying in a solid monolithic waste form with low permeability. The solidification stage eliminates dispersion of the waste and further reduces leachability of the contaminants. Processing was conducted in three steps, i.e., stabilization occurred between 40 and $60^{\circ} \mathrm{C}$, moisture removal between $60-100^{\circ} \mathrm{C}$, and melting, mixing and pouring at $100-120^{\circ} \mathrm{C}$. Stabilization is carried out for approximately two hours and is conducted after purging the mixer with an inert cover gas and closing the system. De-watering is also conducted for about two hours under negative pressure (up to $18 \mathrm{in.} \mathrm{Hg}$ vacuum) through an off-gas system. In the final stage, the SPC is melted and mixing continues for about 30 minutes to ensure homogeneity before pouring into a mold for cooling to produce a solid monolithic waste form. The total processing time from initial loading of the process vessel through pouring of the treated waste was on average under 5.5 hours.

Since dewatering the soil is a critical process step and elemental $\mathrm{Hg}$ is extremely volatile, the system is equipped with an off-gas system to remove residual moisture and ensure that no fugitive $\mathrm{Hg}$ vapors are emitted. It includes dual serpentine condenser coils, a chiller, and an activated carbon filter. The process is operated as a closed system until most of the $\mathrm{Hg}$ has been converted to stable $\mathrm{HgS}$. This reduces the vapor pressure of $\mathrm{Hg}$ so it is not volatilized when the off-gas system is opened and moisture is removed. An analysis of the off-gas components compared with the total amount of $\mathrm{Hg}$ that was 
processed revealed that after all process runs were complete, $99.999 \%$ of the $\mathrm{Hg}$ was retained in the waste form.

Performance metrics for the treated waste included TCLP leaching, mechanical integrity in air and under saturated conditions, $\mathrm{Hg}$ speciation, excess sulfide, and $\mathrm{pH}$. Untreated $\mathrm{Hg}$ enhanced $\mathrm{Y}-12$ soils both failed TCLP testing resulting in Hg concentrations significantly higher than the TCLP allowable $200 \mathrm{ppb}$ $\mathrm{Hg}$, namely 6,600 ppb and 12,000 ppb $\mathrm{Hg}$ for the nominal 2,000 ppm and 10,000 ppm $\mathrm{Hg}$ soils, respectively. After SPSS treatment all three batches of the $2,000 \mathrm{ppm}$ treated soil easily passed TCLP ranging from $1-15 \mathrm{ppb}$ of $\mathrm{Hg}$. Four of the five batches of 10,000 ppm $\mathrm{Hg}$ soil easily passed TCLP with Hg concentrations of $1-47 \mathrm{ppb}$. Only one batch failed TCLP, i.e., the lowest soil loading ( $40 \mathrm{wt} \%$ ) of the $10,000 \mathrm{ppm} \mathrm{Hg}$ soil which resulted in $240 \mathrm{ppb} \mathrm{Hg}$. In all cases the leaching of $\mathrm{Hg}$ was inversely proportional to the quantity of soil in the waste form. This is most likely due to the reduction in particle size from increased frictional forces of the waste particles that occur for the higher waste loadings. The fact that samples of 40 wt\% loading that were pre-treated in the ball mill yielded much lower (by a factor of almost 30 times) TCLP concentrations compared with the baseline process is evidence of this effect. In an attempt to determine the effectiveness of the SPSS stabilization and solidification mechanisms separately, samples of the $50 \mathrm{wt} \%$ soil batch were taken for TCLP analysis after the stabilization phase was completed (approx. $2 \mathrm{hrs}$ of processing). Results showed these samples passed TCLP (172 ppb Hg) but the baseline process including solidification reduced leachability between 4 and 57 times for the baseline and pre-treatment processes, respectively. Another attempt to take samples from the process at varying times to identify the time required to reach stabilization was inconclusive.

The SPSS treated Y-12 soils maintained high compressive strengths to 5,757 psi and 6,459 psi for 30 and $50 \mathrm{wt} \%$ soil loadings respectively. The $30 \mathrm{wt} \%$ loadings did not experience any significant loss in strength after three weeks in water immersion but the 50 wt\% loadings were unable to maintain mechanical integrity and began to swell and crack after several days in immersion. $\mathrm{Hg}$ in the final waste form is present as stable $\mathrm{HgS}$ cinnabar, so additional testing would be required to determine the impact, if any, on leaching following mechanical failure due to immersion. Samples of the uncontaminated Oak Ridge surrogate soil at $43 \mathrm{wt} \%$ withstood swelling in immersion, while $50 \mathrm{wt} \%$ samples lost significant strength, so it is reasonable to conclude that the $\mathrm{Y}-12$ soils could also withstand swelling associated with up to $40-43 \mathrm{wt} \%$ loading. BNL has also shown in previous work that additives can be used to improve waste form resistance to swelling under saturated conditions.

Speciation analyses of the $\mathrm{Y}-12$ soil waste revealed that the majority (90\%) of the $\mathrm{Hg}$ in the soil used in the study was present as $\mathrm{Hg}^{0}$ (elemental $\mathrm{Hg}$ ) and only a small fraction (2\%) was present in the stable $\mathrm{HgS}$ form. Following SPSS treatment containing $50 \mathrm{wt} \% \mathrm{Hg}$ contaminated soil, $92 \%$ and $95 \%$ of the $\mathrm{Hg}$ for the baseline and pre-treated SPSS processes, respectively were converted to stable HgS. These data substantiate the mechanism responsible for the excellent TCLP leaching results. Laboratory analyses confirmed that neither excess sulfide nor the $\mathrm{pH}$ of SPSS waste forms will present problems in storage and disposal.

Applicability of SPSS for treatment of Hg-contaminated mixed waste Y-12 soils has been successfully demonstrated. TCLP leaching criteria can be easily met with waste loadings of 50-60 wt\% soil. Higher 
waste loadings ( $\geq 50 \mathrm{wt} \%$ ) did not withstand swelling of the clay minerals in the soil when subjected to saturated conditions and the waste forms lost some or all mechanical integrity; however, the impact on waste form leaching has not been established. Pre-treatment of the soil by ball milling provided dramatic improvement (28 times lower) in the leachability of the $40 \mathrm{wt} \%$ loading. However, since the leaching of the 50 and $60 \mathrm{wt} \%$ baseline SPSS process waste forms was very low (3.1 and $1.5 \mathrm{ppb}$ ) using the baseline process, additional pre-treatment for $\mathrm{Y}-12$ soil with $\mathrm{Hg}$ concentrations up to $10,000 \mathrm{ppm} \mathrm{Hg}$ wastes may not be warranted. Pre-treatment may reduce process time, however, which could translate to lower overall cost. 


\section{References}

${ }^{1}$ Brooks, S.C., and G.R. Southworth, "History of mercury use and environmental contamination at the Oak Ridge Y12 Plant," Environ Pollut. 2011 Jan;159(1):219-28

${ }^{2}$ Barnett, M., L.A. Harris, R. Turner, R.J. Stevenson, T.J Henson, R.C. Melton, and D.P. Hoffman, Formation of Mercuric Sulfide in Soil, Environmental Science and Technology, Vol 31, No. 11, 1997.

${ }^{3}$ Kalb; P.D., D. Melamed; B. Patel, M. Fuhrmann, “Treatment of mercury containing waste" U.S. Patent No.6,399,849 (June 4, 2002)

${ }^{4}$ Colombo, P., P.D. Kalb, and J.H. Heiser, "Process for the Encapsulation and Stabilization of Radioactive Hazardous and Mixed Wastes," U.S. Patent No. 5,678,234, (Oct. 14, 1997 )

${ }^{5}$ Kalb, P.D., J.W. Adams, and L.W. Milian, Sulfur Polymer Stabilization/Solidification (SPSS) Treatment of Mixed Waste Mercury Recovered from Environmental Restoration Activities at BNL, BNL-52614, Brookhaven National Laboratory, Upton, NY, Jan. 2001

${ }^{6}$ Adams, J.W., B.S. Bowerman, and P.D. Kalb, "Sulfur Polymer Stabilization/Solidification (SPSS) Treatability of Simulated Mixed Waste Mercury Contaminated Sludge" Waste Management '02 Conference Proceedings, Tucson AZ, Feb 24 -28, 2002

${ }^{7}$ Bowerman, B., J. Adams, P. Kalb, R-Y. Wan, and M. LeVier, "Using the Sulfur Polymer Stabilization/Solidification Process to Treat Residual Mercury Wastes from Gold Mining Operations," BNL-71499-2003-CP, Society of Mining Engineers Conference, Cincinnati, OH, Feb. 24 - 26, 2003.

${ }^{8}$ Breskin, I., "Newmont Banking on Technology as Solid Solution for Mercury," American Metal Market, Jan. 27, 2003.

${ }^{9}$ U.S. Environmental Protection Agency, Toxicity Characteristic, Leaching Procedure, Method SW-8461311, Rev 0, July 1992, http://www.epa.gov/osw/hazard/testmethods/sw846/pdfs/1311.pdf

${ }^{10}$ U.S. Environmental Protection Agency, Soil and Waste pH, Method SW- 846, Rev.4, 2004, http://www.epa.gov/osw/hazard/testmethods/sw846/pdfs/9045d.pdf

${ }^{11}$ U.S. Environmental Protection Agency, Titrimetric Procedure for Acid-Soluble and Acid-Insoluble Sulfides, Method SW- 846 9034, Rev 0, 1986, http://www.epa.gov/osw/hazard/testmethods/sw846/pdfs/9034.pdf

12 U.S. Environmental Protection Agency, "Mercury Species Fractionation and Quantification by Microwave Assisted Extraction, Selective Solvent Extraction and/or Solid Phase Extraction", Method SW846-3200, Rev.0, July 2005, www.epa.gov/osw/hazard/testmethods/pdfs/3200.pdf

13 J.R. Manning, URS | CH2M Oak Ridge LLC (UCOR), personal communication, August 6, 2012. 
${ }^{14}$ López, F.A., A. López-Delgaro, I. Padilla, H. Tayibi, F.J. Alguachi, “Formation of metacinnabar by milling of liquid mercury and elemental sulfur for long term mercury storage," Science for thby milling of liquid mercury and elemental sulfur for long term mercury storage," Science for the Total Environment, 408, 4341-4345 (2010)

${ }^{15}$ López-Delgaro, A., F.A. López, F.J. Alguachi, I. Padilla, A. Guerrero, “A microencapsulation process of liquid mercury by sulfur polymer stabilization/solidification technology. Part I: Characterization of materials, Revista de Metalurgia, 48(1) Enero-Febrero, 45-47 (2012)

${ }^{16}$ U.S. Nuclear Regulatory Commission, "Technical Position on Waste Form (Revision 1)", Low Level Waste Management Branch, USNRC, Washington, DC (1991)

${ }^{17}$ American Society of Testing Materials, ASTM Standard C-39, "Standard Test Method for Compressive Strength of Cylindrical Concrete Specimens", ASTM International, West Conshohocken, PA, 2003, DOI: 10.1520/C0033-03, www.astm.org. 
Appendix A

\section{Process Data Plots}




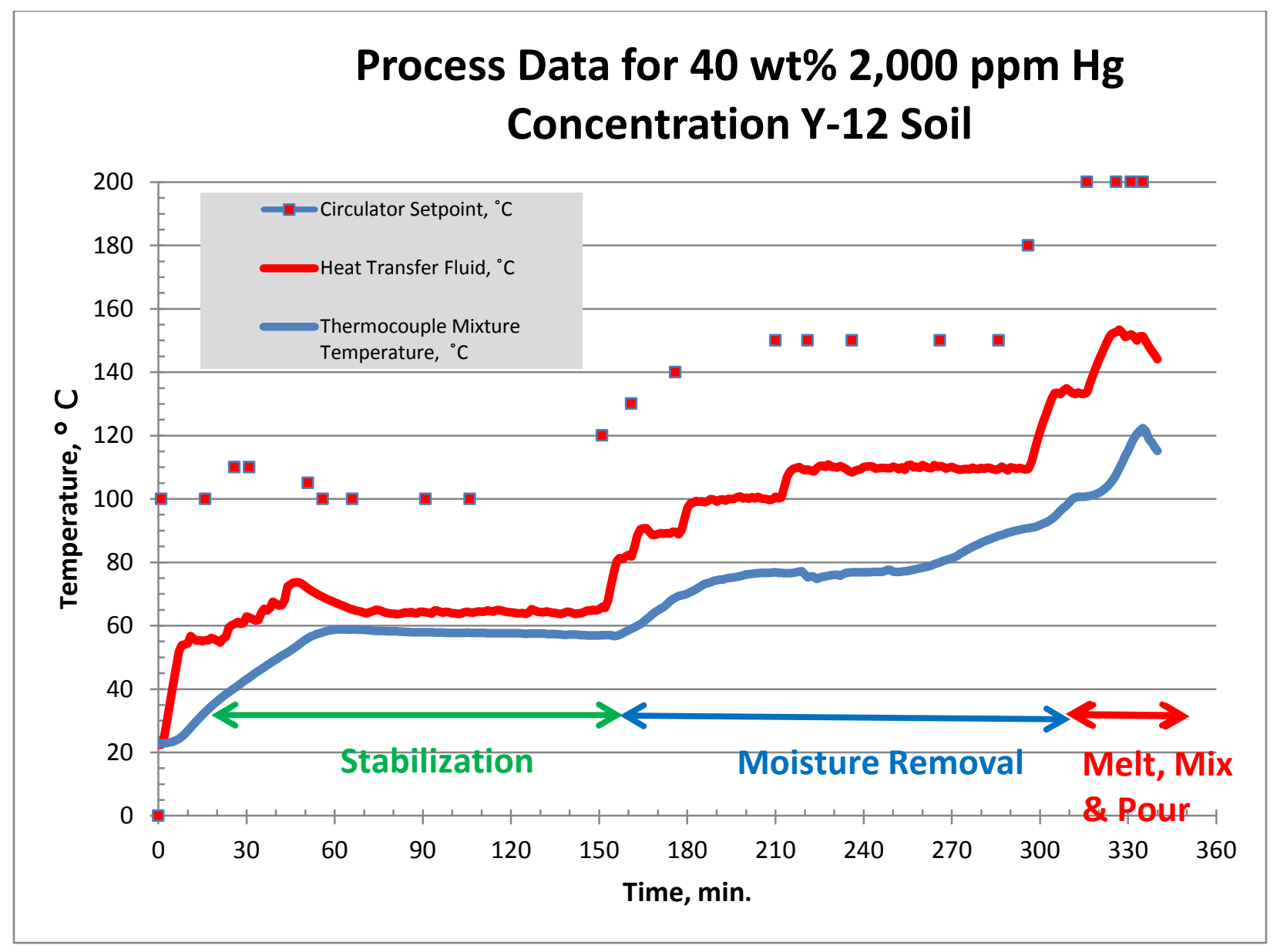




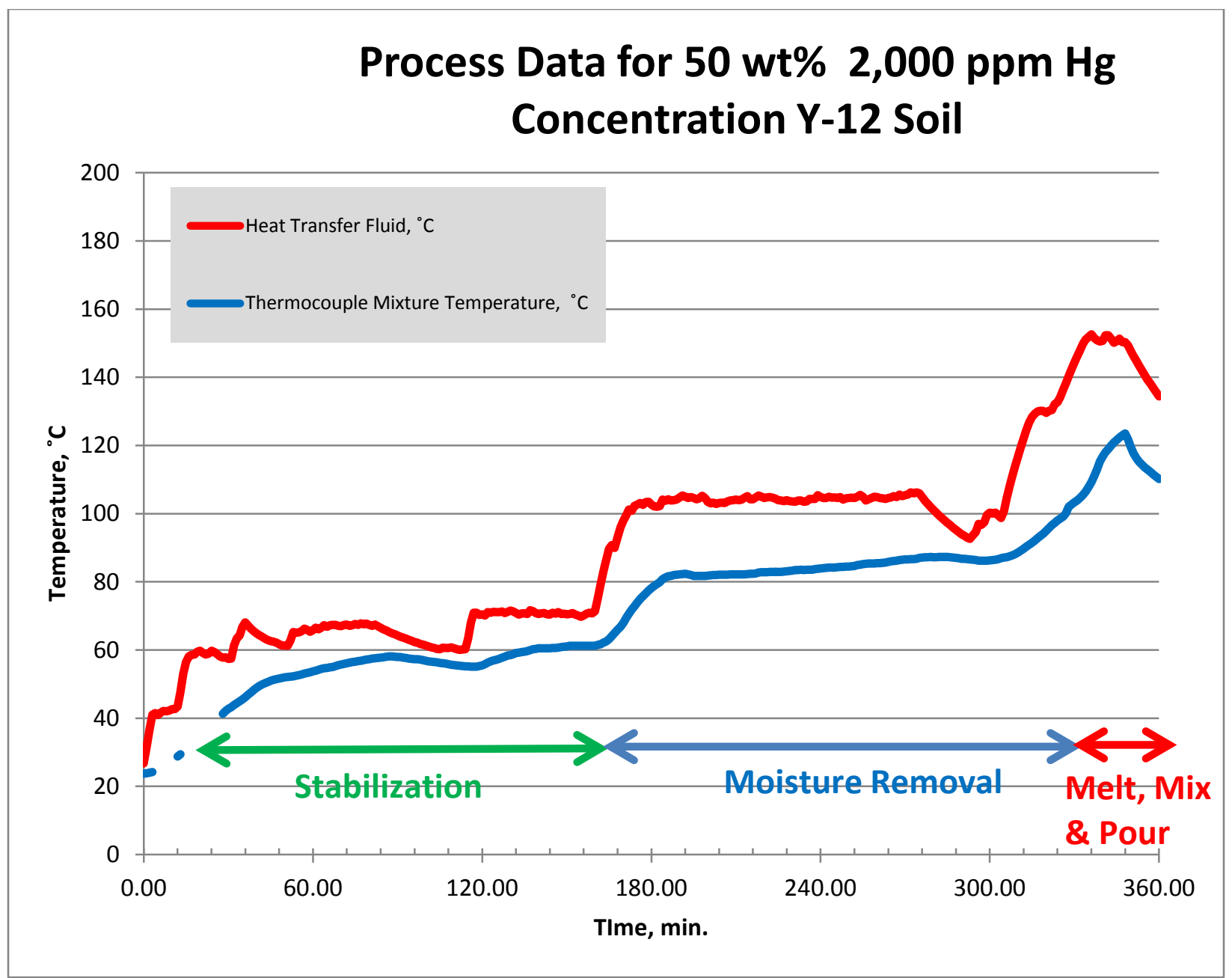




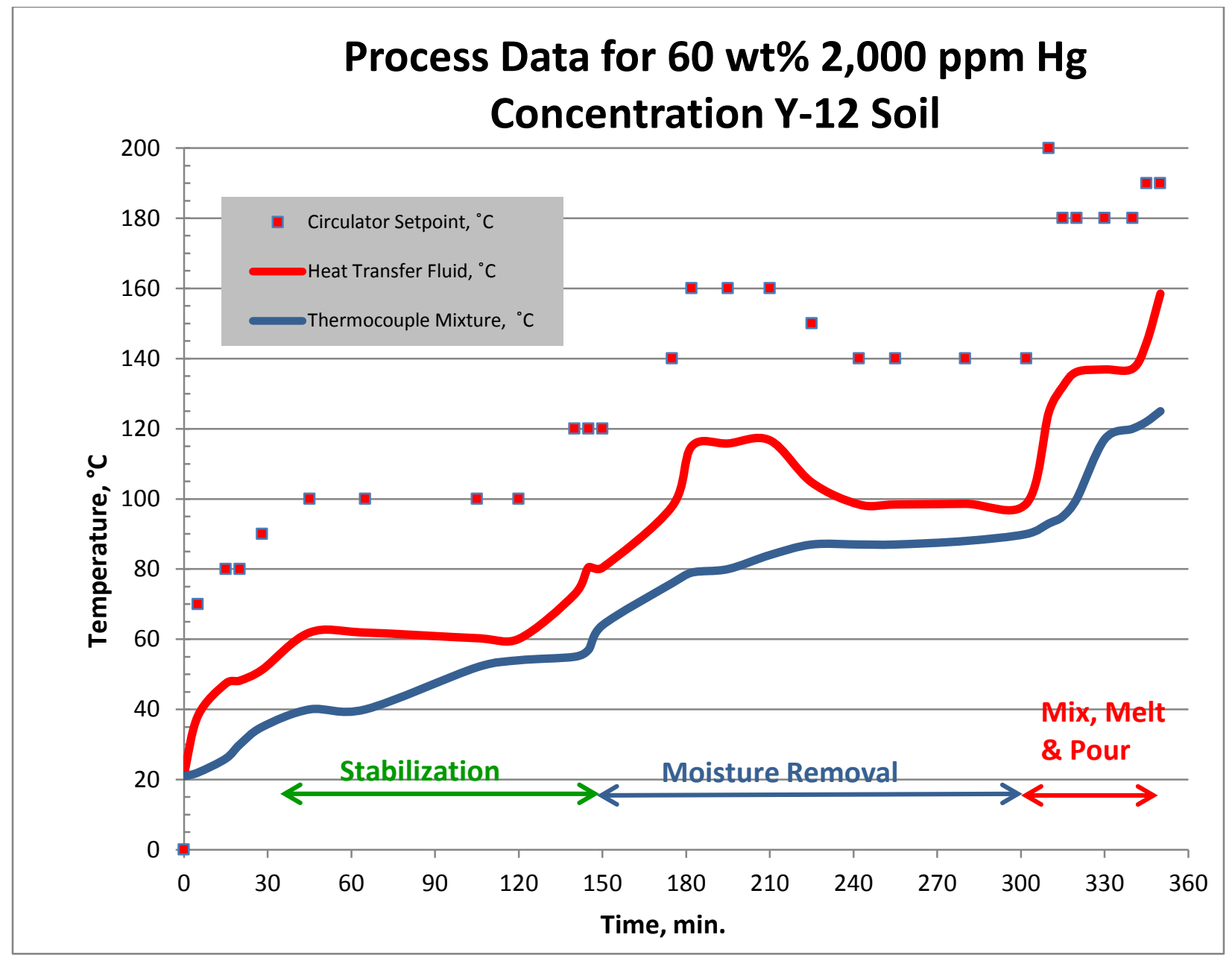




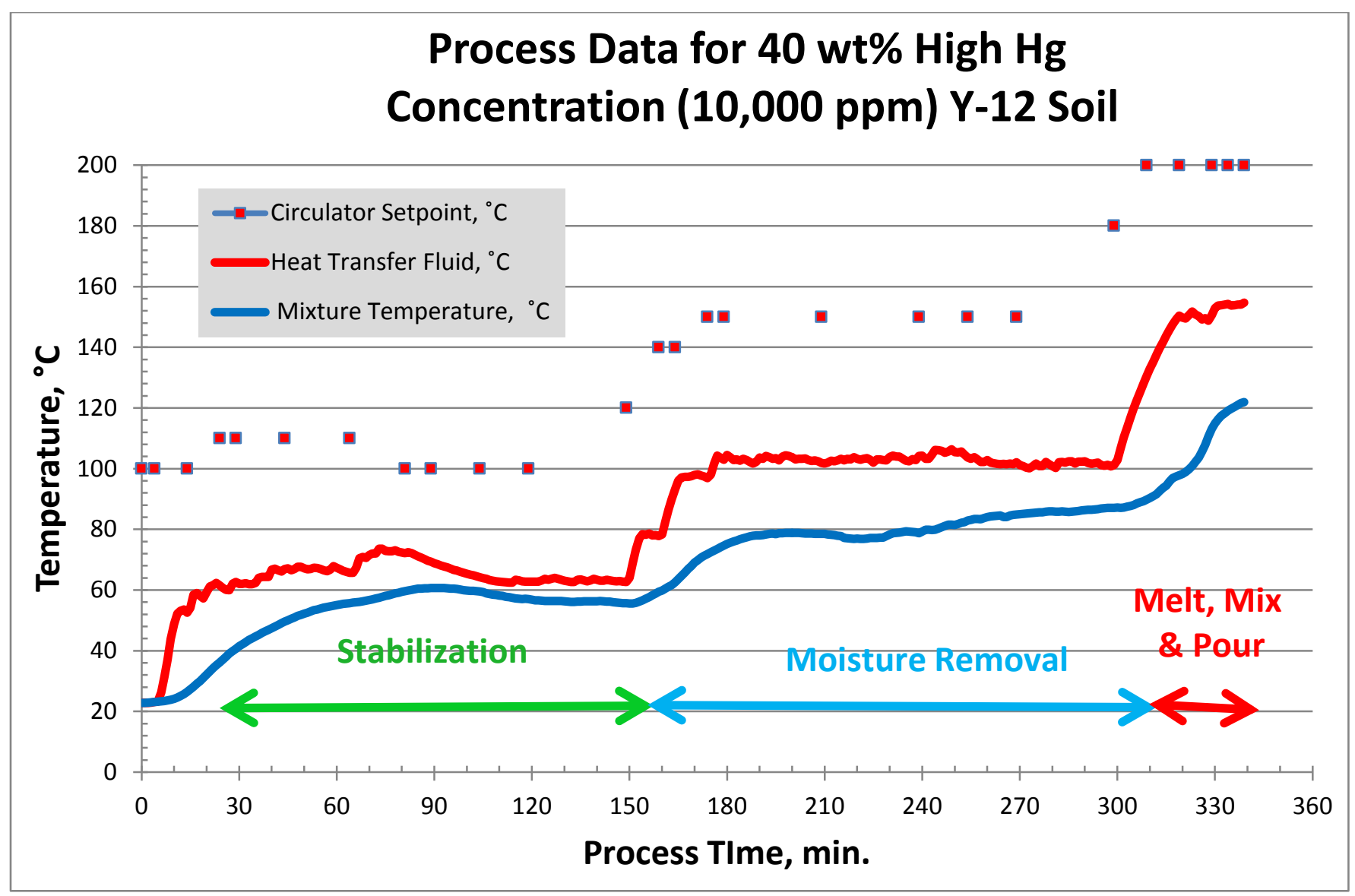




\section{Process Data for $\mathbf{5 0}$ wt\% High $\mathbf{~ H g}$ Concentration (10,000 ppm) Y-12 Soil}

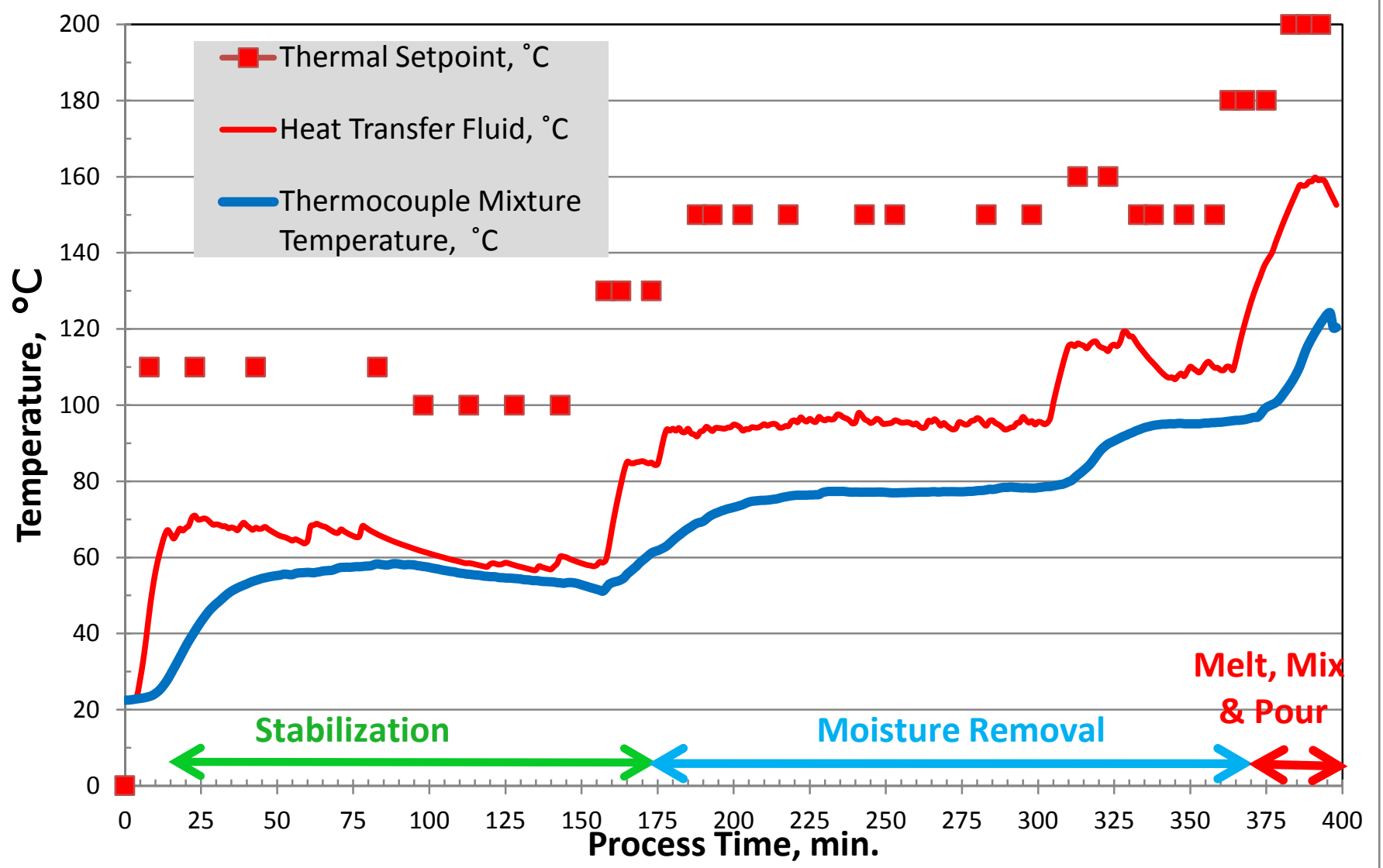




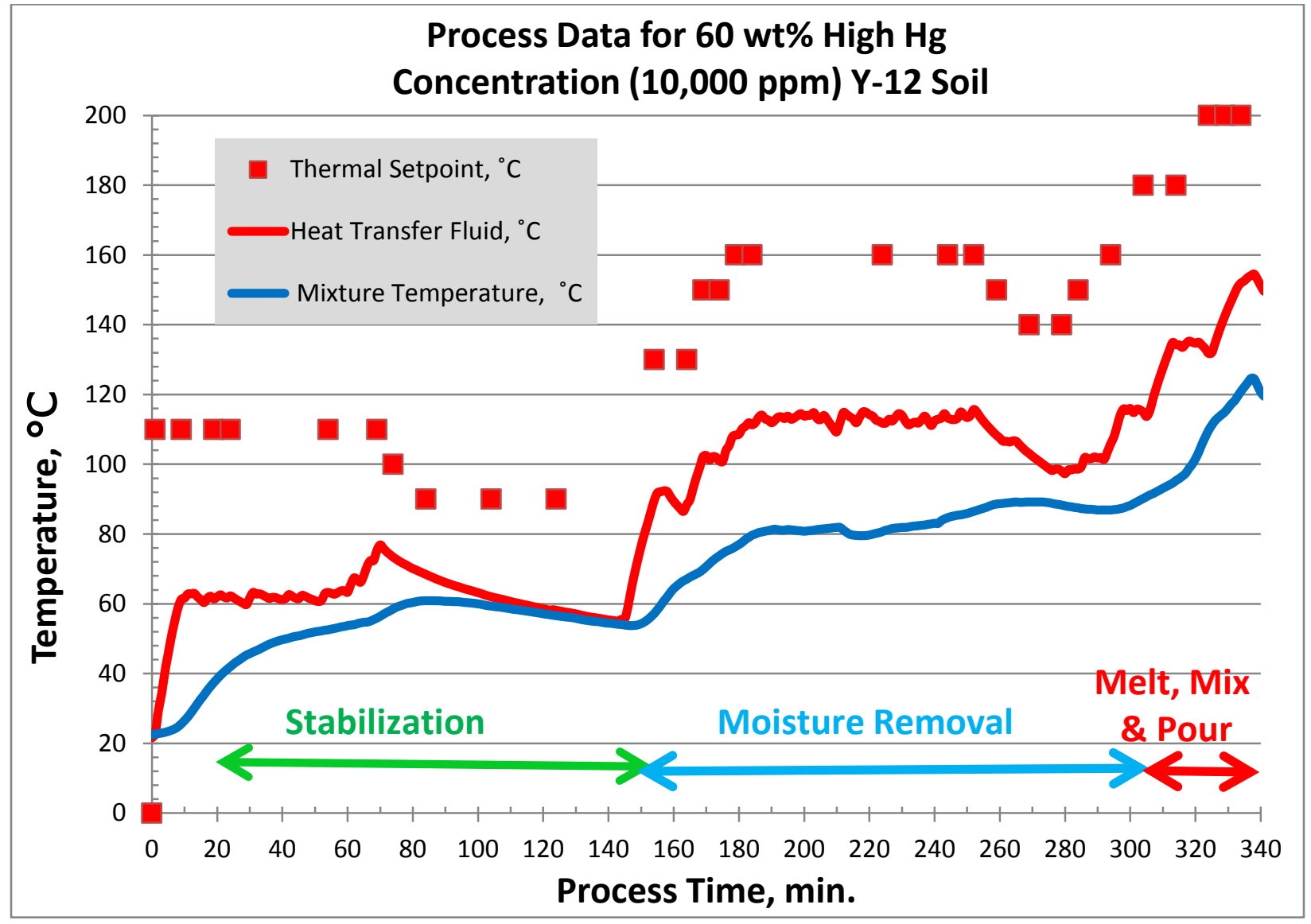




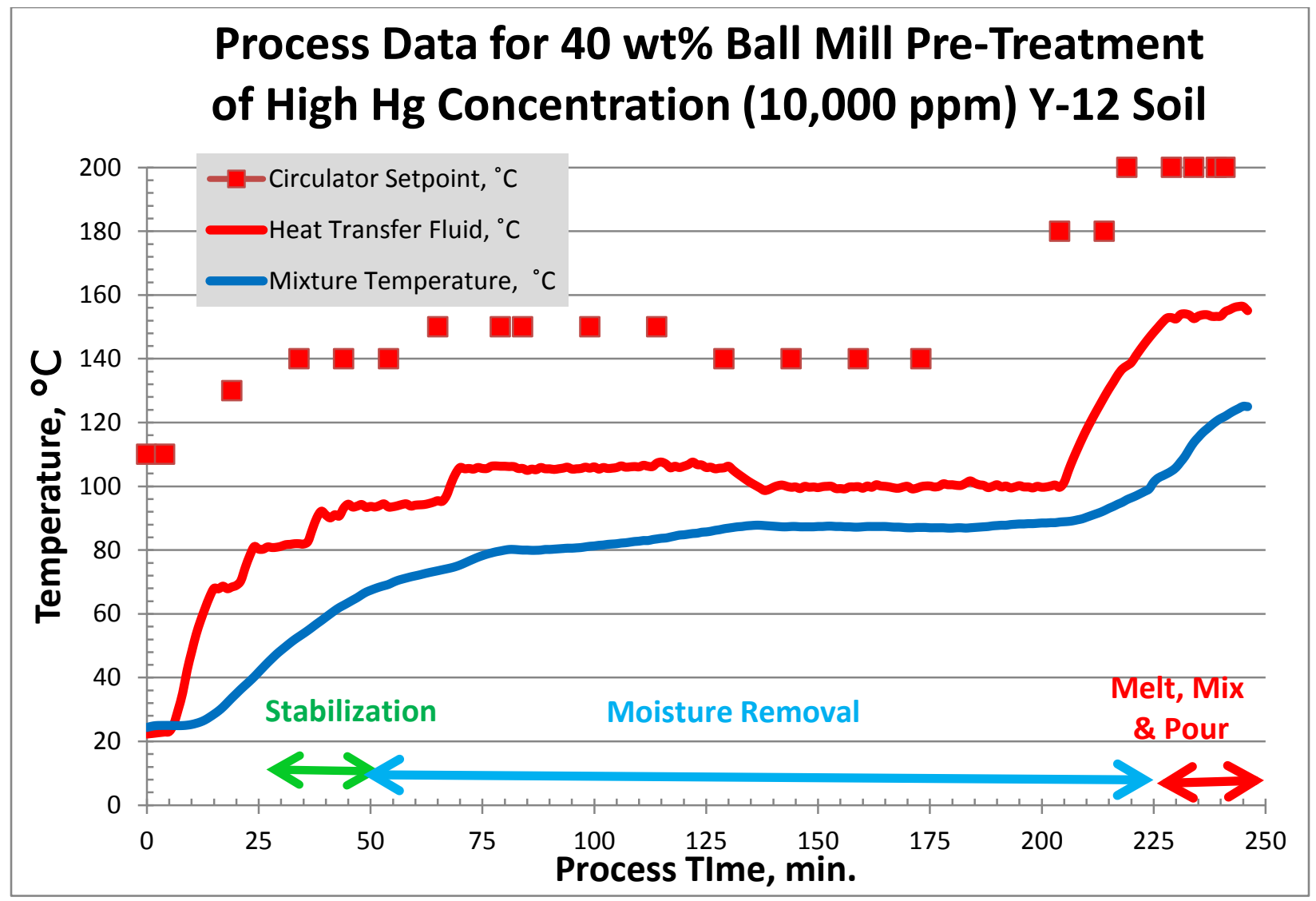




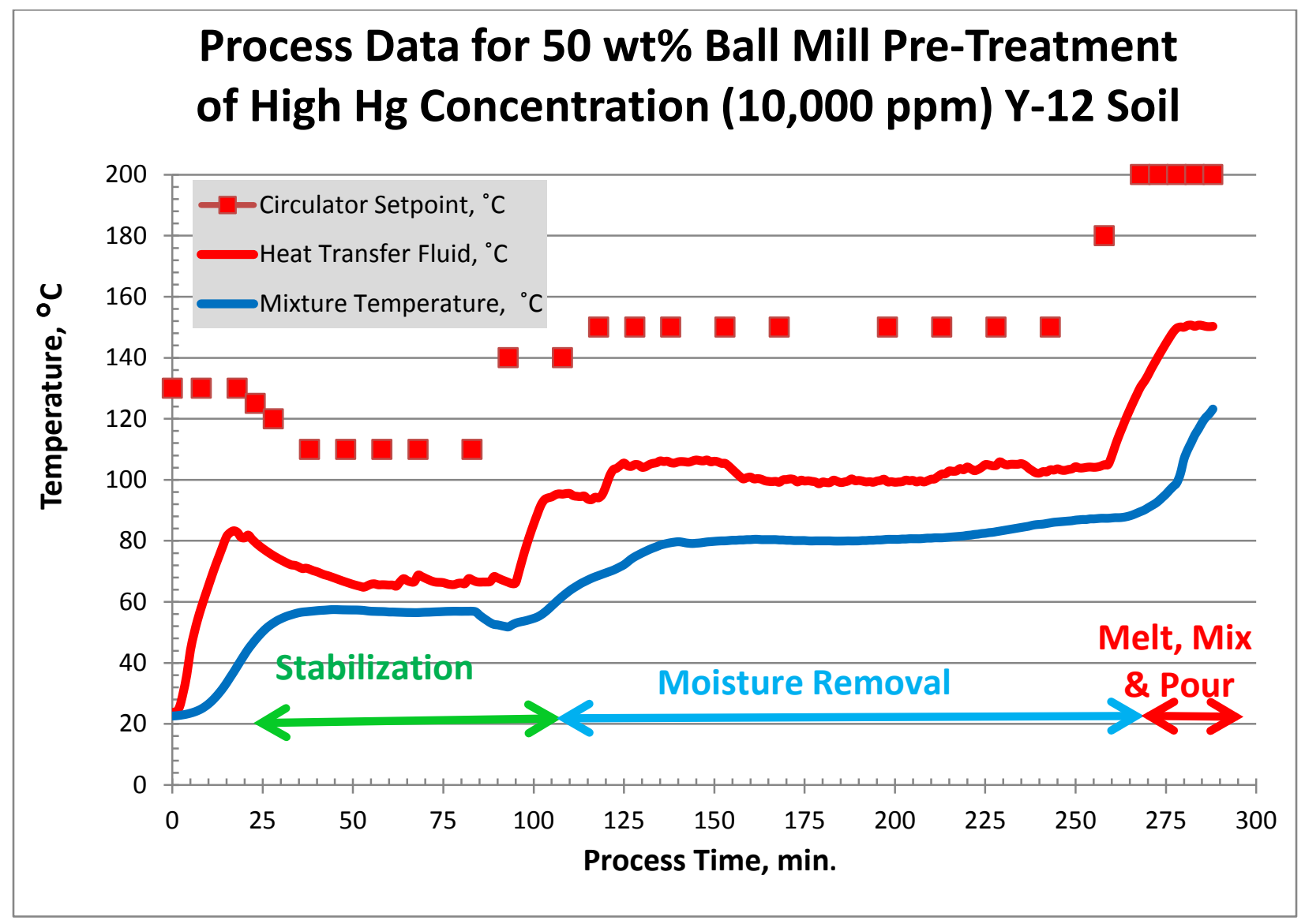




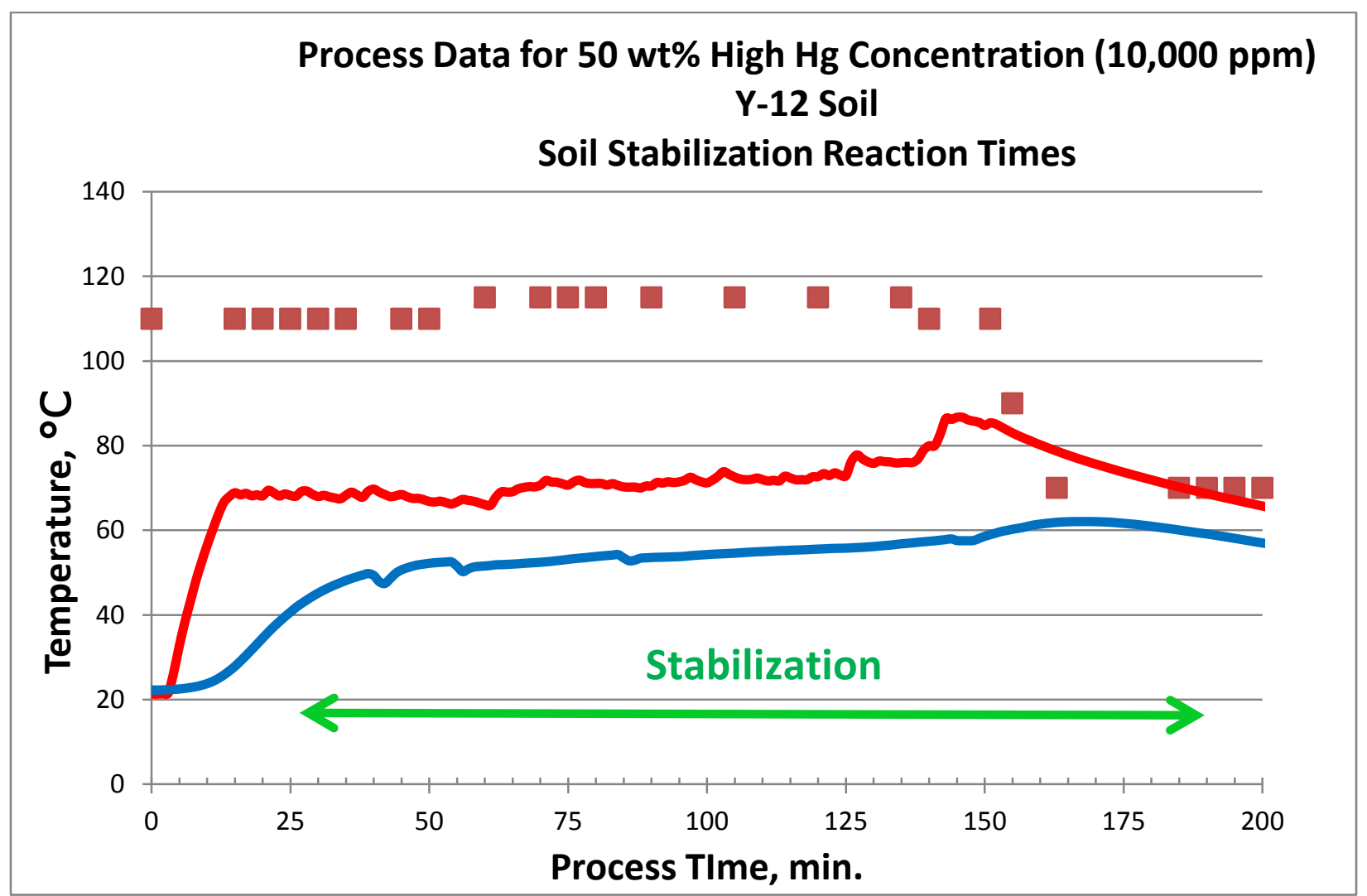




\section{Appendix B:}

\section{Compressive Strength Data}




\section{BROOKHAVEN NATIONAL LABORATORY}

Compression Testing (ASTM-C39)

Method description

System of units

Test type
Compression Testing (ASTM-C39)

All

Compression

COMPRESSION TEST - Specimen 1 to 3

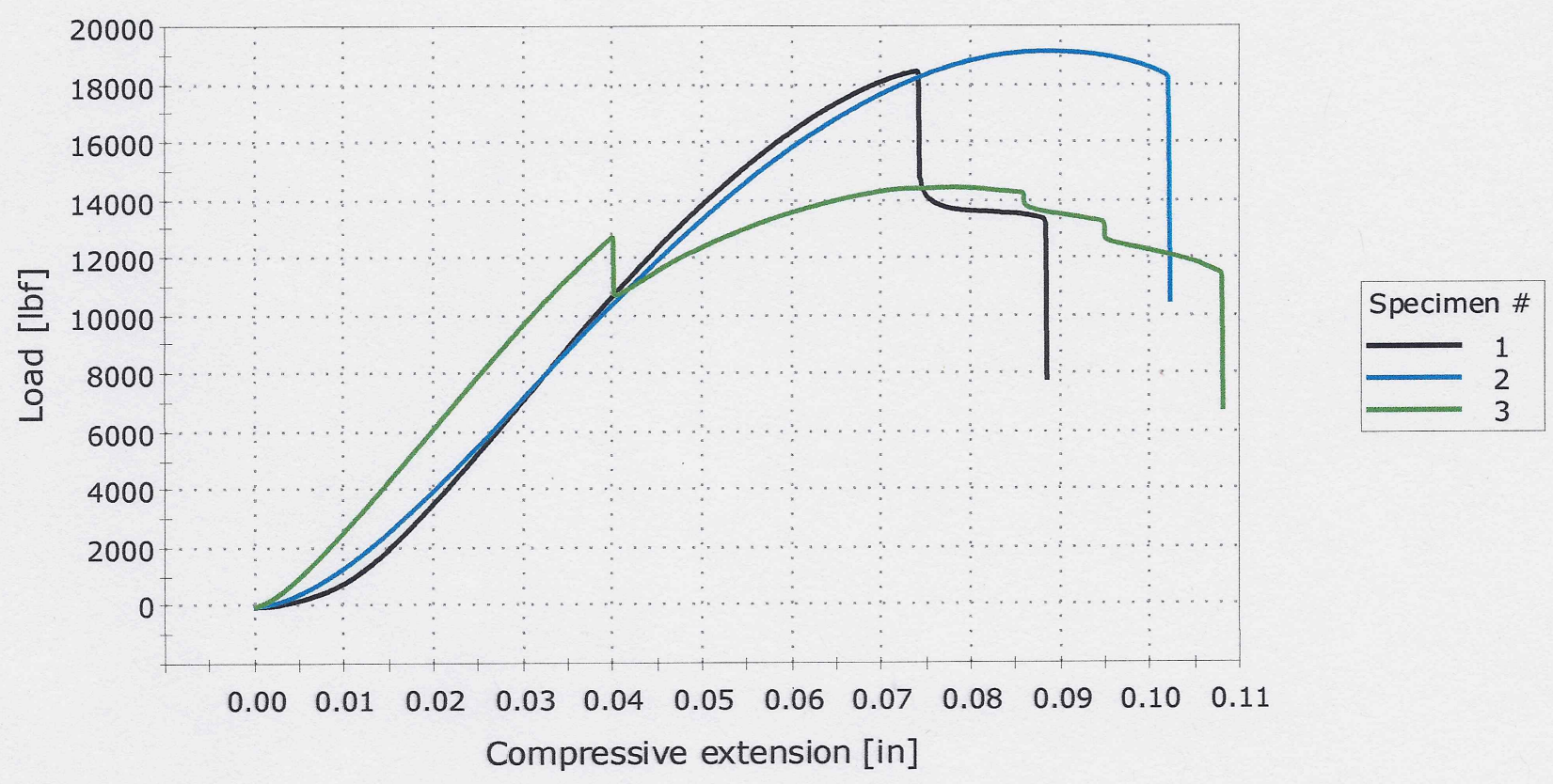

Specimen ID

$$
\begin{aligned}
& I-1 A-30-1 \\
& I-1 A-30-2 \\
& I-1 A-30-3
\end{aligned}
$$

Maximum

Minimum

S.D.

Mean

\section{Maximum Load}

[lbf]

$$
\begin{aligned}
& 18,440.19 \\
& 19,122.51 \\
& 14,440.30 \\
& 19,122.51 \\
& 14,440.30 \\
& 2,529.420 \\
& 17,334.33
\end{aligned}
$$

Compressive stress at Maximum Load

[psi]

$5,623.52$

$5,831.60$

$4,403.71$

$5,831.60$

$4,403.71$

771.372

$5,286.28$ 


\section{BROOKHAVEN NATIONAL LABORATORY}

Compression Testing (ASTM-C39)

Method description

System of units

Test type
Compression Testing (ASTM-C39)

All

Compression

COMPRESSION TEST - Specimen 1 to 2

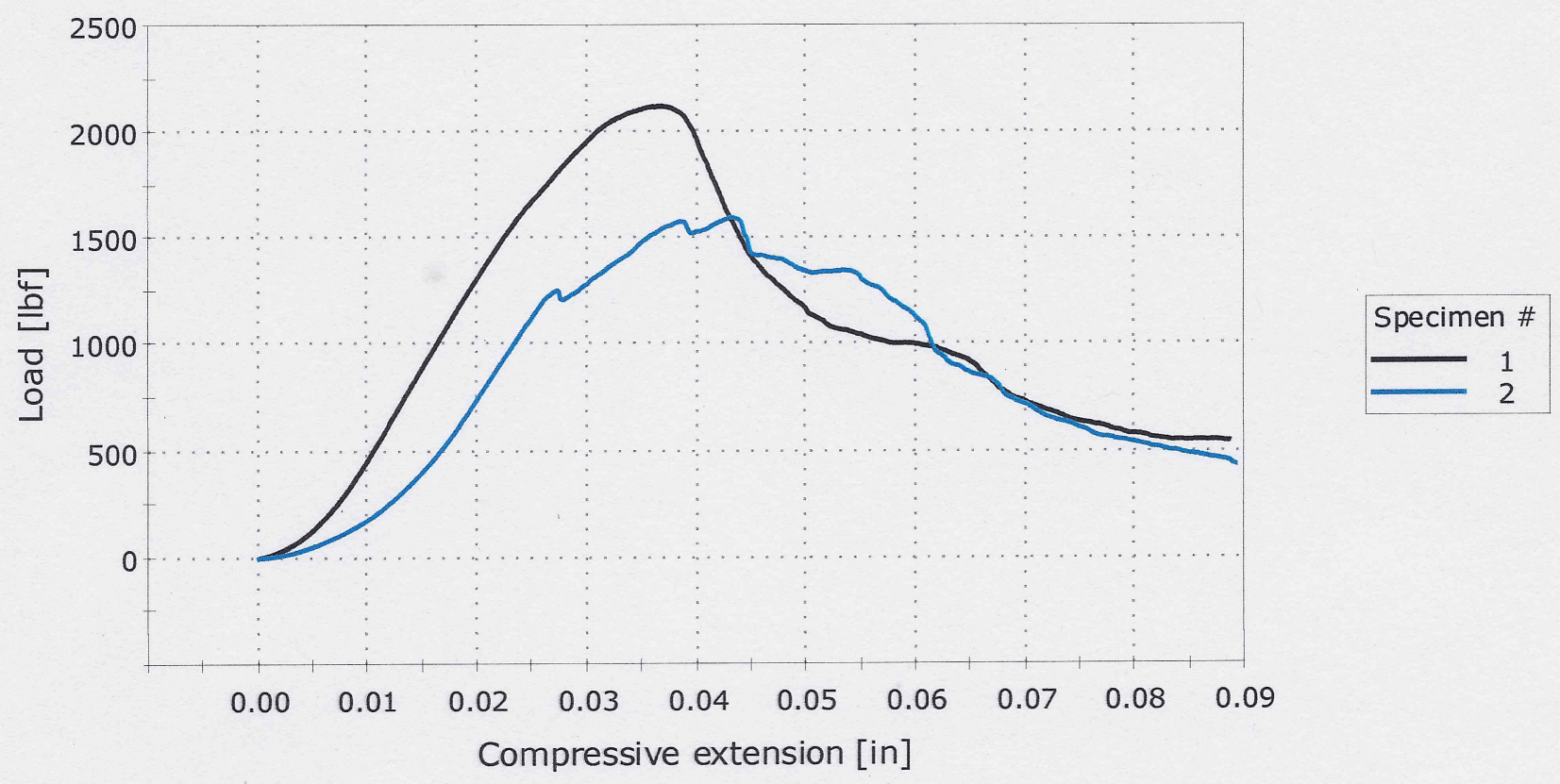

Specimen ID

$\begin{array}{ll}1 & \text { CSI-50-1 } \\ 2 & \text { CSI-50-2 }\end{array}$

Maximum

Minimum

S.D.

Mean
Maximum Load

[lbf]

$2,119.93$

$1,600.40$

$2,119.93$

$1,600.40$

367.361

$1,860.16$
Compressive stress at Maximum Load

[psi]

606.13

455.89

606.13

455.89

106.241

531.01 


\section{BROOKHAVEN NATIONAL LABORATORY}

Compression Testing (ASTM-C39)

Method description

System of units

Test type
Compression Testing (ASTM-C39)

All

Compression

COMPRESSION TEST - Specimen 1 to 2

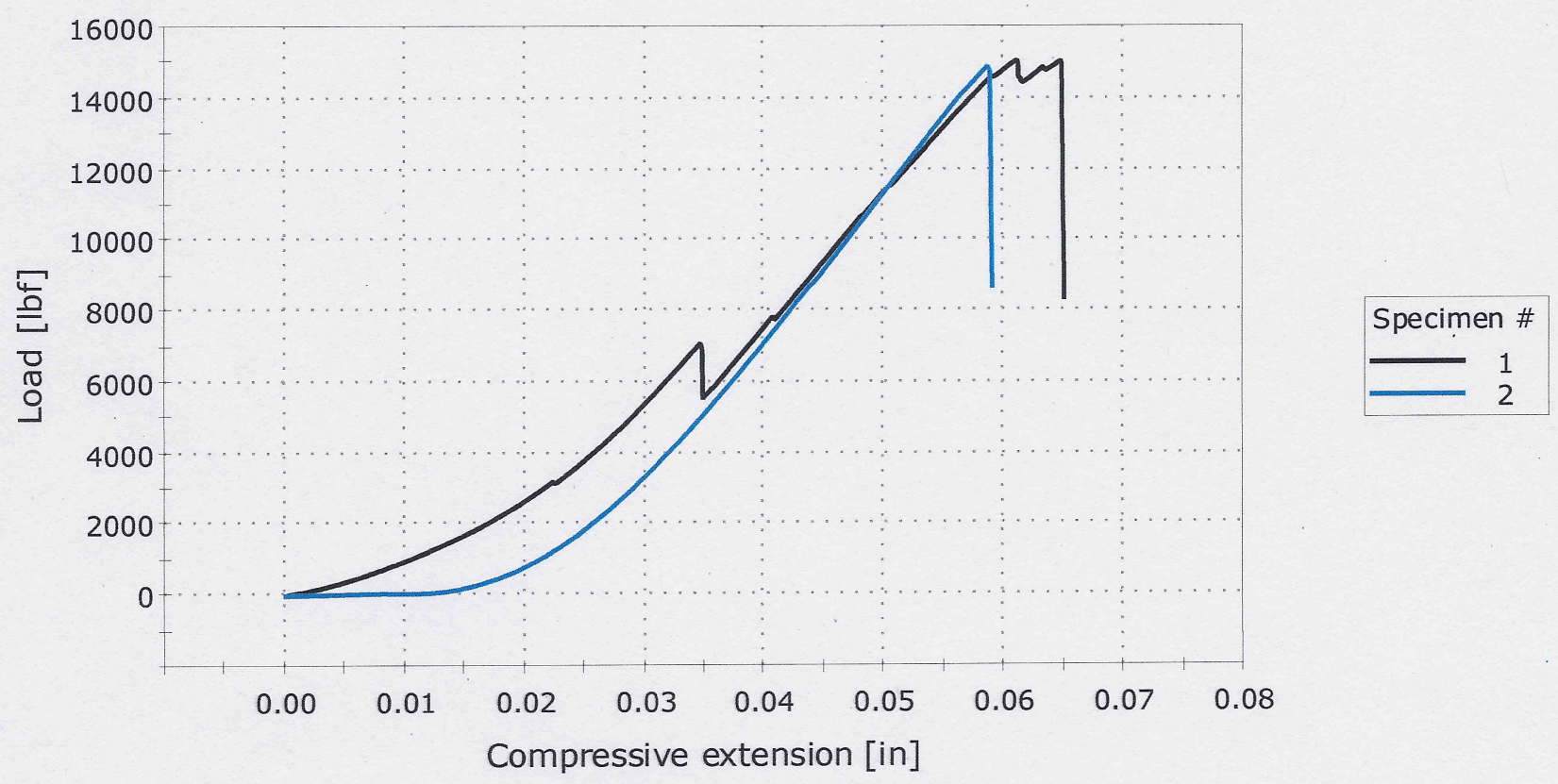

Specimen ID

$\begin{array}{ll}1 & \text { CSI }-43-1 \\ 2 & \text { CSI }-43-2\end{array}$

Maximum

Minimum

S.D.

Mean
Maximum Load
[lbf]

$15,027.58$

$14,883.49$

$15,027.58$

$14,883.49$

101.886

$14,955.53$
Compressive stress at Maximum Load

[psi]

$4,427.91$

$4,385.45$

$4,427.91$

$4,385.45$

30.021

$4,406.68$ 


\section{BROOKHAVEN NATIONAL LABORATORY}

Compression Testing (ASTM-C39)

Method description

System of units

Test type
Compression Testing (ASTM-C39)

All

Compression

COMPRESSION TEST - Specimen 1 to 2

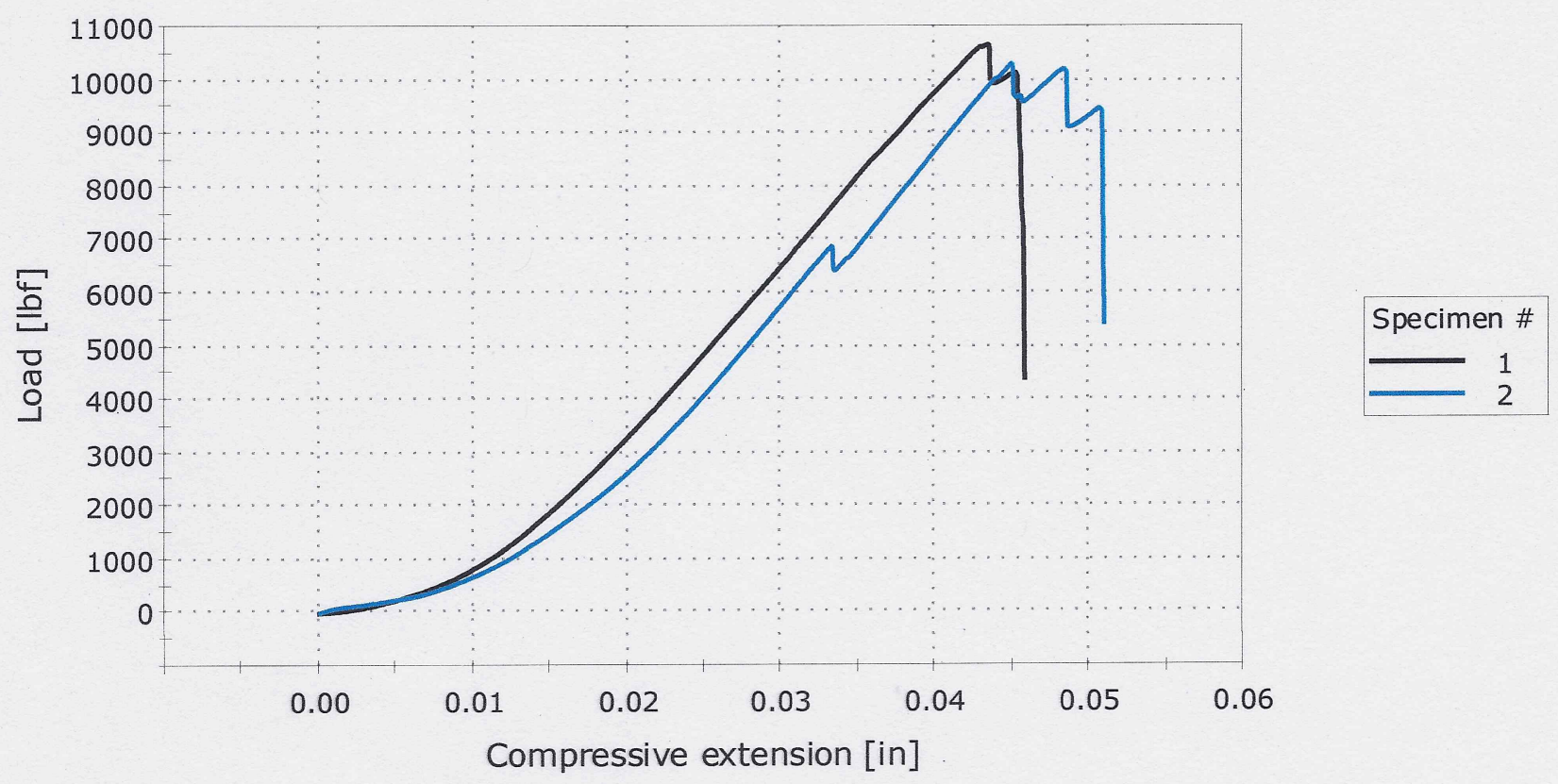

Maximum

Minimum

S.D.

Mean
Specimen ID

$$
\begin{aligned}
& \text { CSI-40-1 } \\
& \text { CSI-40-2 }
\end{aligned}
$$

\section{Maximum Load \\ [lbf]}

$\begin{array}{ll}1 & \text { CSI-40-1 } \\ 2 & \text { CSI-40-2 }\end{array}$

$10,640.47$

$10,289.58$

$10,640.47$

$10,289.58$

248.119

$10,465.02$
Compressive stress at Maximum Load

$$
\text { [psi] }
$$

$3,111.62$

$3,020.40$

$3,111.62$

$3,020.40$

64.506

$3,066.01$ 


\section{BROOKHAVEN NATIONAL LABORATORY}

Compression Testing (ASTM-C39)

Method description

System of units

Test type
Compression Testing (ASTM-C39)

All

Compression

COMPRESSION TEST - Specimen 1 to 2

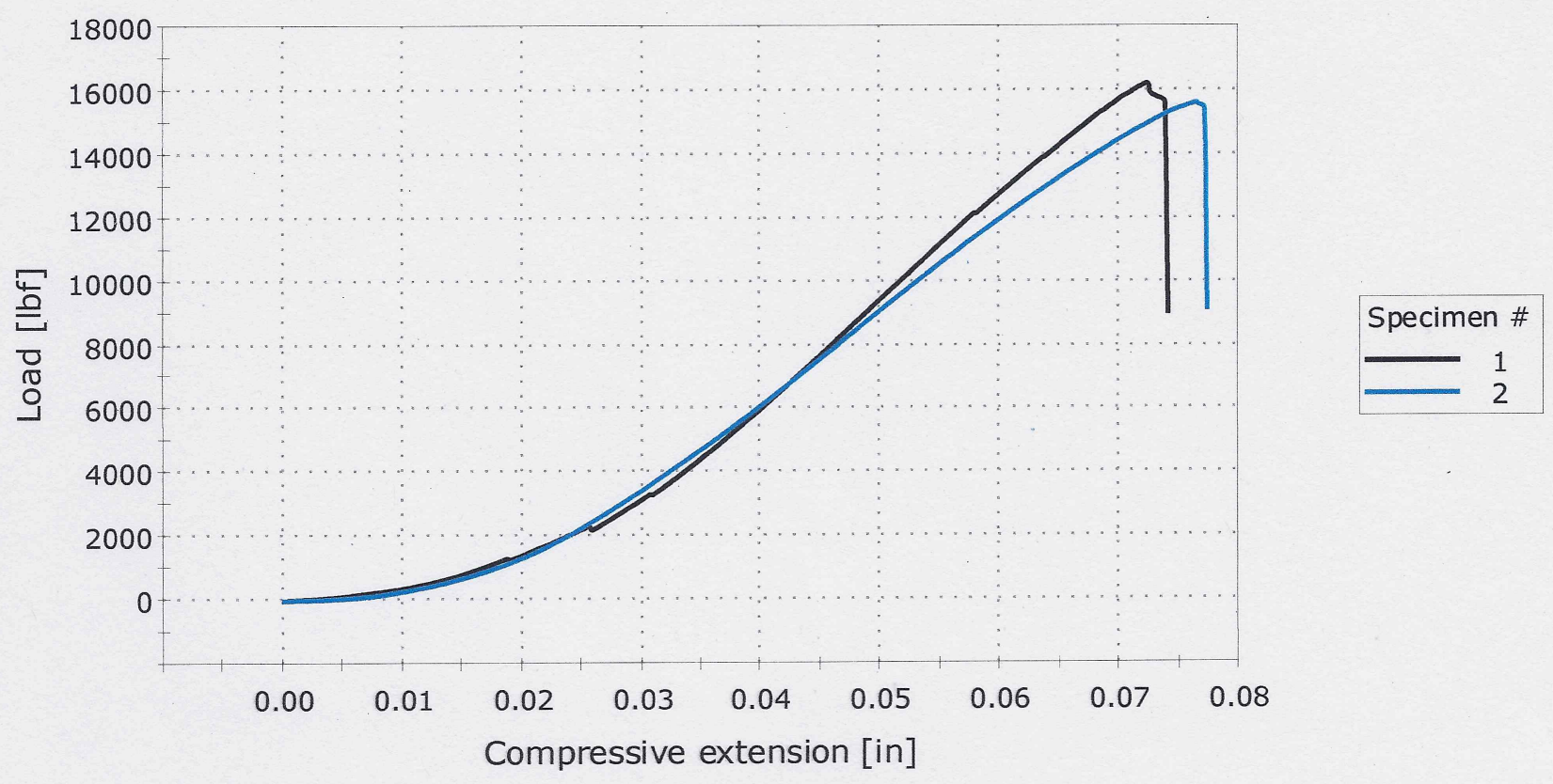

Specimen ID

$\begin{array}{ll}1 & \text { CSI }-30-1 \\ 2 & \text { CSI }-30-2\end{array}$

Maximum

Minimum

S.D.

Mean

\section{Maximum Load}

[lbf]

$16,206.10$

$15,586.72$

$16,206.10$

$15,586.72$

437.970

$15,896.41$
Compressive stress at Maximum Load

[psi]

$4,904.34$

$4,575.31$

$4,904.34$

$4,575.31$

232.657

$4,739.83$ 


\section{BROOKHAVEN NATIONAL LABORATORY}

Compression Testing (ASTM-C39)

Method description

System of units

Test type
Compression Testing (ASTM-C39)

All

Compression

\section{COMPRESSION TEST - Specimen 1 to 3}

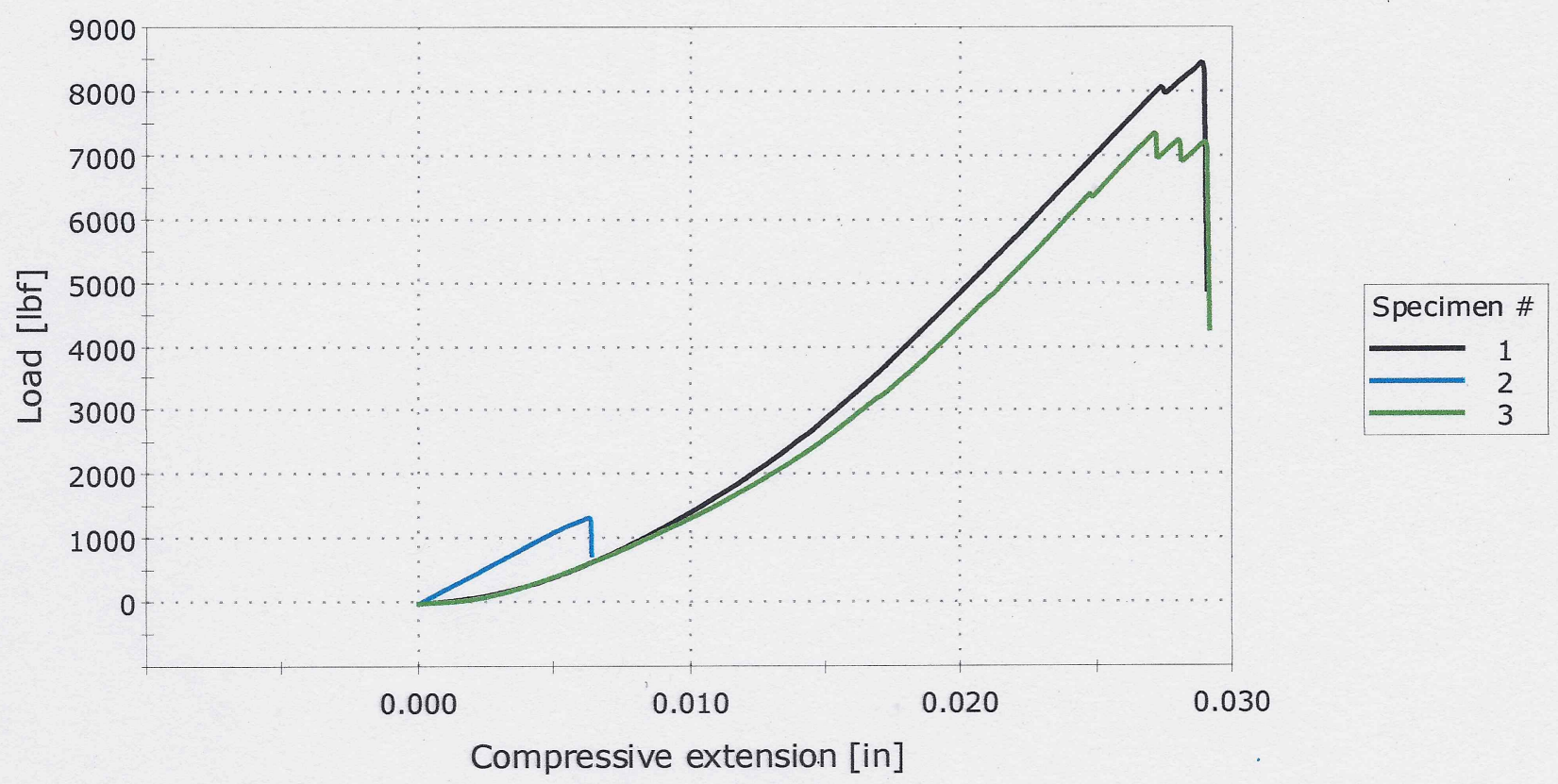

Specimen ID

$$
\begin{aligned}
& \text { CSC }-50-1 \\
& \text { CSC }-50-2 \\
& \text { CSC }-50-3
\end{aligned}
$$

Maximum

Minimum

S.D.

Mean

$\begin{array}{ll}1 & \text { CSC }-50-1 \\ 2 & \text { CSC }-50-2 \\ 3 & \text { CSC }-50-3\end{array}$

.

\section{Maximum Load} [lbf] 


\section{BROOKHAVEN NATIONAL LABORATORY}

Compression Testing (ASTM-C39)

Method description

System of units

Test type
Compression Testing (ASTM-C39)

All

Compression

COMPRESSION TEST - Specimen 1 to 2

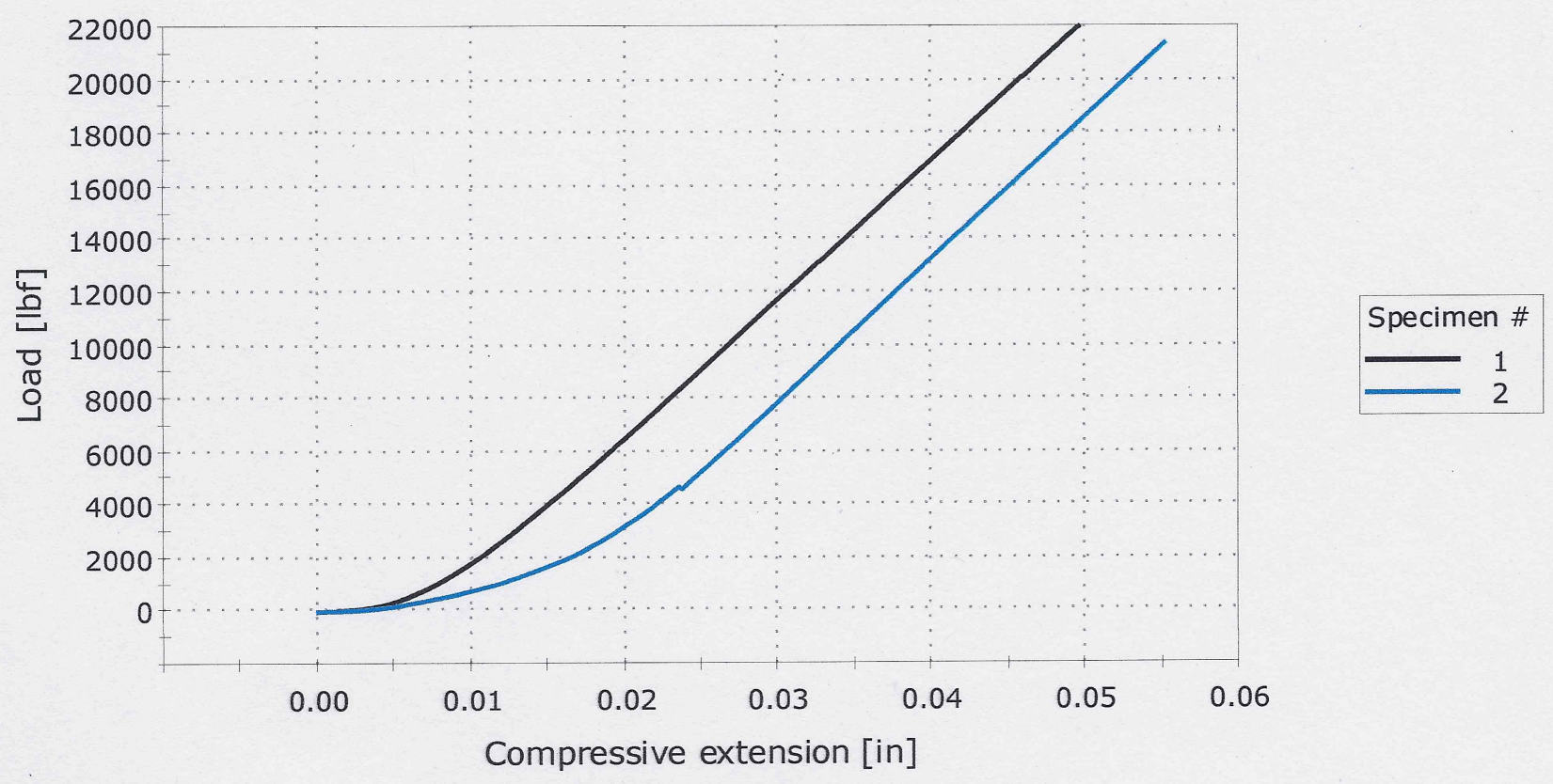

Specimen ID

Maximum Load

[lbf]

CSC-43-1

CSC-43-2
Maximum

Minimum

S.D.

Mean
$21,978.09$

$21,381.47$

$21,978.09$

$21,381.47$

421.873

$21,679.78$
Compressive stress at Maximum Load [psi]

$6,451.43$

$6,300.10$

$6,451.43$

$6,300.10$

107.010

$6,375.76$ 


\section{BROOKHAVEN NATIONAL LABORATORY}

Compression Testing (ASTM-C39)

Method description

System of units

Test type
Compression Testing (ASTM-C39)

All

Compression

COMPRESSION TEST - Specimen 1 to 3

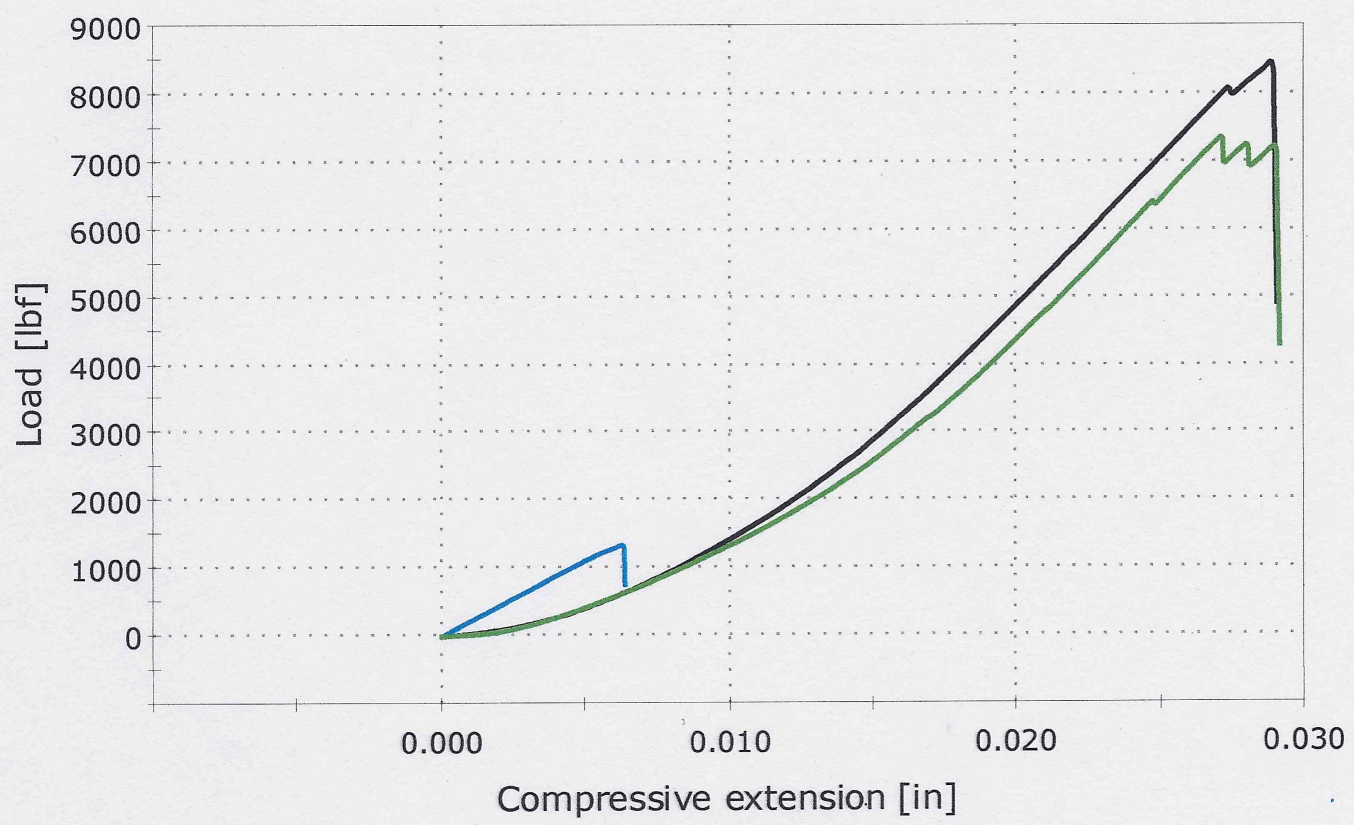

Specimen ID

$$
\begin{aligned}
& \text { CSC-50-1 } \\
& \text { CSC-50-2 } \\
& \text { CSC-50-3 }
\end{aligned}
$$

Maximum

Minimum

S.D.

Mean

\section{Maximum Load}

[lbf]

$8,444.17$

$1,346.56$

$7,337.94$

$8,444.17$

$1,346.56$

$3,818.737$

$5,709.56$
Compressive stress at Maximum Load [psi]

$$
\text { 2,488.09 }
$$

396.77

$2,153.97$

$2,488.09$

396.77

$1,123.467$

$1,679.61$ 


\section{BROOKHAVEN NATIONAL LABORATORY}

Compression Testing (ASTM-C39)

Method description

System of units

Test type
Compression Testing (ASTM-C39)

All

Compression

\section{COMPRESSION TEST - Specimen 1 to 2}

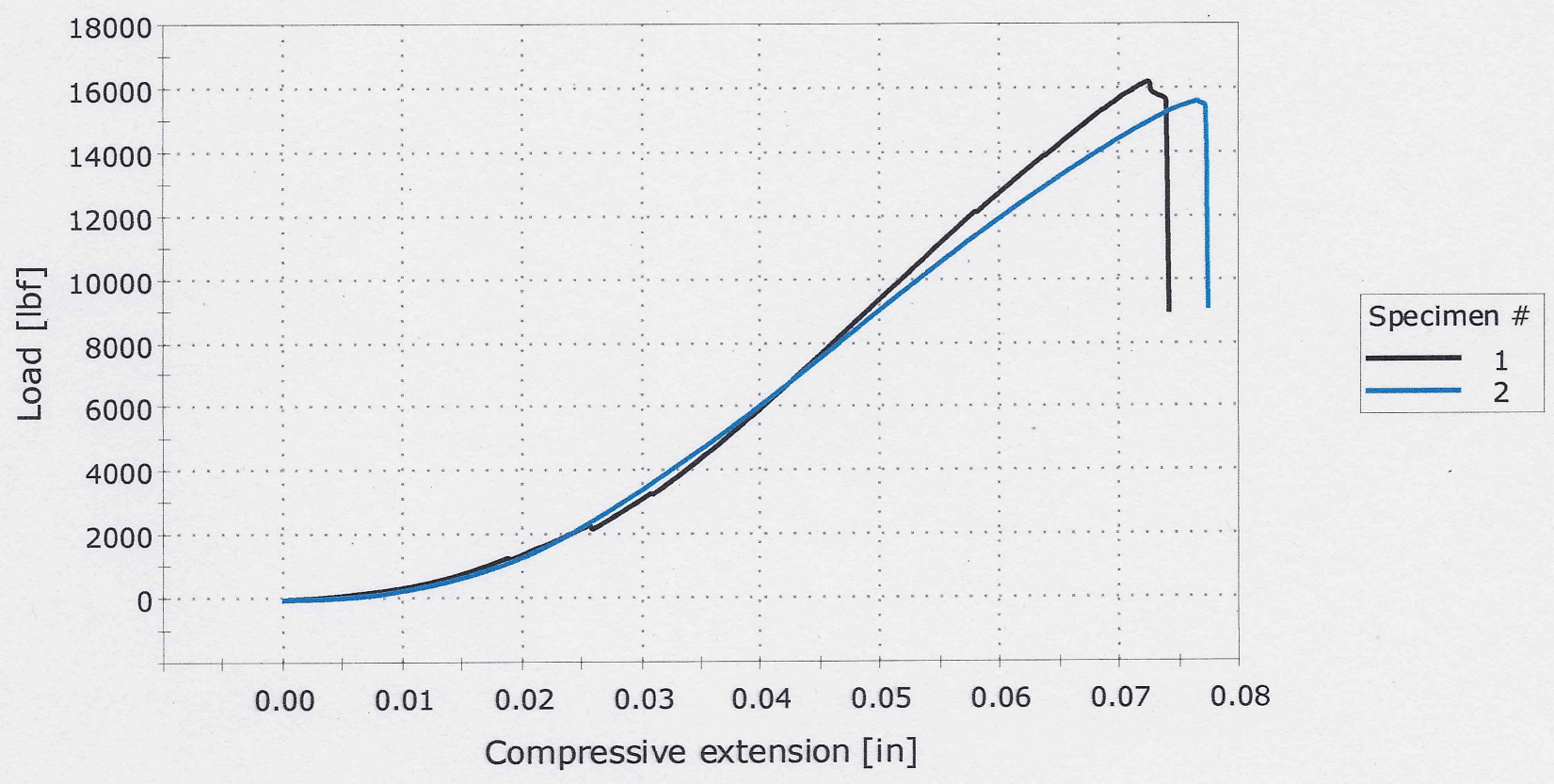

Specimen ID

$\begin{array}{ll}1 & \text { CSI-30-1 } \\ 2 & \text { CSI-30-2 }\end{array}$

Maximum

Minimum

S.D.

Mean
Maximum Load

[lbf]

$16,206.10$

$15,586.72$

$16,206.10$

$15,586.72$

437.970

$15,896.41$
Compressive stress at Maximum Load

$$
\text { [psi] }
$$

$4,904.34$

$4,575.31$

$4,904.34$

$4,575.31$

232.657

$4,739.83$ 


\section{BROOKHAVEN NATIONAL LABORATORY}

Compression Testing (ASTM-C39)

Method description

System of units

Test type
Compression Testing (ASTM-C39)

All

Compression

\section{COMPRESSION TEST - Specimen 1 to 2}

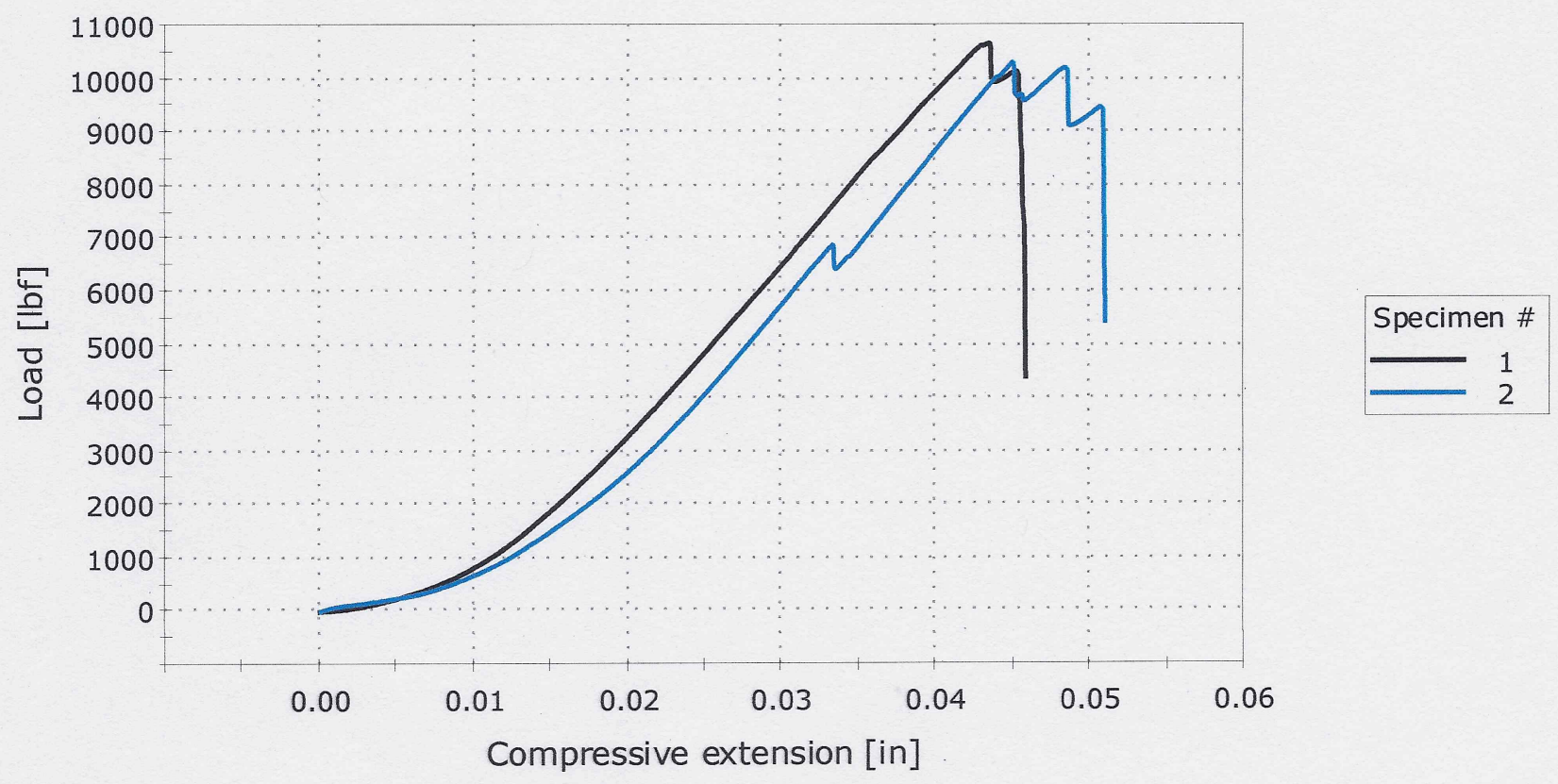

Specimen ID

$\begin{array}{ll}1 & \text { CSI }-40-1 \\ 2 & \text { CSI-40-2 }\end{array}$

Maximum

Minimum

S.D.

Mean

\section{Maximum Load \\ [lbf]}

$10,640.47$

$10,289.58$

$10,640.47$

$10,289.58$

248.119

$10,465.02$
Compressive stress at Maximum Load

$$
\text { [psi] }
$$

$3,111.62$

$3,020.40$

$3,111.62$

$3,020.40$

64.506

$3,066.01$ 


\section{BROOKHAVEN NATIONAL LABORATORY}

Compression Testing (ASTM-C39)

Method description

System of units Test type
Compression Testing (ASTM-C39)

All

Compression

COMPRESSION TEST - Specimen 1 to 2

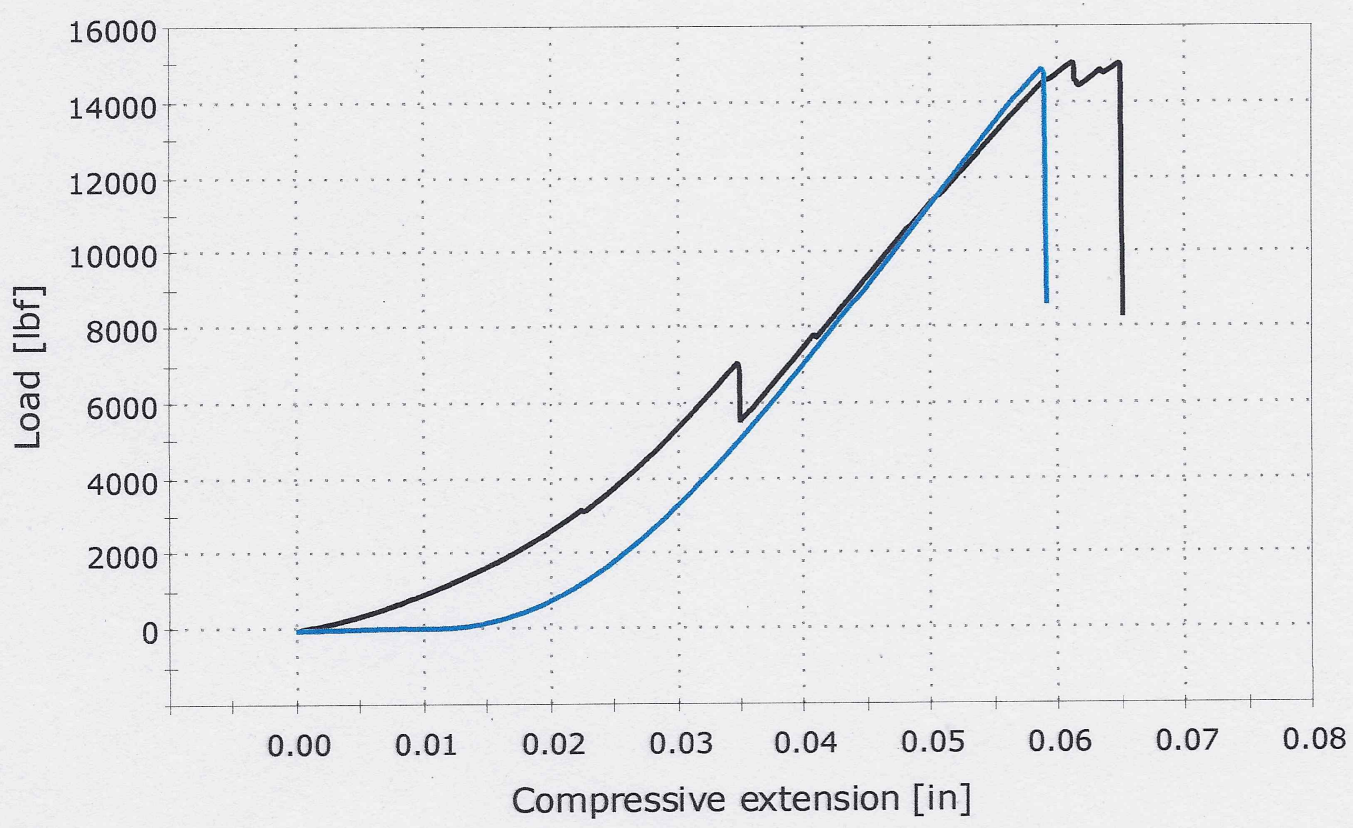

Specimen ID

1

2

Maximum

Minimum

S.D.
Maximum Load

[lbf]

CSI-43-1

CSI-43-2
$15,027.58$

$14,883.49$

$15,027.58$

$14,883.49$

101.886

14955.53
Compressive stress at Maximum Load [psi]

$4,427.91$

$4,385.45$

$4,427.91$

$4,385.45$

30.021

4.406 .68 


\section{BROOKHAVEN NATIONAL LABORATORY}

Compression Testing (ASTM-C39)

Method description

System of units

Test type
Compression Testing (ASTM-C39)

All

Compression

COMPRESSION TEST - Specimen 1 to 2

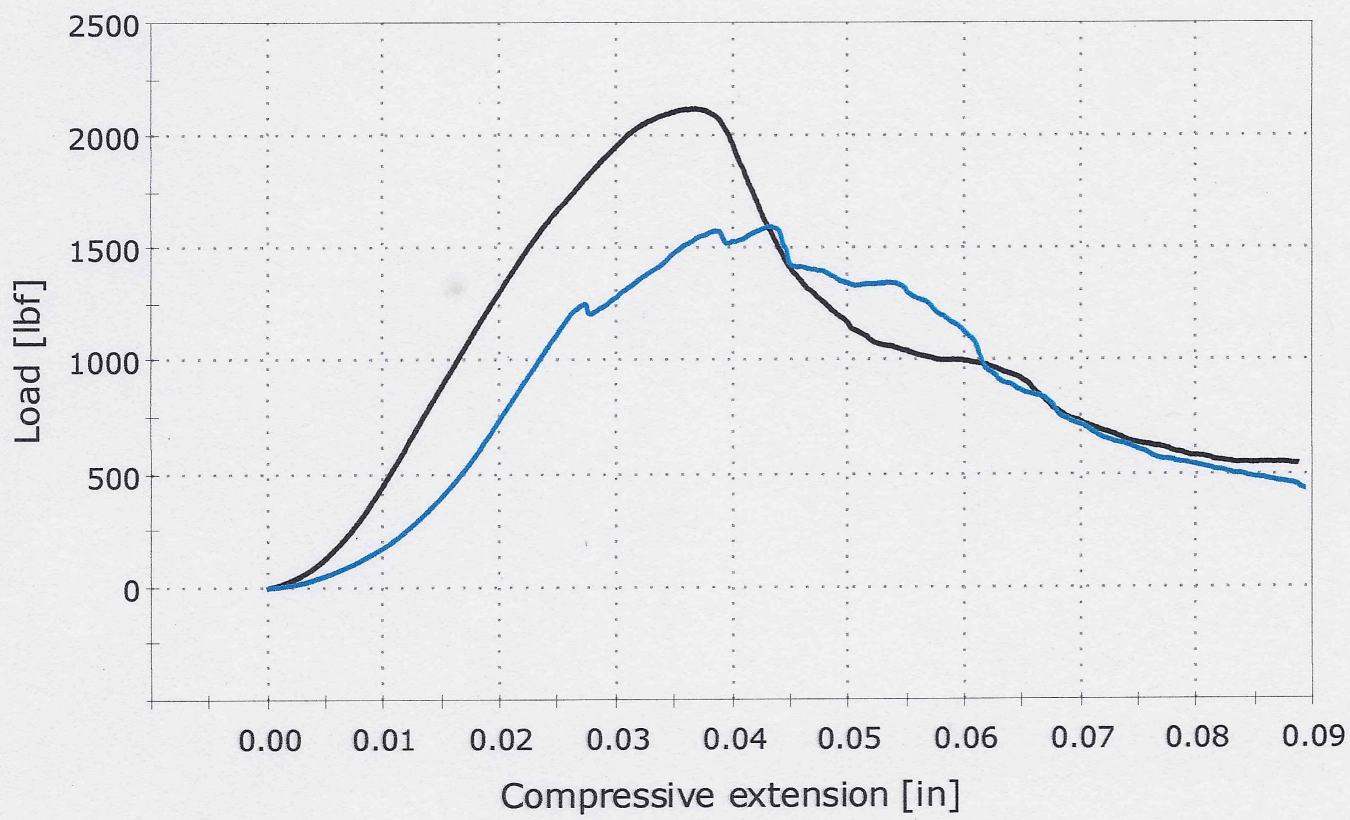

Specimen \#

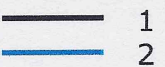

Specimen ID

1

2

Maximum

Minimum

S.D. Mean
Maximum Load

[lbf]

CSI- $50-1$

CSI-50-2
$2,119.93$

$1,600.40$

$2,119.93$

$1,600.40$

367.361

1.860 .16
Compressive stress at Maximum Load [psi] 606.13 455.89 606.13 455.89 106.241 531.01 


\section{BROOKHAVEN NATIONAL LABORATORY}

Compression Tesing (ASTM-C39)

Method description

System of units

Test type
Compression Tesing (ASTM-C39)

All

Compression

\section{COMPRESSION TEST - Specimen 1 to 3}

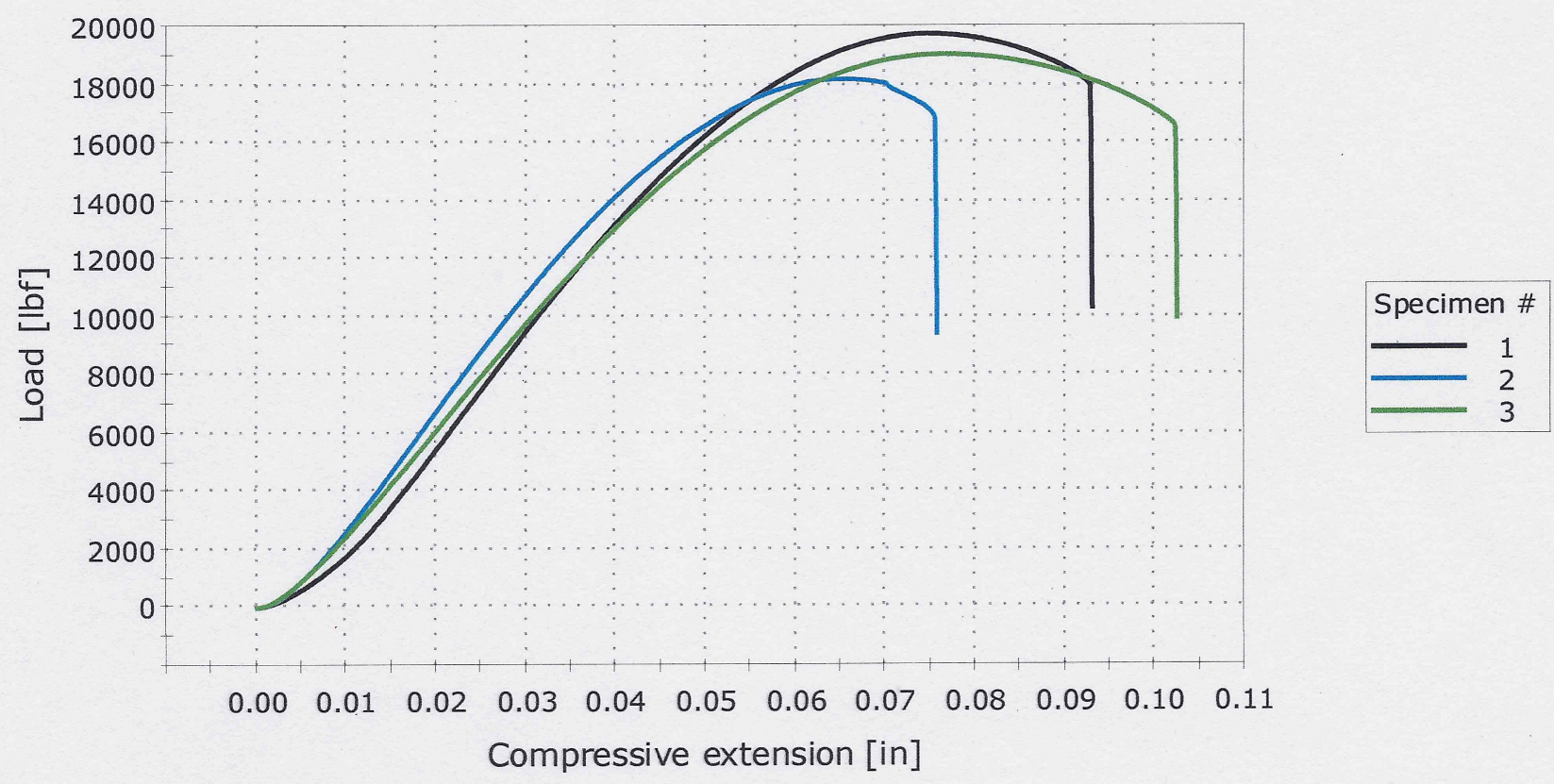

Specimen ID

$$
\begin{aligned}
& C-1 A-30-1 \\
& C-1 A-30-2 \\
& C-1 A-30-3
\end{aligned}
$$

Maximum

Minimum

S.D.

Mean

\section{Maximum Load \\ [lbf]}

$19,697.49$

$18,153.44$

$18,995.98$

$19,697.49$

$18,153.44$

773.097

$18,948.97$
Compressive stress at Maximum Load [psi]

$5,983.86$

$5,514.80$

$5,770.75$

$5,983.86$

$5,514.80$

234.858

$5,756.47$ 


\section{BROOKHAVEN NATIONAL LABORATORY}

Compression Testing (ASTM-C39)

Method description

System of units

Test type
Compression Testing (ASTM-C39)

All

Compression

COMPRESSION TEST - Specimen 1 to 3

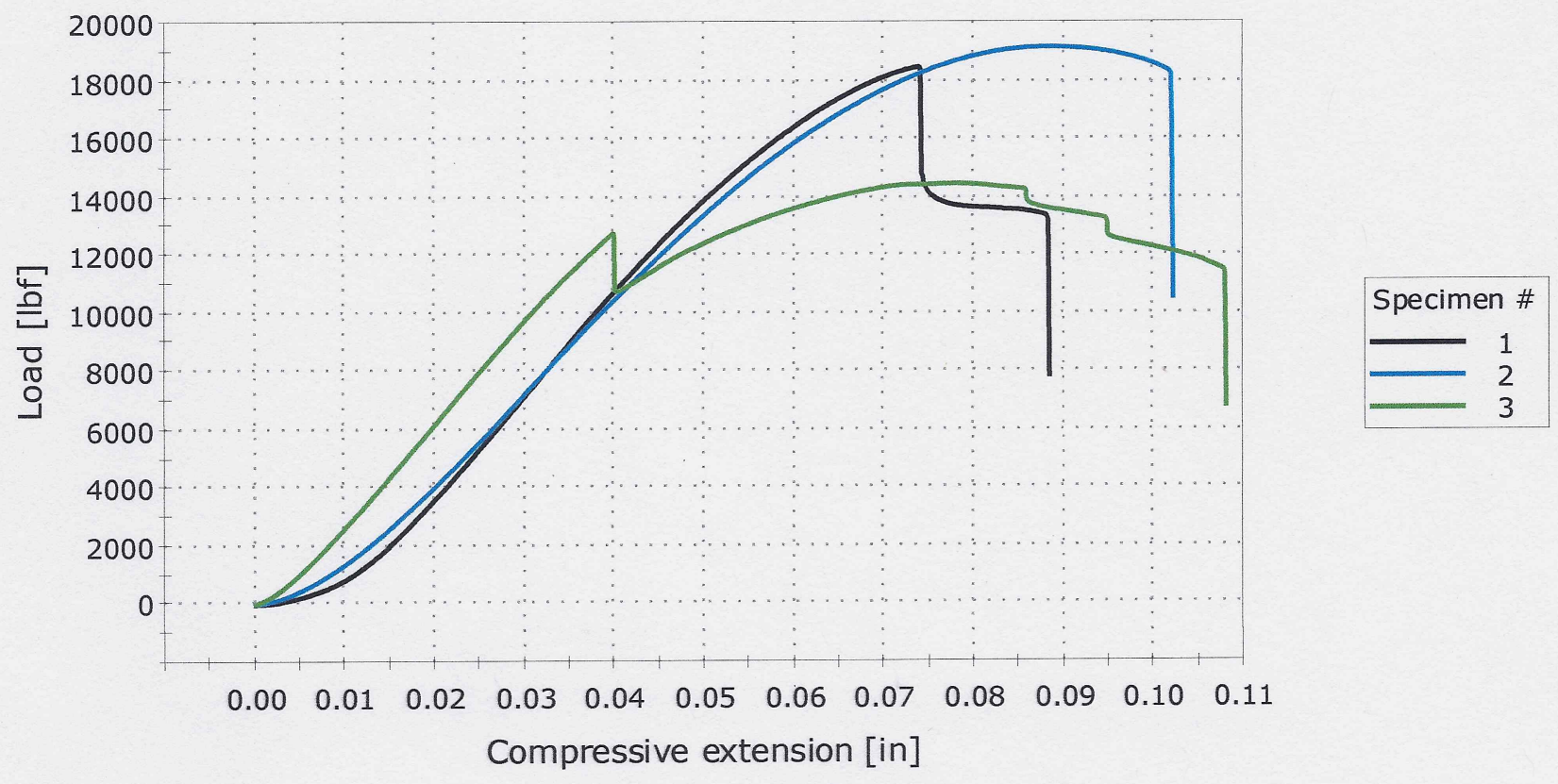

Specimen ID

$$
\begin{aligned}
& I-1 A-30-1 \\
& \text { I- } 1 A-30-2 \\
& I-1 A-30-3
\end{aligned}
$$

Maximum

Minimum

S.D.

Mean

\section{Maximum Load}

[lbf]

$18,440.19$

$19,122.51$

$14,440.30$

$19,122.51$

$14,440.30$

$2,529.420$

$17,334.33$
Compressive stress at Maximum Load

[psi]

$5,623.52$

$5,831.60$

$4,403.71$

$5,831.60$

$4,403.71$

771.372

$5,286.28$ 


\section{BROOKHAVEN NATIONAL LABORATORY}

Compression Testing (ASTM-C39)

Method description

System of units

Test type
Compression Testing (ASTM-C39)

All

Compression

COMPRESSION TEST - Specimen 1 to 3

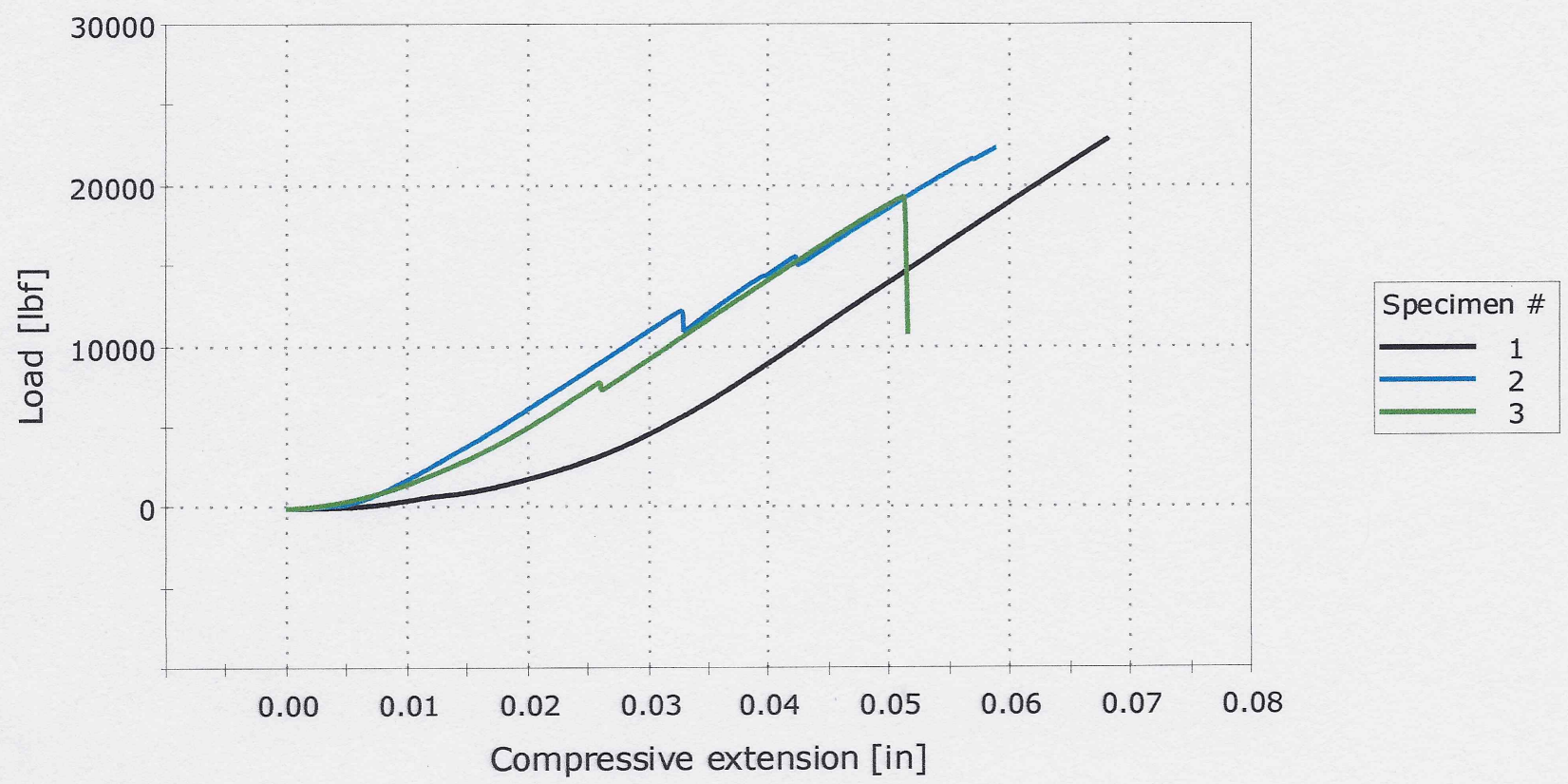

Specimen ID

Maximum Load

[lbf]

$22,931.51$

$22,356.75$

$19,316.98$

$22,931.51$

$19,316.98$

$1,942.309$

$21,535.08$
Compressive stress at Maximum Load

[psi]

$6,886.63$

$6,688.42$

$5,801.14$

$6,886.63$

$5,801.14$

578.049

$6,458.73$
Mean

$C-1 A-50-2$
$C-1 A-50-3$

Minimum 


\section{BROOKHAVEN NATIONAL LABORATORY}

Compression Testing (ASTM-39)

Method description

System of units

Test type
Compression Testing (ASTM-39)

All

Compression

COMPRESSION TEST - Specimen 1 to 2

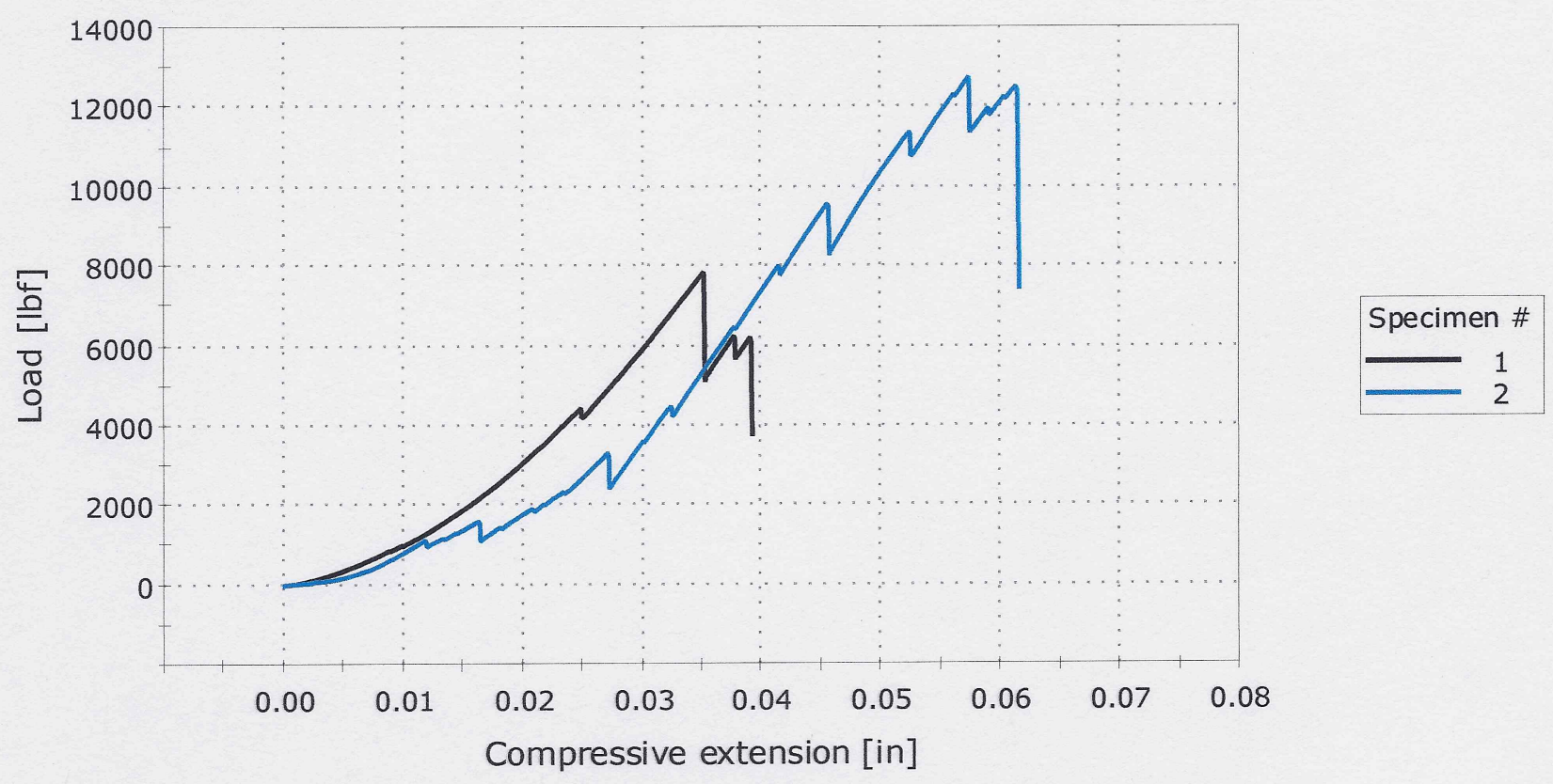

Specimen ID

$\begin{array}{ll}1 & \text { CSC }-40-1 \\ 2 & \text { CSC }-40-2\end{array}$

Maximum

Minimum

S.D.

Mean
Maximum Load

[lbf]

$7,840.58$

$12,731.74$

$12,731.74$

$7,840.58$

$3,458.572$

$10,286.16$
Compressive stress at Maximum Load

[psi]

2,319.02

$3,765.69$

$3,765.69$

2,319.02

$1,022.947$

$3,042.35$ 


\section{BROOKHAVEN NATIONAL LABORATORY}

Compression Testing (ASTM-C39)

Method description

System of units

Test type
Compression Testing (ASTM-C39)

All

Compression

\section{COMPRESSION TEST - Specimen 1 to 3}

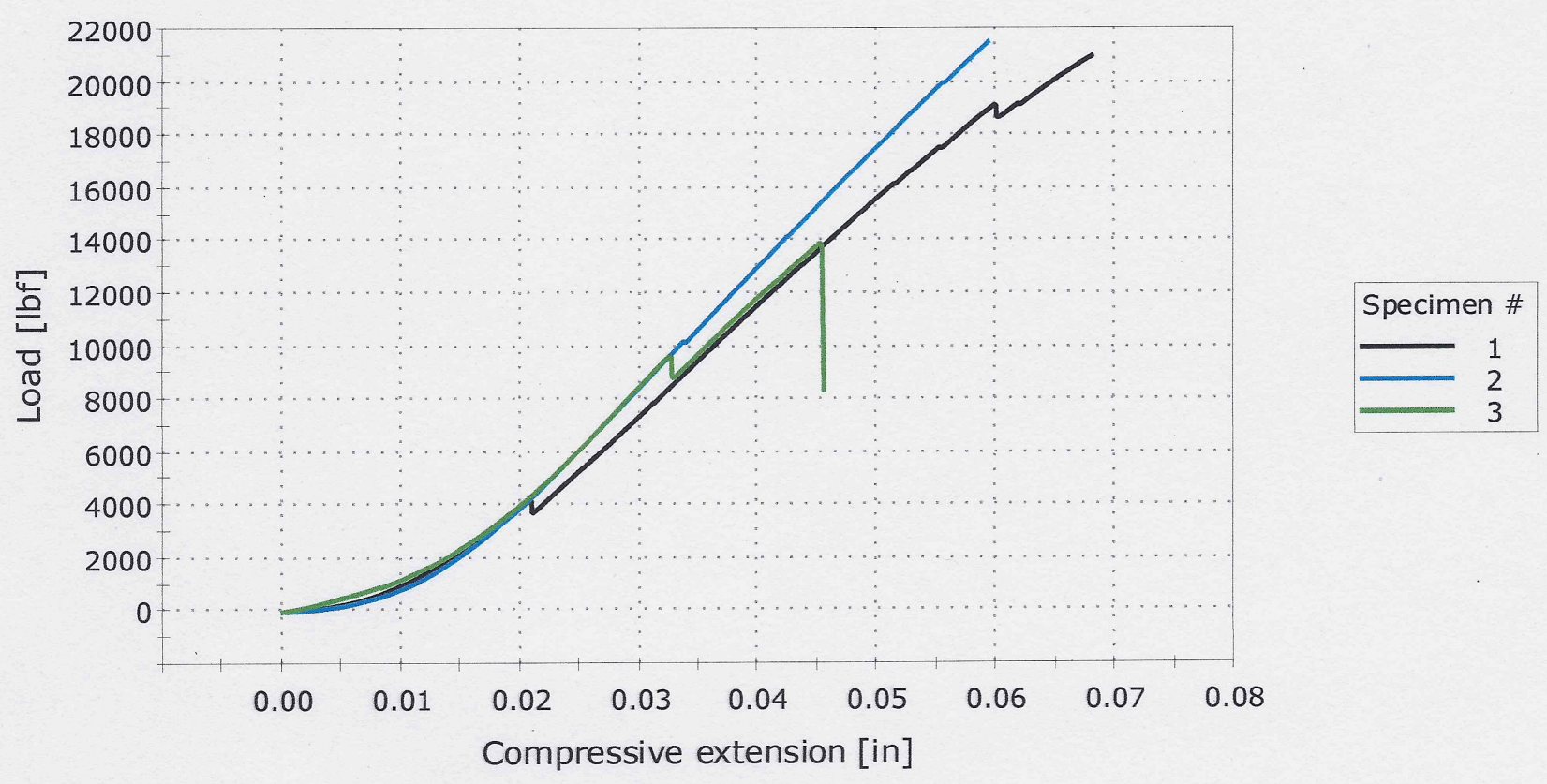

Specimen ID

$$
\begin{aligned}
& \text { CSC-30-1 } \\
& \text { CSC-30-2 } \\
& \text { CSC-30-3 }
\end{aligned}
$$

\section{Maximum Load \\ [lbf]}

$20,972.03$

$21,503.71$

$13,912.02$

$21,503.71$

$13,912.02$

$4,237.924$

$18,795.92$
Compressive stress at Maximum Load [psi] $6,420.35$ $6,482.61$ $4,130.44$ $6,482.61$ $4,130.44$ $1,340.414$ $5,677.80$ 


\section{BROOKHAVEN NATIONAL LABORATORY}

Compression Testing (ASTM-C39)

Method description

System of units

Test type
Compression Testing (ASTM-C39)

All

Compression

\section{COMPRESSION TEST - Specimen 1 to 3}

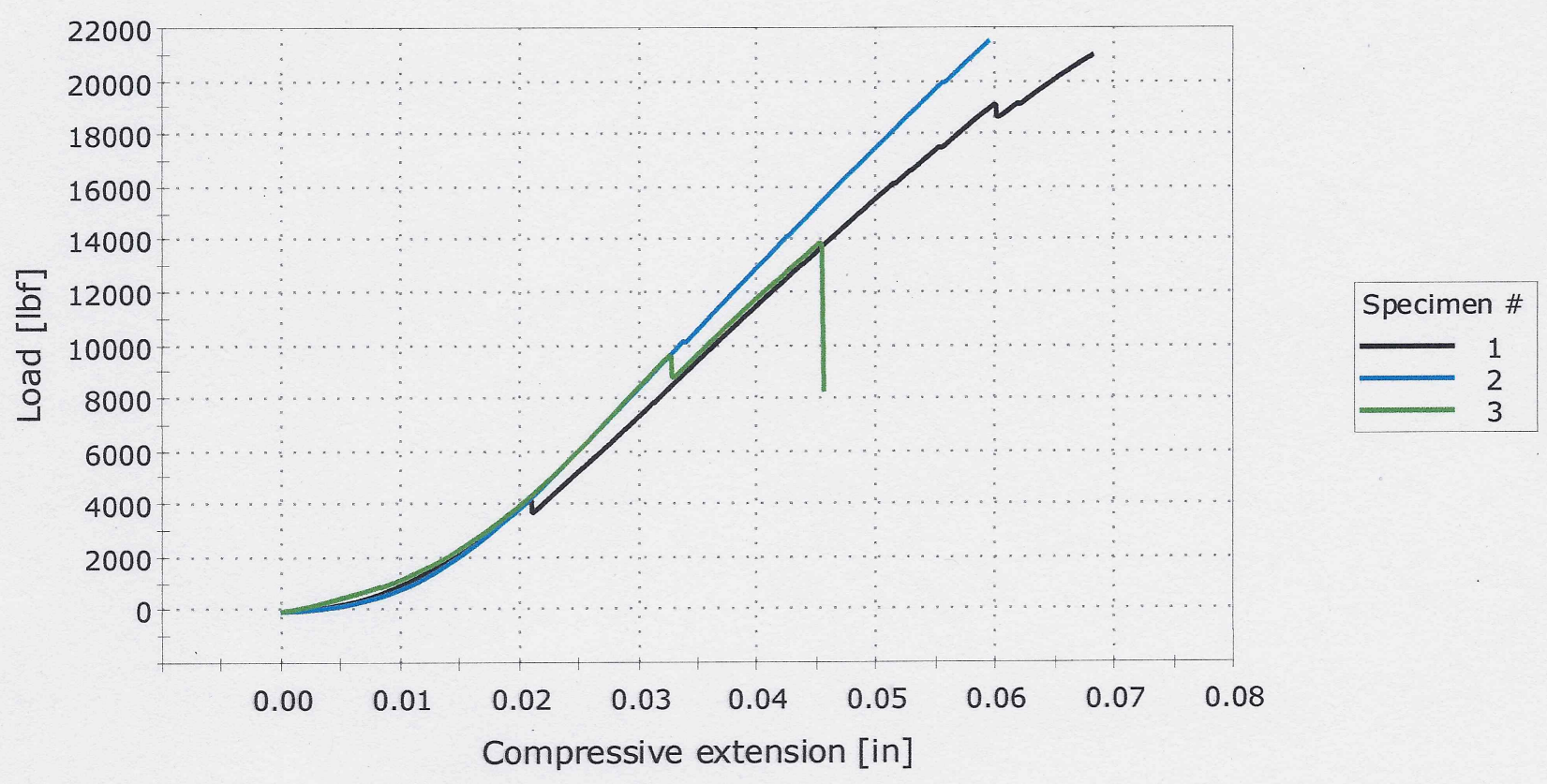

Maximum

Minimum

S.D.

Mean
Specimen ID

$\begin{array}{ll}1 & \text { CSC }-30-1 \\ 2 & \text { CSC }-30-2 \\ 3 & \text { CSC }-30-3\end{array}$

\section{Maximum Load \\ [lbf]}

$20,972.03$

$21,503.71$

$13,912.02$

$21,503.71$

$13,912.02$

$4,237.924$

$18,795.92$
Compressive stress at Maximum Load

$$
\text { [psi] }
$$

$6,420.35$

$6,482.61$

$4,130.44$

$6,482.61$

$4,130.44$

$1,340.414$

$5,677.80$ 


\section{BROOKHAVEN NATIONAL LABORATORY}

Compression Testing (ASTM-39)

Method description

System of units

Test type
Compression Testing (ASTM-39)

All

Compression

COMPRESSION TEST - Specimen 1 to 2

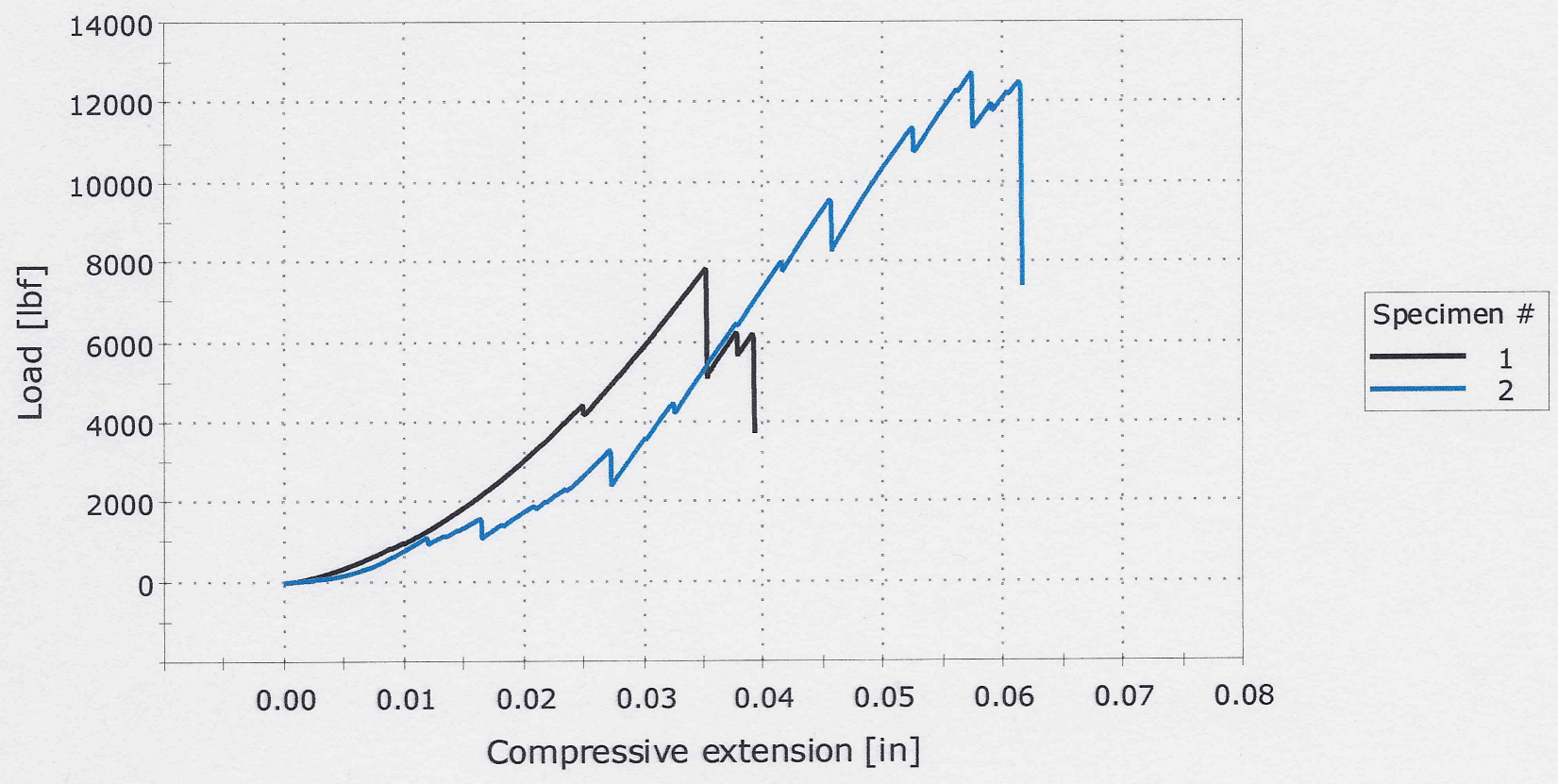

Specimen ID

$\begin{array}{ll}1 & \text { CSC }-40-1 \\ 2 & \text { CSC }-40-2\end{array}$

Maximum

Minimum

S.D.

Mean
Maximum Load

[lbf]

$7,840.58$

$12,731.74$

$12,731.74$

$7,840.58$

$3,458.572$

$10,286.16$
Compressive stress at Maximum Load

[psi]

$$
\begin{gathered}
2,319.02 \\
3,765.69 \\
3,765.69 \\
2,319.02 \\
1,022.947 \\
3,042.35
\end{gathered}
$$




\section{BROOKHAVEN NATIONAL LABORATORY}

Compression Testing (ASTM-C39)

Method description

System of units

Test type
Compression Testing (ASTM-C39)

All

Compression

COMPRESSION TEST - Specimen 1 to 3

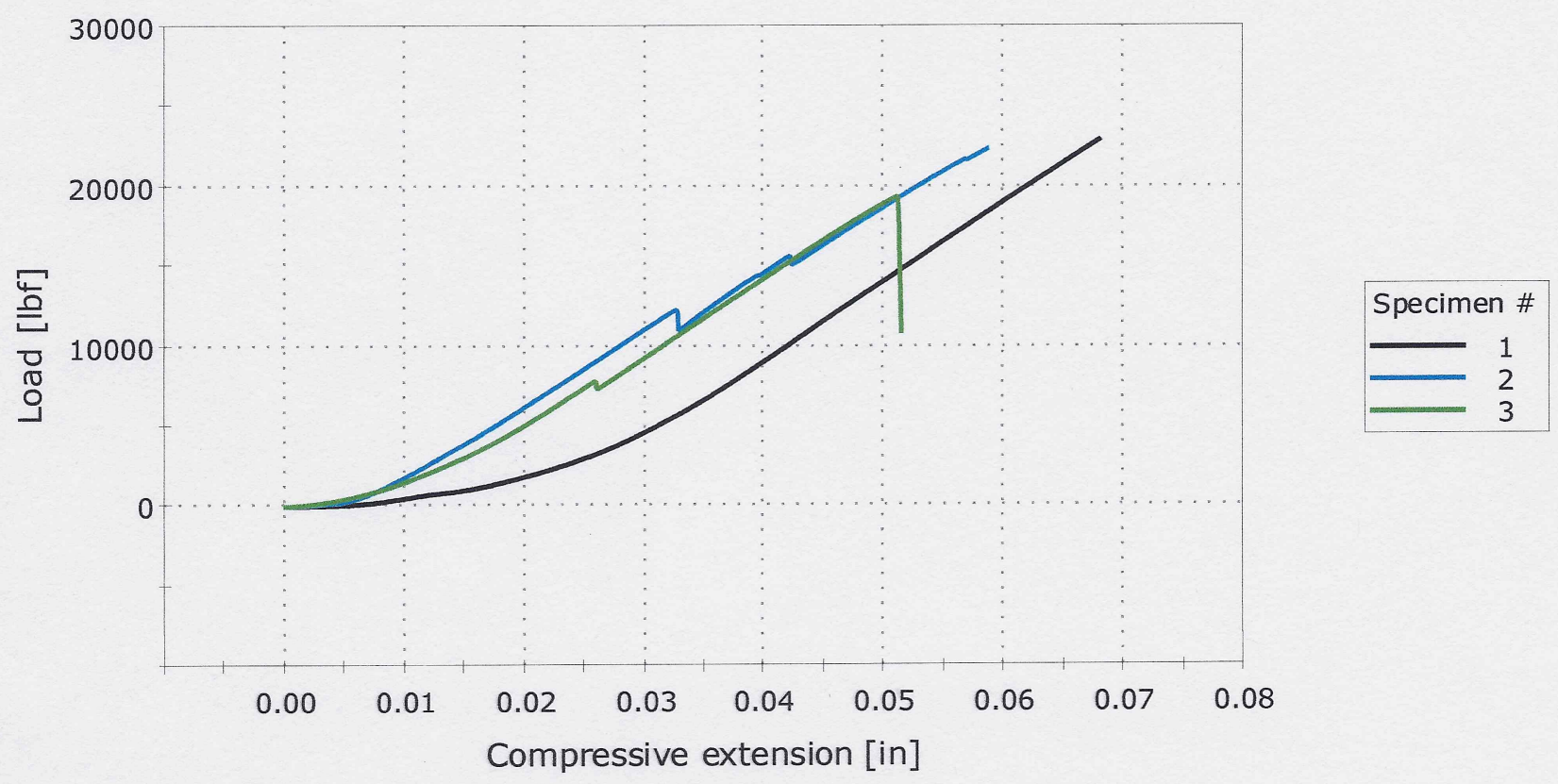

Specimen ID

$$
\begin{aligned}
& C-1 A-50-1 \\
& C-1 A-50-2 \\
& C-1 A-50-3
\end{aligned}
$$

Maximum

Minimum

S.D.

Mean

\section{Maximum Load \\ [lbf]}

$22,931.51$

$22,356.75$

$19,316.98$

$22,931.51$

$19,316.98$

$1,942.309$

$21,535.08$
Compressive stress at Maximum Load

$$
\text { [psi] }
$$

$6,886.63$

$6,688.42$

$5,801.14$

$6,886.63$

$5,801.14$

578.049

$6,458.73$ 


\section{BROOKHAVEN NATIONAL LABORATORY}

Compression Tesing (ASTM-C39)

Method description

System of units

Test type
Compression Tesing (ASTM-C39)

All

Compression

\section{COMPRESSION TEST - Specimen 1 to 3}

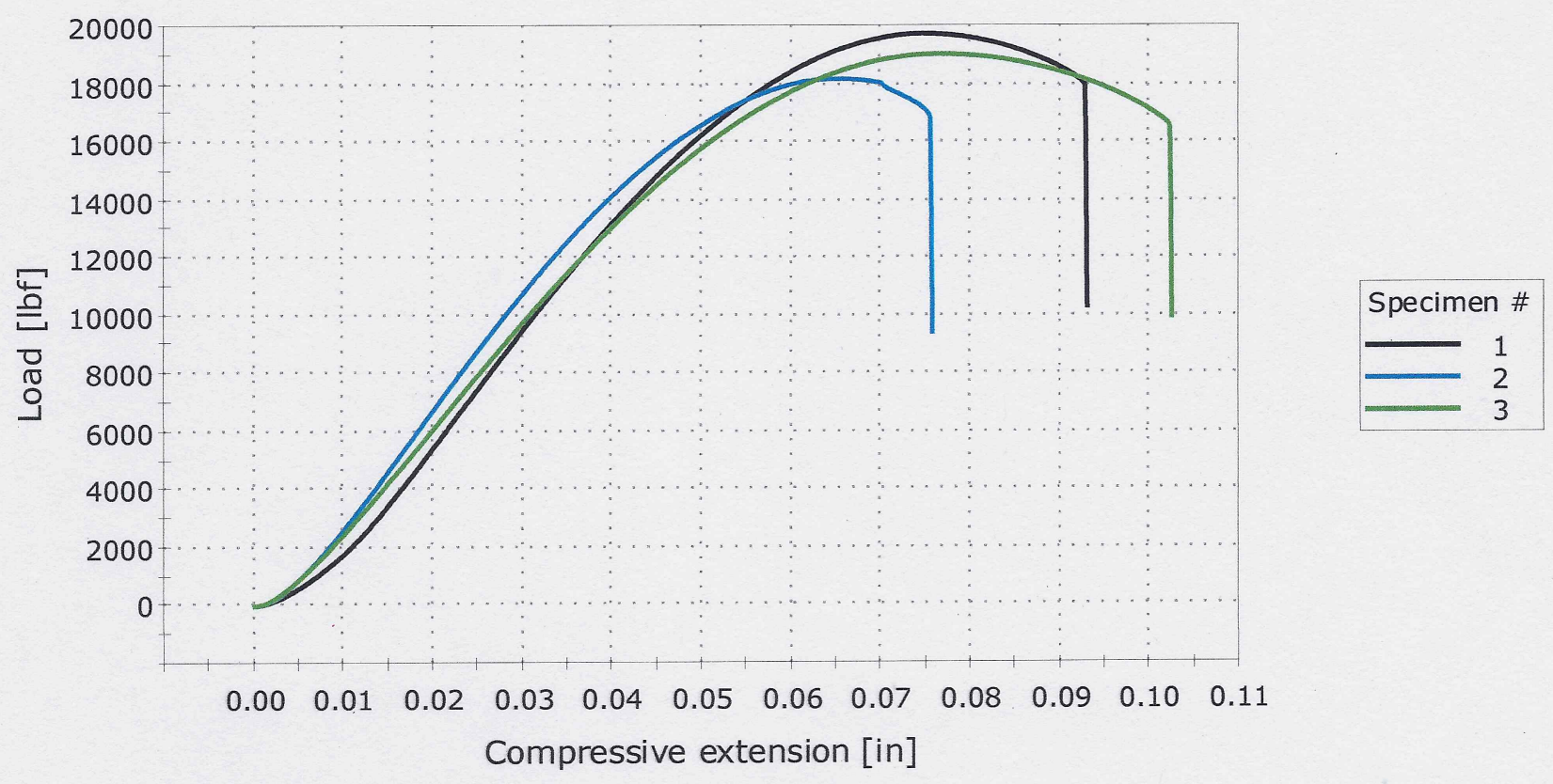

Specimen ID

$$
\begin{aligned}
& C-1 A-30-1 \\
& C-1 A-30-2
\end{aligned}
$$$$
\text { C }-1 A-30-3
$$

Maximum

Minimum

S.D.

Mean

\section{Maximum Load \\ [lbf]}

$19,697.49$

$18,153.44$

$18,995.98$

$19,697.49$

$18,153.44$

773.097

$18,948.97$
Compressive stress at Maximum Load

[psi]

$5,983.86$

$5,514.80$

$5,770.75$

$5,983.86$

$5,514.80$

234.858

$5,756.47$ 